CENTRO UNIVERSITÁRIO FEI

SIDNEY GITCOFF TELLES

ANÁLISE DO DESEMPENHO DE ALGORITMOS PARA O RECONHECIMENTO DE OBJETOS APLICADOS EM AMBIENTES RESIDENCIAIS

São Bernardo do Campo 

SIDNEY GITCOFF TELLES

\title{
ANÁLISE DO DESEMPENHO DE ALGORITMOS PARA O RECONHECIMENTO DE OBJETOS APLICADOS EM AMBIENTES RESIDENCIAIS
}

\begin{abstract}
Dissertação de Mestrado, apresentada ao Centro Universitário da FEI para obtenção do título de Mestre em Engenharia Elétrica. Orientado pelo Prof. Dr. Flavio Tonidandel.
\end{abstract}

São Bernardo do Campo 
Telles, sidney gitcoff.

Análise do desempenho de algoritmos para o reconhecimento de objetos aplicados em ambientes residenciais / sidney gitcoff Telles. São Bernardo do Campo, 2017. $135 \mathrm{p}$.

Dissertação - Centro Universitário FEl. Orientador: Prof. Dr. Flavio Tonidandel.

1. Robôs Autônomos Residenciais. 2. Reconhecimento de Objetos. 3. Visão Computacional. 4. Classificação de Objetos. I. Tonidandel, Flavio, orient. II. Título.

Elaborada pelo sistema de geração automática de ficha catalográfica da FEI com os dados fornecidos pelo(a) autor(a). 
Aluno: Sidney Gitcoff Telles

Matrícula: $115319-6$

Título do Trabalho: Análise do desempenho de algoritmos para o reconhecimento de objetos aplicados em ambientes residenciais.

Área de Concentração: Inteligência Artificial Aplicada à Automação

Orientador: Prof. Dr. Flavio Tonidandel

Data da realização da defesa: 06/10/2017

\section{ORIGINAL ASSINADA}

Avaliação da Banca Examinadora:

São Bernardo do Campo, 06 / 10 / 2017.

\section{MEMBROS DA BANCA EXAMINADORA}

Prof. Dr. Flavio Tonidandel

Prof. Dr. Paulo Sérgio Silva Rodrigues

Prof. Dr. Francisco de Assis Zampirolli
Ass. :

Ass. :

Ass. :

A Banca Julgadora acima-assinada atribuiu ao aluno o seguinte resultado:

APROVADO \ REPROVADO

\section{VERSÃO FINAL DA DISSERTAÇÃO}

APROVO A VERSÃO FINAL DA DISSERTAÇ̃̃O EM QUE FORAM INCLUÍDAS AS RECOMENDAÇÕES DA BANCA EXAMINADORA
Aprovação do Coordenador do Programa de Pós-graduação

Prof. Dr. Carlos Eduardo Thomaz 

Aos meus pais. 



\section{AGRADECIMENTOS}

Agradeço aos meus pais pelo incentivo e total apoio que me foi dado.

Agradeço ao meu orientador Prof. Dr. Flavio Tonidandel, pelo apoio, motivação, pelas sugestões, pelas aulas ministradas, pela oportunidade dada e por acreditar no meu trabalho.

Aos professores do Centro Universitário da FEI pelo incentivo e pelas aulas ministradas: Prof. Dr. Paulo Sergio Silva Rodrigues e Prof. Dr. Plinio Thomaz Aquino Junior.

Aos amigos do grupo da RoboFei, Msc. Claudio de Oliveira Vilão Junior, Msc. Isaac, Aislan, Msc. Thiago P. Homem, Msc. Danilo Perico, Vinícius Nicassio e Msc. Marcos Laureano.

Aos amigos do Laboratório @ HOME, Leonardo, Lucas, Thiago, Rodrigo, Rafael e Marina pelo apoio, descontração e ajuda.

Ao meu amigo Msc. Eng. Cleber Willian Gomes pelo incentivo em iniciar o curso de mestrado.

Agradeço a minha noiva Giuliana de Gouveia Moia pelo total apoio, incentivo e companheirismo nas horas mais difíceis.

Agradeço a Capes pela bolsa de estudos de mestrado.

E o último e mais importante agradecimento à minha querida Avó Maria de Lourdes Ferreira Peres, um exemplo de pessoa. Confiou em minha capacidade e me deu muita força. Hoje não está mais entre nós fisicamente, mas sempre esteve em meus pensamentos quando precisei de respostas para os problemas que enfrentei durante esse 1 ano de sua partida. 



\section{RESUMO}

A visão computacional e os desafios de trabalhar dentro do campo de reconhecimento de objetos para robôs autônomos residenciais motivam o desenvolvimento de novas técnicas e o estudo para encontrar os seus melhores resultados. Extrair informações de uma imagem envolve em observar a imagem toda, pixel a pixel, à procura de informações relevantes em uma determinada região. Reunir essas informações e distinguir os conjuntos de dados é um dos principais desafios durante o reconhecimento de objetos. A insuficiência do conhecimento de qual a melhor técnica para cada tipo de objeto em estudo (retangular, cilíndrico e irregular), juntamente com as variações que podem ocorrer na imagem (borrões, ruídos, iluminação, entre outros), tornam aleatórias as utilizações das técnicas, podendo perder em eficiência e desempenho. Este trabalho estudou as técnicas para reconhecimento de objetos para robôs autônomos residenciais com o foco na competição da RoboCup, categoria @ Home, com o intuito de analisar, para cada objeto deste estudo, qual é a melhor técnica a ser utilizada. As técnicas escolhidas para o experimento foram SIFT, SURF, ORB, HAAR e HOG, sendo que, essas duas últimas, HAAR e HOG, não atenderam aos requisitos mínimos para a competição e foram retirados do experimento deste trabalho. Assim, os testes executados com as técnicas SIFT, SURF e ORB, tiveram resultados expressivos para a descrição dos objetos em cena. Para a classificação das informações geradas, foi utilizado o classificador SVM, que gerou as Matrizes de Erro (Matrizes de Confusão), com as quais foram feitos todos os cálculos e comparativos para determinar qual técnica se comportou melhor para cada tipo de objeto. Dois testes foram realizados: Divisão (base de imagens da ALOI) verificou qual a quantidade mínima de imagens necessárias para treino, para que cada técnica tenha bons resultados; Luminosidade (base de imagens da ALOI e base de imagens do ambiente real) verificou o desempenho em reconhecer objetos com diferentes incidências de luz para cada técnica. No primeiro teste identificou-se que, para o bom funcionamento das técnicas, foi necessário, no mínimo, 30\% de imagens para treino. No segundo teste, determinou-se qual foi a melhor técnica para cada tipo de objeto. O SIFT e o ORB tiveram bons desempenhos para os objetos cilíndricos, SURF para os retangulares e, por fim, o SURF e o ORB para os objetos do tipo irregulares. Chegou-se a conclusão que, a junção das três técnicas é a melhor solução para o reconhecimento da gama de tipos de objetos estudado neste trabalho.

Palavras-chave: Robôs Autônomos Residenciais. Reconhecimento De Objeto. Visão Computacional. Classificação De Objetos. 



\begin{abstract}
The Computer vision and the challenges of working in the object recognition field for residential autonomous robots motivate the development of new techniques and the study to find the best results. Extracting information from an image means to observe the whole picture, pixel by pixel, searching for relevating information in a determined region. To group this information and distinguish the data sets is one of the main challenges during the object recognition. The knowledge insufficiency of which technique is the best for each kind of object being studied (rectangular, cylindrical and irregular), along with the variations that may occur in the image (blur, noises, illumination, and many others), make the utilization of the techniques to become random, causing a loss in efficiency and performance. This work studied the techniques within the object recognition for residential autonomous robots with the focus turned into the RoboCup competition, @ Home category, in order to analyze, for each object in this study, which is the best technique that should be used. The chosen techniques to this experiment were SIFT, SURF, ORB, HAAR and HOG, however HAAR and HOG couldn't attend to the competition minimum requirements, so they were taken out of this work experiments. Thus, SIFT, SURF and ORB tests had expressive results for the description of the objects presented in the scene. For the generated information classification, the SVM was used as a classificatory, which created Error Matrix (Confusion Matrix), allowing then to make all the calculations and comparisons to determinate which technique had the best behavior for each object type. Two tests were realized: Division (ALOI image database) verified the minimum quantity of images necessary for the training, so that every technique had good results; Luminosity (ALOI database and real environment images database) verified the object recognition performance with different light incidence for each technique. In the first test, it was observed that, for a good performance in the techniques, it was necessary to have at least $30 \%$ of the images for the training. In the second test, was verified which was the best technique for each object type. SIFT and ORB had good results for cylindrical objects, SURF for the rectangular objects and, at end, SURF and ORB with the irregular ones. It was concluded that grouping these three techniques is the best solution for the object set type recognition studied in this work.
\end{abstract}

Keywords: Residential Autonomous Robots. Object Recognition. Computer Vision. Object Classification. 



\section{LISTA DE ILUSTRAÇÕES}

Ilustração 1 - Pirâmide gaussiana. . . . . . . . . . . . . . . . . . . . . 30

Ilustração 2 - Processo para encontrar os melhores pontos chaves (detalhes definidos no texto). .......................... 31

Ilustração 3 - Construção do descritor do ponto de interesse. . . . . . . . . . . . . . . . 32

Ilustração 4 - Características SIFT do cenário correspondendo com as do treinamento. . 33

Ilustração 5 - Retângulos para identificação de pontos HAAR . . . . . . . . . . . . . . . 34

Ilustração 6 - Retângulos para identificação de pontos HAAR com adicionais inclinados. 34

Ilustração 7 - Sequência para identificação de pessoas na rua. . . . . . . . . . . . . . 35

Ilustração 8 - Retângulos para detecção dos pontos chaves. . . . . . . . . . . . . . . . . 37

Ilustração 9 - Pirâmide invertida. . . . . . . . . . . . . . . . . . . . 38

Ilustração 10-Pontos de interesse encontrados em espaços de escalas diferentes. .... 39

Ilustração 11 -Filtros ondaletas de HAAR nas direções $x$ e $y$, respectivamente. . . . . . . 39

Ilustração 12 - Determinando orientação do vetor dos pontos chaves. . . . . . . . . . . . . . 39

Ilustração 13 -Ponto de interesse com a orientação. . . . . . . . . . . . . . . . . . . . . 40

Ilustração 14-Orientação dos vetores dos pontos chaves do cenário. . . . . . . . . . . . . 40

Ilustração 15 -Correspondência dos pontos utilizando ORB. . . . . . . . . . . . . . . . 42

Ilustração 16-Exemplo de classificação do SVM. . . . . . . . . . . . . . . . . . . . . . 43

Ilustração 17 -Gráfico de comparativo da execução das técnicas. . . . . . . . . . . . . . 46

Ilustração 18 -Símbolos utilizados para diferenciar jogadores no campo de futebol de robôs. . . . . . . . . . . . . . . . . 4 47

Ilustração 19-Desempenho do algoritmo SIFT com CPU e GPU. . . . . . . . . . . . . 48

Ilustração 20-Câmera Logitech C920 PRO 15MP Full HD. . . . . . . . . . . . . . . . 52

Ilustração 21 - Diagrama de bloco da arquitetura utilizada neste trabalho. . . . . . . . . . . 53

Ilustração 22 - Imagem de um objeto da base de dados ALOI com variação de Luminosidade. . . . . . . . . . . . . . . . . . . 54 54

Ilustração 23 - Configuração do ambiente da ALOI para extração das imagens. . . . . . . . 54

Ilustração 24 -Fluxograma das metodologias aplicadas nos experimentos. . . . . . . . . 56

Ilustração 25 - Diagrama de atividade para extração de imagens. . . . . . . . . . . . . . 57

Ilustração 26-Arena RoboCup@ @ome. . . . . . . . . . . . . . . . . . . . . . . . . . 58

Ilustração 27 -Prateleira com os objetos. . . . . . . . . . . . . . . . . . . . . . . . 59

Ilustração 28 - Imagem dos objetos da base de dados ALOI escolhidos para os testes. . . 61

Ilustração 29 - Imagem do objeto cilíndrico com pouca e muita luminosidade para reconhecimento. . . . . . . . . . . . . . . . 62

Ilustração 30 - Imagem do objeto retangular com pouca e muita luminosidade para reconhecimento. . . . . . . . . . . . . . . . 62

Ilustração 31 - Imagem do objeto irregular com pouca e muita luminosidade para reconhecimento. . . . . . . . . . . . . . . . 62 
Ilustração 32 - Gráfico dos valores da precisão pela divisão dos dados em porcentagem do vetor de Teste - SIFT ALOI. . . . . . . . . . . . . . . . . . . . . 64

Ilustração 33 - Gráfico das médias das precisões geradas com a variação de luminosidade para cada classe - SIFT ALOI. . . . . . . . . . . . . . . 65

Ilustração 34 - Gráfico do desvio padrão e erro padrão - SIFT ALOI. . . . . . . . . . . . 66

Ilustração 35 - Gráfico dos valores da precisão pela divisão dos dados em porcentagem de teste - SURF ALOI. . . . . . . . . . . . . . . . . . . 67

Ilustração 36 - Gráfico das médias das precisões geradas com a variação de luminosidade para cada classe - SURF ALOI. . . . . . . . . . . . . . . . . 68

Ilustração 37 - Gráfico do desvio padrão e erro padrão - SURF ALOI. . . . . . . . . . . 69

Ilustração 38 - Gráfico dos valores da precisão pela divisão dos dados em porcentagem de teste - ORB ALOI. . . . . . . . . . . . . . . . . . 70

Ilustração 39-Gráfico das médias das precisões geradas com a variação de luminosidade para cada classe - ORB ALOI. . . . . . . . . . . . . . . . 71

Ilustração 40 - Gráfico do desvio padrão e erro padrão - ORB ALOI. . . . . . . . . . . . 71

Ilustração 41 -Gráfico de média das técnicas - ALOI. . . . . . . . . . . . . . . . . . . 72

Ilustração 42 - Gráfico de desvio padrão e erro padrão das técnicas - ALOI. . . . . . . . 72

Ilustração 43 - Prateleira do laboratório com os objetos dispostos. . . . . . . . . . . . . 73

Ilustração 44 - Cenário para extração das imagens para formação da base de imagens do laboratório. . . . . . . . . . . . . . . . . . . . 74

Ilustração 45 -Imagem dos objetos da base de dados do lab. . . . . . . . . . . . . . . 74

Ilustração 46 -Cenário para extração das imagens do ambiente. . . . . . . . . . . . . . 75

Ilustração 47 -Imagem do objeto caixa extraída do laboratório. . . . . . . . . . . . . 76

Ilustração 48 -Imagem do objeto lata extraída do laboratório. . . . . . . . . . . . . . 76

Ilustração 49 -Imagem do objeto irregular extraídas do laboratório. . . . . . . . . . . . . 76

Ilustração 50 - Gráfico das médias das precisões geradas com a variação de luminosidade para cada classe - SIFT lab. . . . . . . . . . . . . . . . . . . . . 77

Ilustração 51 - Gráfico do desvio padrão e erro padrão - SIFT lab. . . . . . . . . . . . . . 78

Ilustração 52 - Gráfico das médias das precisões geradas com a variação de luminosidade para cada classe - SURF lab. . . . . . . . . . . . . . . 79

Ilustração 53 - Gráfico do desvio padrão e erro padrão - SURF lab. . . . . . . . . . . . 79

Ilustração 54 - Gráfico das médias das precisões geradas com a variação de luminosidade para cada classe - ORB lab. . . . . . . . . . . . . . . 80

Ilustração 55 - Gráfico do desvio padrão e erro padrão - ORB lab. . . . . . . . . . . . . . 80

Ilustração 56 -Gráfico de média das técnicas - lab. . . . . . . . . . . . . . . . 81

Ilustração 57 - Gráfico de desvio padrão e erro padrão das técnicas - lab. . . . . . . . . . 81 


\section{LISTA DE TABELAS}

Tabela 1 - Tabela das técnicas utilizadas pelas equipes na competição RoboCup . . . . 49

Tabela 2 - Tabela da arquitetura do computador utilizado. . . . . . . . . . . . 53

Tabela 3 - Resultados finais .................... 83 



\section{LISTA DE ABREVIATURAS}

BRIEF Binary Robust Independent Elementary Features.

FAST Features from Accelerated Segment Test.

HOG Histogram of Gradients.

ORB Oriented FAST and Rotated BRIEF.

SIFT Scale Invariant Feature Transform.

SURF Speed-Up Robust Features.

SVM Support Vector Machine. 



\section{SUMÁRIO}

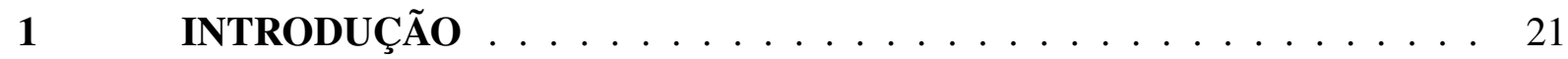

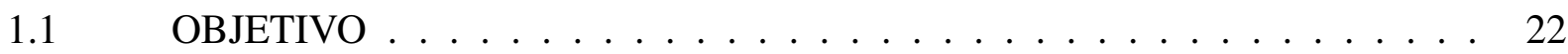

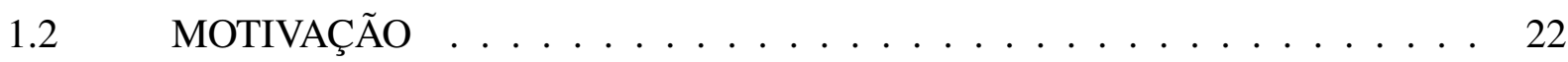

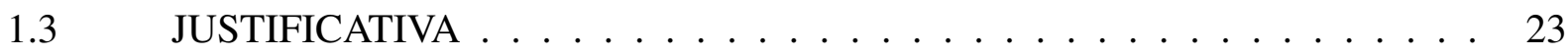

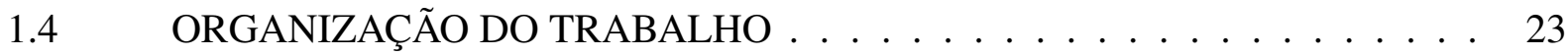

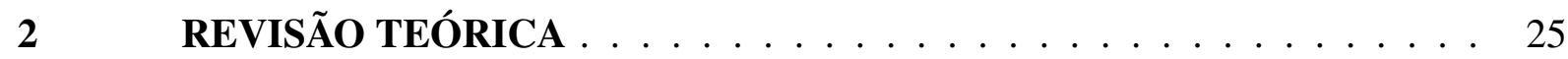

2.1 RECONHECIMENTO DE OBJETOS . . . . . . . . . . . . . . . . 25

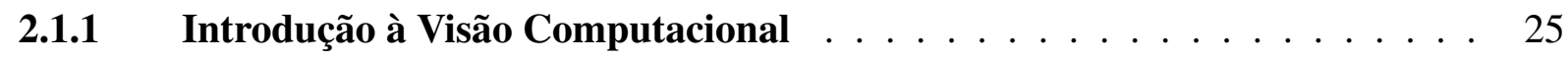

2.1.2 Detectores De Pontos Chaves . . . . . . . . . . . . . . . . . . . 26

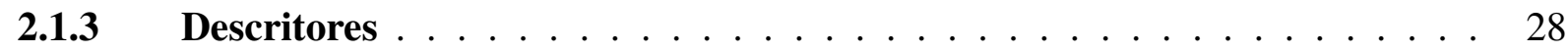

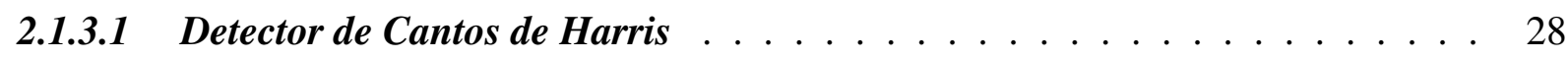

2.1.3.2 Scale Invariant Feature Transform (SIFT) . . . . . . . . . . . . . . . . 29

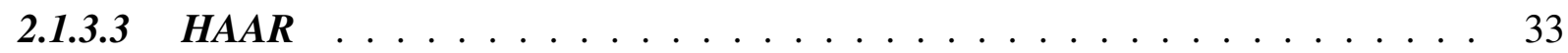

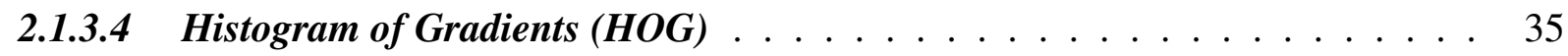

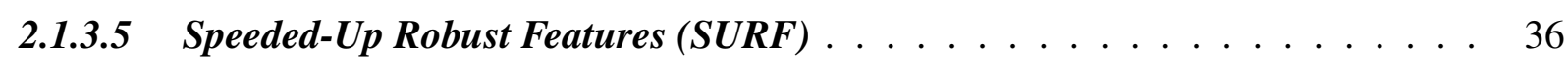

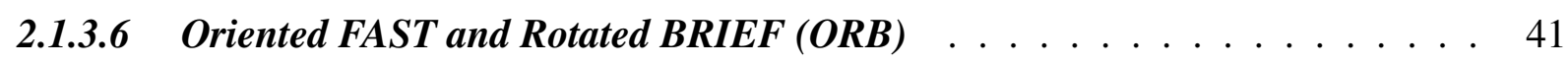

2.1.4 Classificadores . . . . . . . . . . . . . . . . . . . . . . 42

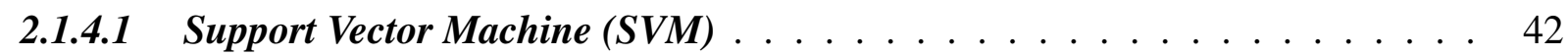

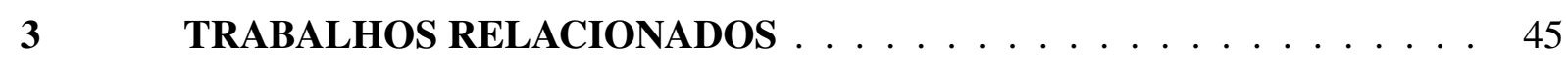

4 ANÁLISE DE ALGORITMOS PARA RECONHECIMENTO DE OBJE-

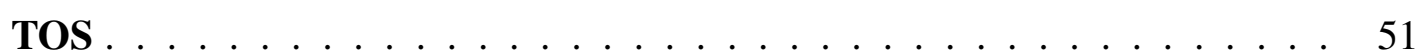

4.1 MATERIAIS E MÉTODOS $\ldots \ldots \ldots \ldots \ldots \ldots \ldots \ldots \ldots \ldots$

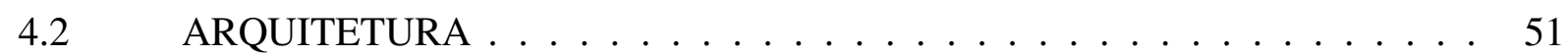

4.3 BASE DE IMAGEM $\ldots \ldots \ldots \ldots \ldots \ldots \ldots \ldots \ldots \ldots \ldots$

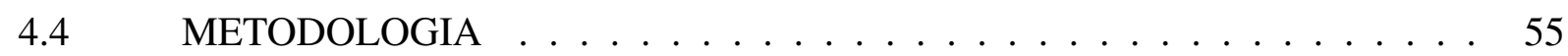

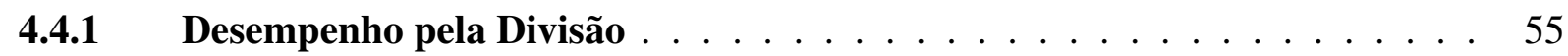

4.4.2 Desempenho com Alteração de Luminosidade . . . . . . . . . . . . . . 55

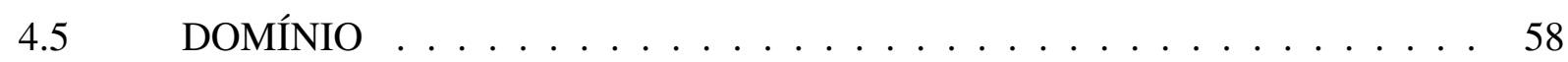

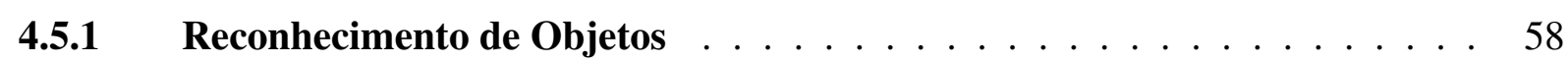

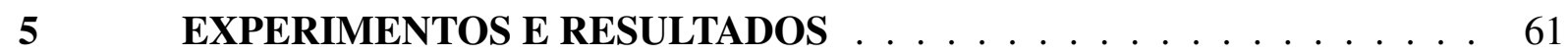

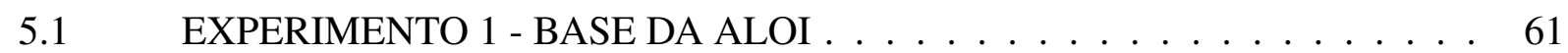

5.1.1 Experimento - SIFT . . . . . . . . . . . . . . . . . . . . 64

5.1.1.1 Desempenho Pela Divisãa . . . . . . . . . . . . . . . . . . . . 64

5.1.1.2 Desempenho com Alteração de Luminosidade . . . . . . . . . . . . . . . 65

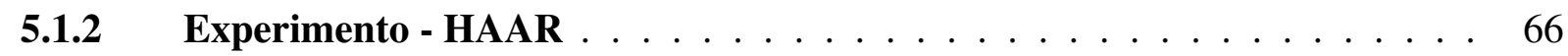

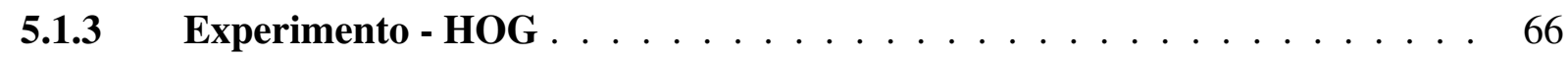

5.1.4 Experimento-SURF $\ldots \ldots \ldots \ldots \ldots$ 
5.1.4.1 Desempenho Pela Divisão . . . . . . . . . . . . . . . . . . . . . . . . 67

5.1.4.2 Desempenho com Alteração de Luminosidade . . . . . . . . . . . . . . . . . 68

5.1.5 Experimento - ORB . . . . . . . . . . . . . . . . . . . . 69

5.1.5.1 Desempenho Pela Divisão . . . . . . . . . . . . . . . . . . . . . . . 69

5.1.5.2 Desempenho com Alteração de Luminosidade . . . . . . . . . . . . . . . . . 70

5.2 DISCUSSÃO - COMPARANDO OS RESULTADOS COM A BASE ALOI . . 71

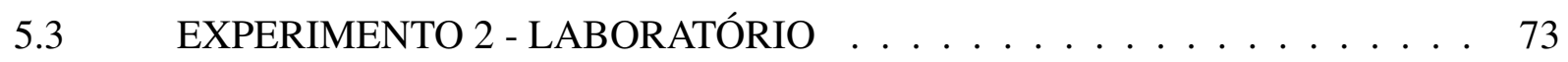

5.3.1 Experimento - SIFT . . . . . . . . . . . . . . . . 77

5.3.1.1 Desempenho com Alteração de Luminosidade . . . . . . . . . . . . . . . . 77

5.3.2 Experimento - SURF . . . . . . . . . . . . . . . . . 78

5.3.2.1 Desempenho com Alteração de Luminosidade . . . . . . . . . . . . . . . . 78

5.3.3 Experimento - ORB . . . . . . . . . . . . . . . . . . 79

5.3.3.1 Desempenho com Alteração de Luminosidade . . . . . . . . . . . . . . . . . 79

5.4 DISCUSSÃO - COMPARANDO OS RESULTADOS DO LABORATÓRIO . . 81

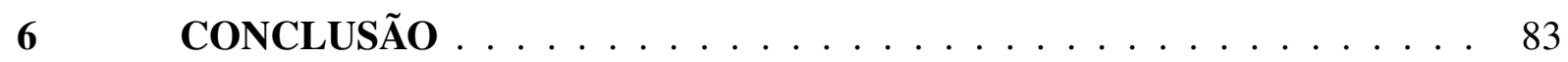

REFERENCIAS . . . . . . . . . . . . . . . . . . 85

APÊNDICE A - Dados Coletados dos Experimentos - Precisão Pela Divisão 89 APÊNDICE B - Dados Coletados dos Experimentos - Desempenho Com

Alteração De Luminosidade . . . . . . . . . . . . . . . . . . . . . 127 


\section{INTRODUÇÃO}

Quando se fala em robôs autônomos residenciais, uma das coisas que vem à mente é: como o robô enxergará os objetos e como irá distinguir um dos outros na tomada de decisão? O principal sensor utilizado é a câmera, por onde entram as informações necessárias e importantes para o processamento e para o auxílio da tomada de decisão.

Com dados capturados pela câmera, houve a necessidade do processamento e interpretação da imagem, o que motivou o desenvolvimento da área conhecida como visão computacional, que nada mais é do que, os diversos processamentos das imagens capturadas do mundo real para o digital. Surgindo assim, muitas técnicas que façam o processo de extração de informações relevantes das imagens que possibilitaram a tomada de decisão. Assim, juntando as informações extraídas da imagem com a tomada de decisão, surge o reconhecimento de objetos.

Existem técnicas de processamento de imagem para descrever e classificar todas as informações capturadas pela câmera. Algumas dessas técnicas efetuam a descrição da imagem, tais como, por extração de cantos (HARRIS; STEPHENS, 1988), extração de pontos chaves (LOWE, 1999; BAY et al., 2008; RUBLEE et al., 2011), extração de características (VIOLA; JONES, 2001; DALAL; TRIGGS, 2005), reconhecimento pelas características globais de um objeto (RODRIGUES, P. S.; ALBUQUERQUE ARAÚJO, 2002), entre muitas outras. Na classificação das informações geradas pelos descritores, existem técnicas que utilizam separadores de dados em um plano com uma reta baseada em seus delimitadores (CORTES; VAPNIK, 1995). Alguns aplicam diversos classificadores para serem mais robustos (FREUND; SCHAPIRE, 1995) e, diversos outros, classificam os dados que foram encontrados dos descritores das imagens processadas pela câmera do robô do mundo real para o digital.

As técnicas utilizadas neste trabalho para extração das características da imagem, são todas baseadas nos cálculos de gradientes de imagem, isto é, as técnicas aplicam equações para encontrarem características importantes na imagem e, ao final de todos os processos, os gradientes são uns dos mais importantes a serem considerados. As técnicas que serão apresentadas neste trabalho (Seção 2.1.3) que utilizam cálculos de gradientes serão: Detector de Canto de Harris (HARRIS; STEPHENS, 1988), SIFT (LOWE, 1999), HAAR (VIOLA; JONES, 2001), HOG (DALAL; TRIGGS, 2005), SURF (BAY et al., 2008), ORB (RUBLEE et al., 2011). E na classificação dos dados extraídos da imagem, onde serão extraídos os resultados do reconhecimento de objetos, será apresentado o SVM (CORTES; VAPNIK, 1995), que consiste em um separador de dados em um plano guiado por dois vetores de suporte, que são encontrados à partir dos máximos e mínimos da amostra (Subseção 2.1.4.1). Um classificador com boa generalização, depende de ajustes finos dos parâmetros para que execute uma boa separação e consiga concluir, através de matrizes de confusão, a precisão de acerto sobre qual objeto está na imagem.

No entanto, apesar das técnicas existentes, diversos são os problemas para o reconhecimento de objetos em robôs autônomos residenciais. Como por exemplo, as quantidades de 
formas diferentes de objetos, variações na luminosidade, diferença de escala, rotação e até obstrução parcial, variáveis que não podem ser desconsideradas durante qualquer formulação de solução de problemas em residências. A visão computacional de um robô autônomo é extremamente sensível a essas variações do ambiente que um objeto pode ter, mesmo sendo em pequena proporção, resultando na não extração ou classificação das informações na imagem corretamente.

Thomas Wissepeintner et al. (2009) criaram uma categoria a qual chamaram de @ Home (BEEK et al., 2017) em uma das mais famosas e importantes competições de robótica mundial, a RoboCup, com o principal objetivo de incentivar pesquisadores do mundo todo a desenvolverem pesquisas na área de robôs autônomos residenciais. O principal propósito é o desenvolvimento e compartilhamento de novas tecnologias para esse âmbito, a fim de colaborar com o mundo científico e trazer novas formas de resolver os problemas mais complexos (WISSPEINTNER et al., 2009).

Assim, este trabalho pretende contribuir para demonstrar qual técnica é a melhor para reconhecer um determinado tipo de objeto, seja ele cilíndrico, ou retangular, ou irregular, permitindo que seja possível juntar técnicas que obtiverem melhores resultados com intuito de reconhecer a maior quantidade possível de objetos, mesmo em condições adversas encontradas em residências e nos ambientes de competição da RoboCup@Home.

\subsection{OBJETIVO}

O objetivo deste trabalho é estudar a acurácia e o desempenho das técnicas SIFT (LOWE, 1999), HAAR (VIOLA; JONES, 2001), HOG (DALAL; TRIGGS, 2005), SURF (BAY et al., 2008) e ORB (RUBLEE et al., 2011), utilizando o classificador SVM (CORTES; VAPNIK, 1995), para identificar três tipos diferentes de objetos: cilíndricos, retangulares e irregulares.

A avaliação será feita utilizando comparativo das matrizes de confusão geradas para cada técnica com os tipos de objetos cilíndricos, retangulares e irregulares. Serão feitas variações no objeto como luminosidade e alteração da posição, afim de testar a robustez da técnica e atribuir um rótulo para cada técnica de qual tipo de objeto (cilíndrico, retangular ou irregular) foi mais robusta em reconhecer. Ao final deste processo, espera-se ter um comparativo entre todas as matrizes de todas as técnicas e as que obtiverem melhor desempenho, sejam unidas em um robô para que tenha sucesso na tarefa de reconhecer diversos objetos na competição RoboCub, categoria @Home, mesmo com ou sem as variações do ambiente.

\subsection{MOTIVAÇÃO}

A motivação para este trabalho surgiu pela quantidade de técnicas existentes que executam a extração e classificação dos dados retirados de imagens para efetuar o reconhecimento de objetos. Como em uma residência existem diversos objetos, surgiu a necessidade também 
de reconhecer uma gama maior de objetos. Para cada técnica, pouco se sabe sobre qual é a melhor para reconhecer determinados tipos de objetos, mesmo esses estando, ou em posições diferentes, ou com iluminações diferentes. Portanto, a falta de conhecimento de qual a melhor técnica a ser aplicada para cada tipo de objeto e suas variações (luminosidade e posição), que possam existir em residências, motiva o desenvolvimento deste estudo.

\subsection{JUSTIFICATIVA}

Em uma competição de robôs em ambientes que simulam residências e tarefas diárias, destaca-se a complexidade em reconhecer diversos objetos encontrados ao redor no ambiente, como também, problemas com diferentes posições que os objetos possam assumir, luminosidades diferentes que podem incidir sobre o objeto, até mesmo obstruções que possam ocorrer por outros objetos ou móveis encontrados em quaisquer residências. Tais dificuldades motivam o estudo para unir técnicas, nas quais cada uma deverá conter um rótulo de mais adequada para cada tipo de objeto e que superem as possíveis variações que possam ocorrer, auxiliando na execução com sucesso das tarefas de reconhecimento de objetos, tanto na competição de robótica como de uso em residências.

\subsection{ORGANIZAÇÃO DO TRABALHO}

Este trabalho está dividido em 6 capítulos. O primeiro capítulo apresenta os objetivos do trabalho, a justificativa e a forma de organização do mesmo. No capítulo seguinte será apresentado o embasamento teórico para compreensão do trabalho. No Capítulo 3, apresentamos estudos relacionados ao trabalho proposto. Os métodos e materiais aplicados neste trabalho são apresentados no Capítulo 4. No Capítulo 5, é descrito o experimento realizado. E por fim, apresenta-se a conclusão deste trabalho. 



\section{REVISÃO TEÓRICA}

Nesta seção é apresentado o referencial teórico dos conceitos necessários para a realização deste trabalho de pesquisa no que se refere às técnicas que auxiliam no reconhecimento de objetos. Nesta seção é apresentado o reconhecimento de objetos dividido em quatro subseções: Introdução à Visão Computacional, Detectores de Pontos Chaves, Descritores e Classificadores.

A primeira subseção trata da introdução à visão computacional. Na segunda subseção é apresentado o que é ponto chave e quais são os requisitos mínimos para encontrar bons pontos chaves. Na terceira subseção são descritas as técnicas que auxiliam no reconhecimento de objetos, algumas das quais são baseadas em detectores de pontos chave e outros na extração de características da imagem. E por último, na subseção classificadores, é apresentado a técnica que será utilizada para classificação dos dados gerados pelas técnicas de extração de características da imagem.

\subsection{RECONHECIMENTO DE OBJETOS}

Reconhecimento de objetos é um dos ramos na área de visão computacional e, para que seja efetuado, é necessária uma descrição e classificação das características encontradas do cenário com o intuito de identificar e atribuir um rótulo para o objeto visto (GONZALEZ; WOODS, 2000).

Para executar o reconhecimento de um objeto é necessária a utilização de técnicas que façam a detecção de características do objeto alvo (objeto alvo é o que deverá ser reconhecido). Essas técnicas são conhecidas por técnicas de descrição, que serão apresentadas na Seção 2.1.3.

Ao final de cada processo de descrição, há a necessidade de processamento das características encontradas do cenário e do objeto alvo. Para isso, são utilizadas técnicas de classificação das características. Existindo diversas delas, uma das técnicas de classificação será apresentada na Seção 2.1.4.

\subsubsection{Introdução à Visão Computacional}

Para melhor entendimento sobre reconhecimento de objetos, esta seção irá apresentar os conceitos básicos de visão computacional. Sabe-se que tudo que vemos é considerado uma imagem e, na área tecnológica tudo que é visto do mundo real e transferido para a tela de um computador é considerado como uma Imagem Digital.

\footnotetext{
"Uma imagem pode ser definida como uma função bidimensional, $f(x, y)$ em que $x$ e $y$ são coordenadas espaciais (plano), e a amplitude de $f$ em qualquer par de coordenadas $(x, y)$ é chamada de intensidade ou nível de cinza na imagem nesse ponto. Quando $x$, $y$ e os valores de intensidade de $f$ são quantidades finitas e discretas, chamamos de imagem digital."

(GONZALEZ; WOODS, 2000) pg. 1.
} 
Em uma imagem digital existe uma quantidade finita de elementos que possuem localização e valores definidos. Esses elementos são essenciais para a formação da imagem e são conhecidos pelo nome de pixel. Podemos citar, por exemplo, a utilização de critério de diferenciação de televisores utilizados no mercado: uma televisão com resolução 1920 x 1080, contem 1920 pixels nas colunas verticais por 1080 pixels em sua linhas horizontais, formando assim uma matriz de pixels que ao se juntarem formam a imagem (GONZALEZ; WOODS, 2000).

Segundo Gonzalez e Woods (GONZALEZ; WOODS, 2000), a visão computacional é o processamento de imagens digitais. Esse processamento é divido em três níveis:

a) baixo Nível - O processo de baixo nível tem como principal foco melhorar a qualidade da imagem, como remoção dos ruídos, melhora do contraste, remoções de borrões que podem ocorrer captação da câmera e correções de qualquer tipo de falha que possa ocorrer da aquisição e envio da imagem;

b) médio Nível - O processo de médio nível tenta, de alguma forma, destacar as características em regiões da imagem que sejam importantes, utilizando diversos métodos. Um deles é a segmentação, que faz com que a imagem seja particionada em regiões de interesse, podendo também, obter a classificação de objetos individuais. Portanto, extrai da imagem regiões que possam ser úteis ao processo. Neste nível é possível efetuar o reconhecimento de objetos pela forma, quando a segmentação da região é muito específica, pode-se rotular o objeto;

c) alto Nível - O processo de alto nível encontra-se muito mais próximo à cognição humana. Faz a extração e classificação das informações da imagem tendo como auxílio as técnicas de interpretação de objetos e cenas. Em resumo, seria raciocínio cognitivo e a inferência de informações de um ser humano ao ver no ambiente um determinado objeto e poder rotulá-lo com um devido nome. Portanto, o alto nível é onde o reconhecimento de objeto é efetuado pelas técnicas que serão apresentadas na Subseção 2.1.3.

Apresentaremos as técnicas neste trabalho que utilizam os níveis Baixo e Médio durante a extração de características da imagem e, para a realização deste trabalho será utilizado o Alto Nível.

\subsubsection{Detectores De Pontos Chaves}

Detectores de pontos chaves fazem parte do processamento de imagem de alto nível, conforme foi visto na Seção 2.1.1, e indica que foi feito todo o processamento da imagem, melhora da qualidade da imagem e seleção da região de interesse, até o alto nível. O principal foco é fazer a verificação na imagem utilizando pixel por pixel à procura de características que possam ser consideradas como importantes (BYEONG-HO, 2007). As técnicas que utilizam a detecção de pontos chaves são SIFT, SURF e ORB (serão apresentados na subseção 2.1.3), e cada uma precisa atender a requisitos de propriedades de cada ponto encontrado na imagem 
para que sejam considerados bons pontos chaves. As características importantes para o processo de procura pelos pontos chaves são vértices, bordas ou regiões, e nela estão contidas as análises de intensidade e cor para que possam encontrar um ponto em que se mantenham estáveis com relação às variações de escala, ruído, iluminação ou outras propriedades. Portanto, uma característica ou ponto chave é um padrão de imagem local sendo diferente de toda sua vizinhança (TUYTELAARS et al., 2008).

Para que os pontos encontrados na imagem sejam bons pontos chaves, conforme Tuytelaars et al.(2008) (um dos criadores da técnica SURF (subseção 2.1.3.5)), deverão apresentar as seguintes propriedades:

a) repetibilidade: Quando há duas imagens do mesmo objeto, a quantidade de pontos característicos detectados em ambas as imagens deverá ser alta e tendo alta correspondência entre os pontos de cada imagem encontrados. Existem duas propriedades para tornar um ponto chave com repetibilidade:

- invariância: Mapear as deformações que poderão ocorrer em uma imagem e, a partir dela, formular matematicamente um método que anule a deformação e mantenha as características do ponto encontrado;

- robustez: Capacidade de tornar o método menos sensível às pequenas variações de deformações, tornando-o mais preciso na detecção da característica. As deformações consideradas são: ruídos, borrões, artefatos de compressão, entre outros;

b) distinção: É analisada em volta de cada ponto à procura de padrões de intensidade com muita variância, fazendo assim, uma combinação desses elementos para distinguir o ponto encontrado dos demais pontos;

c) localidade: Todas as características devem ser locais. Com isso, reduzir-se-ão as chances de acontecer oclusões, permitindo aproximações simples dos modelos matemáticos de deformações geométricas e fotométricas;

d) precisão: Dependendo da localidade do ponto, a precisão é necessária durante o cálculo de correspondências dos pontos. Podendo ser útil para cálculos de geometria epipolar ou calibração de câmera;

e) eficiência: Encontrar as características do ponto para definir se é um ponto chave, devendo ser executado em menor tempo possível.

Há uma grande variedade de detectores de características, muito deles são dependentes do tipo de característica que se deseja encontrar. Existem 3 categorias que são as mais utilizadas na detecção, as quais são: borda, canto ou região (TUYTELAARS et al., 2008).

As propriedades mostradas estão contidas no processamento das técnicas SIFT, SURF e ORB, portanto não serão consideradas neste trabalho como metodologia de análise e comparativo com outras aplicações, mas servem como demonstrativo de que cada ponto encontrado tem sua propriedade e sua avaliação para ser considerado um bom ponto chave.

Na próxima seção serão apresentadas as técnicas de descrição: Detector de Cantos de HARRIS (HARRIS; STEPHENS, 1988); Transformações de Características Invariantes em 
Escala (Scale Invariant Features Transform - SIFT) (LOWE, 1999); HAAR (VIOLA; JONES, 2001); Histogramas de Gradientes Orientados (Histogram of Gradients - HOG) (DALAL; TRIGGS, 2005); Acelerador de Características Robusto (Speed Up Robust Features - SURF) (BAY et al., 2008) e Orientado FAST e Rotacionado BRIEF (Oriented FAST and Rotated BRIEF - ORB) (RUBLEE et al., 2011).

\subsubsection{Descritores}

Descritores são técnicas que executam a extração dos pontos chaves ou características de imagens, de um objeto móvel ou imóvel, pessoa, curvaturas de calçadas nas ruas, entre qualquer outro objeto que venha à aparecer na imagem. Durante a extração, essas técnicas deverão seguir as propriedades descritas anteriormente (Seção 2.1.2). Existem diversas técnicas que fazem a extração e descrição e, a seguir, serão apresentadas algumas técnicas, respeitando a ordem em que elas foram inventadas.

\subsubsection{Detector de Cantos de Harris}

O detector de canto de Harris foi proposto por Harris e Stephens (1988) para encontrar cantos da rua para carros autônomos. Seu método utiliza matriz de auto-correlação (Equação 1) para a detecção de características locais em imagens. Ela é conhecida também pelo nome de matriz de segundo momento, descrevendo a distribuição dos gradientes em uma vizinhança local.

$\mathrm{Na}$ execução da detecção de cantos é passada uma janela, sendo uma pequena matriz de pixels que começa no canto superior esquerdo e é passada por toda a imagem finalizando na parte inferior direita à procura de pontos onde existam grandes variações de intensidade que podem ser considerados cantos.

$$
M=\sum_{x, y} w(x, y) *\left[\begin{array}{cc}
I_{x}^{2}\left(x, \sigma_{D}\right) & I_{x}\left(x, \sigma_{D}\right) I_{y}\left(x, \sigma_{D}\right) \\
I_{x}\left(x, \sigma_{D}\right) I_{y}\left(x, \sigma_{D}\right) & I_{y}^{2}\left(x, \sigma_{D}\right)
\end{array}\right],
$$

a) $(x, y)$ é a coordenada do ponto na imagem;

b) $w(x, y)$ é a janela na coordenada do ponto $(x, y)$;

c) $I$ é a intensidade na coordenada do ponto $(x, y)$,

com

$$
\begin{gathered}
I_{x}\left(x, \sigma_{D}\right)=\frac{\partial}{\partial x} g\left(\sigma_{D} * I(x)\right), \\
g(\sigma)=\frac{1}{2 \pi \sigma^{2}} e^{-\frac{x^{2}+y^{2}}{2 \sigma^{2}}},
\end{gathered}
$$

Onde $\sigma_{D}$ é núcleo gaussiano que será utilizado para os cálculos de derivada da imagem local. Formando uma janela de gaussianas para suavizar os pontos que estão ao redor do ponto chave, 
utilizando uma escala de integração $\sigma_{I}$. Após o resultado do cálculo, os pontos da vizinhança que tiverem alterações de sinais serão considerados os autovalores da matriz de auto-correlação (M). Portanto, para encontrar os cantos de uma imagem, basta observar onde os sinais estão variando e se seus autovalores são altos (HARRIS; STEPHENS, 1988). Como os valores e os autovalores terão que combinar, Harris e Stephens (1988) pensaram em uma equação que pudesse combinar sem ter um custo computacional muito alto. Eles chamaram a equação de Cornerness (Equação 4). Essa equação é utilizada para extrair o ponto chave, o canto, considerando os máximos locais utilizando supressão não máxima, fazendo assim, os pontos serem invariantes a rotação, translação e iluminação.

$$
\text { corneness }=\operatorname{det}(M)-\lambda \operatorname{tr}(M)
$$

\footnotetext{
"Onde $\operatorname{det}(M)$ é o determinante de $M$ e $\operatorname{tr}(M)$ é seu traço, inserindo o traço para redução da resposta dos operadores de contornos retos fortes."(HARRIS; STEPHENS, 1988).
}

$\lambda$ é um fator para o traço e geralmente é alternado entre os valores de 0,04 e 0,15 para reduzir melhor os operadores de contornos retos fortes.

O resultado da Equação 4, sendo alto, aumenta a possibilidade de existência de um canto na região da imagem onde está sendo feita a verificação.

Esta técnica foi apresentada por ser utilizada na base do descritor FAST (TUYTELAARS et al., 2008), utilizada para descrever os dados da imagem da técnica ORB (será explicado na Subseção 2.1.3.6), que será utilizada nos testes deste trabalho.

\subsubsection{Scale Invariant Feature Transform (SIFT)}

SIFT Lowe (1999) é uma técnica de extração de pontos chaves, utilizado para encontrar pontos de interesse, curvaturas únicas, em imagens que se mantenham estáveis à transformações de escala, invariância a rotação e invariante a luminosidade. Invariância de escala é quando o objeto poderá estar em distâncias focais diferentes captadas pela câmera, não sofrendo assim, alterações durante o processo de extração dos pontos chaves; os mesmos pontos deverão ser encontrados em todas as variações de distâncias focais entre o objeto e a câmera. Na invariação de rotação, mesmo o objeto estando rotacionado, o ponto chave encontrado terá uma orientação, tornando a característica do ponto única e independente da posição que o objeto estará no cenário. Na invariação de luminosidade, a técnica consegue extrair pontos mesmo que haja muita ou pouca luminosidade (LOWE, 1999).

SIFT foi criado por Lowe (1999) com o propósito de reconhecer objetos que possam estar em outra posição no cenário ou parcialmente obstruído. Lowe (1999) garante que para reconhecer qualquer objeto em uma cena é necessário apenas identificar 3 pontos de interesse do objeto. Para o caso do objeto estar obstruído parcialmente, a quantidade mínima de pontos de interesse necessários para encontrar, reconhecer e reconstruir são de 10 pontos. 
Para explicar o funcionamento da técnica, a primeira etapa para a extração dos pontos de interesse é calcular uma pirâmide gaussiana (GONZALEZ; WOODS, 2000). O objetivo de se fazer a pirâmide é reduzir as dimensões da imagem em patamares e, para cada patamar criado, é feita uma suavização com uma gaussiana (Equação 5), chamando esse processo de Espaço de Escala. Executando uma busca por pontos de interesse nos níveis adjacentes da pirâmide, como mostra na Figura 1, utilizando blocos de 8x8 pixels para calcular em cada patamar do espaço de escala os máximos e mínimos da gaussiana (Equação 6), esse processo será recursivamente executado por toda imagem até que alcancem todos os pontos de interesse de cada patamar do espaço de escala.

$$
L(x, y, \sigma)=G(x, y, \sigma) * I(x, y)
$$

onde $L(x, y, \sigma)$ é a convolução da imagem original $I(x, y), x$ e $y$ são as coordenadas do centro do quadro, $\sigma$ é a escala aplicada na imagem e $G$ a função Gaussiana definida como:

$$
G(x, y, \sigma)=\frac{1}{\sqrt{2 \pi \sigma}} e^{-\left(x^{2}+y^{2}\right) / 2 \sigma^{2}}
$$

Figura 1 - Pirâmide gaussiana.

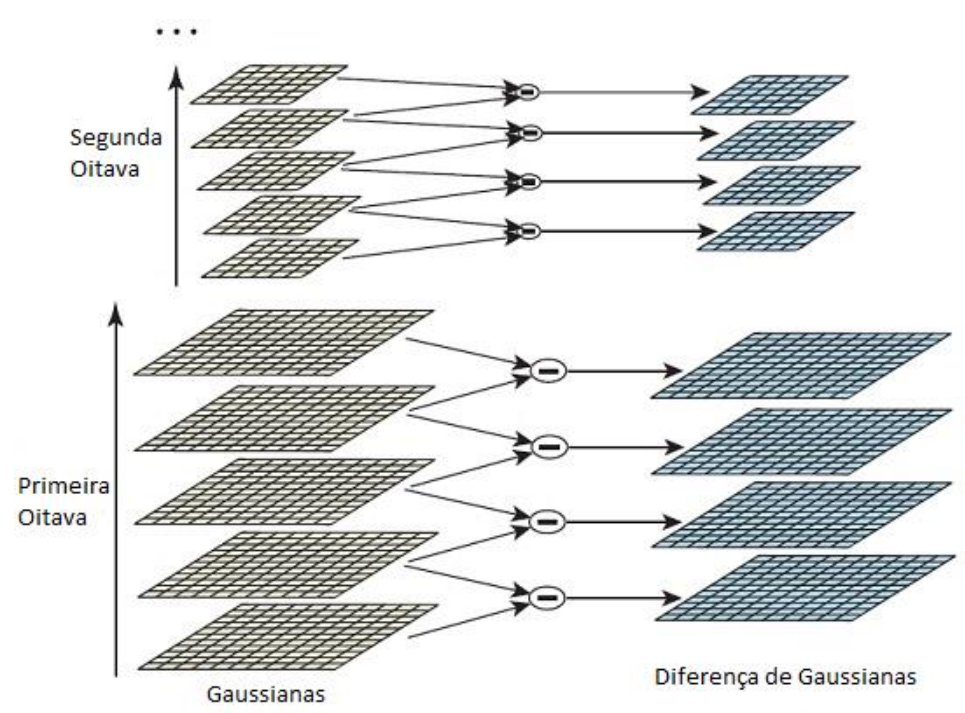

Fonte: Autor "adaptado de"Lowe, 1999.

A técnica utiliza o núcleo da gaussiana (Equação 6) para conseguir delimitar os máximos e mínimos em cada nível do patamar do espaço de escala gerado e a utilização dos mesmos para encontrar os possíveis pontos de interesse na imagem. Na próxima etapa é feito o cálculo utilizando a Equação 7 que é chamada de Diferença de Gaussianas (DoG), por utilizar a diferença dos pares de filtros gaussianos criados nos patamares do espaço de escala juntamente com todos os pontos de interesse encontrados, concluindo assim, a diferença dos pontos encontrados por cada par de patamar do espaço de escala (LOWE, 1999). 


$$
\begin{array}{r}
D(x, y, \sigma)=(G(x, y, k \sigma)-G(x, y, \sigma)) * I(x, y) \\
=L(x, y, k \sigma)-L(x, y, \sigma),
\end{array}
$$

Onde $k$ é o fator constante de separação entre os espaços de escalas.

Com os possíveis pontos chaves encontrados em todos os níveis do espaço de escala, a técnica faz um processo de descartar pontos que não são interessantes, fazendo isso em duas etapas. Na primeira são descartados os pontos que tiveram baixo contraste que podem ser sensíveis a ruído ou mal localizados ao longo de uma borda ou próximos a centros de planos. $\mathrm{Na}$ segunda é feita uma verificação de pontos que estão em arestas à procura se estes estão em curvaturas principais; os que não estiverem são considerados pontos de bordas e são descartados. Tendo ao final na imagem apenas pontos chaves únicos e definidos sendo de curvaturas (LOWE, 1999).

Figura 2 - Processo para encontrar os melhores pontos chaves (detalhes definidos no texto).

(a)

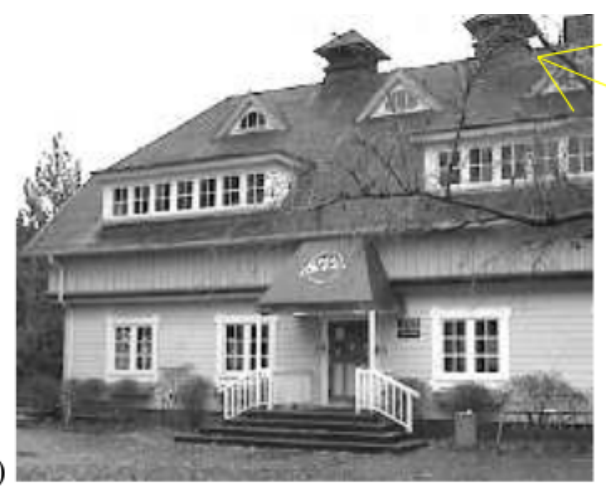

(c)

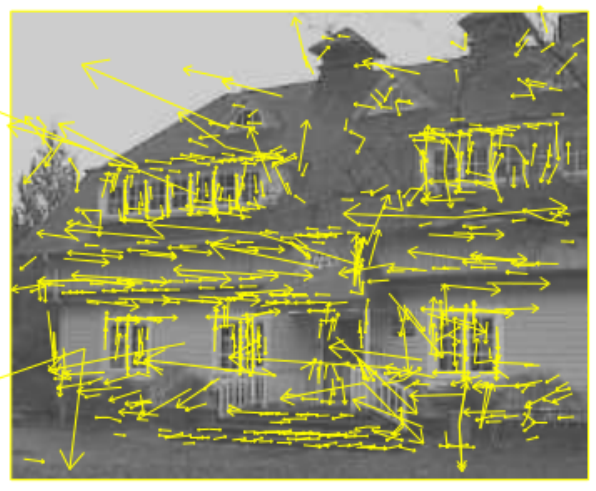

(b)

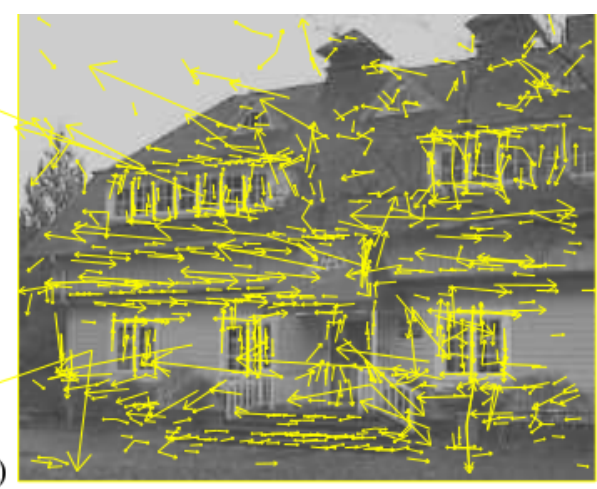

(d)

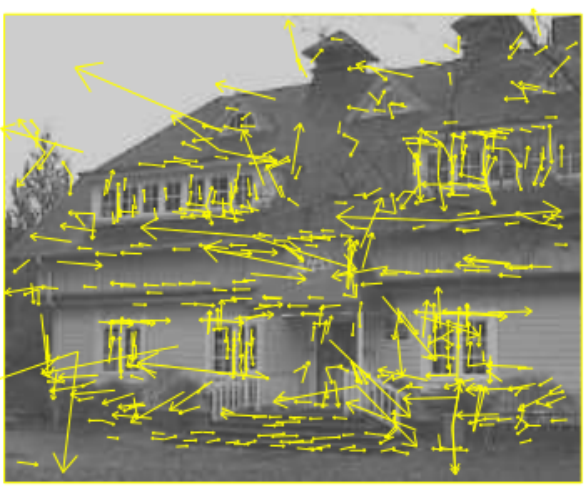

Fonte: Lowe, 1999.

Como pode ser visto, o demonstrativo do funcionamento da técnica na Figura 2, em que são encontrados os pontos de interesse na imagem. Primeiro é inserida uma imagem (Figura 2 (a)) depois é encontrado todos os máximos e mínimos da diferença de gaussianas (Figura 2 (b)). Lowe (1999) demonstrou os pontos de interesse por vetores, cada um com sua intensidade e magnitude. O descarte dos pontos com baixo contraste é executado e resulta na Figura 2 (c), e o descarte dos pontos de bordas resulta na Figura 2 (d). Tendo ao final apenas pontos de curvaturas únicos e distintos dos demais. 
Após definição dos pontos chaves em curvaturas, é adicionada uma ou mais orientações para cada ponto utilizando gradiente de imagem local. Para encontrar a orientação de um ponto, é necessário considerar as orientações das regiões vizinhas ao ponto, fazendo com que ao adicionar esses pontos da vizinhança no histograma, seja adicionado junto uma ponderação da magnitude de gradiente.

No histograma, quando todas as orientações forem colocadas, os picos que forem encontrados serão correspondentes às direções dominantes dos gradientes locais e, no final, serão utilizados para definir a orientação do ponto. Esse processo é chamado de descritor de pontos chaves. No descritor computa-se as magnitudes e orientações dos gradientes amostrados, conforme pode-se ver na Figura 3. Na esquerda temos os gradientes ponderados de cada vizinho do ponto chave centralizado por uma gaussiana e, na direita, a soma desses gradientes mostrando qual será a orientação, com base no maior gradiente, ponto chave (LOWE, 1999). Formando assim a descrição do ponto chave encontrado.

Figura 3 - Construção do descritor do ponto de interesse.
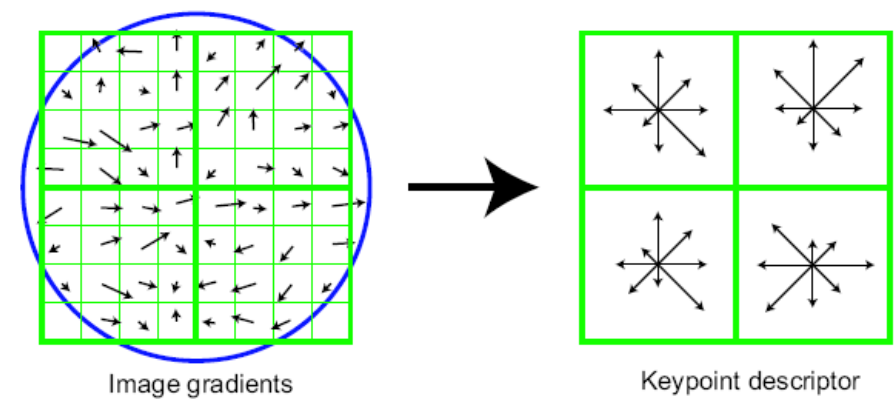

Fonte: Autor "adaptado de"Lowe, 1999.

Após essas etapas, as orientações que tiverem os maiores resultados serão chamadas de características SIFT. Com a obtenção das características, qualquer classificador poderá ser usado para classificar possíveis objetos em uma imagem. Portanto, quando a técnica encontrar um conjunto de características que possam ser parecidas com as que já foram processadas no treinamento do classificador, há grande possibilidade de essas características serem do mesmo objeto. Um exemplo de funcionamento da técnica SIFT com classificador FANN (aproximação rápida de vizinhos mais próximos (MUJA; LOWE, 2009)) é mostrado na Figura 4, na qual à esquerda temos a imagem do cenário e na direita a imagem com as características do objeto alvo sendo comparadas com a imagem do cenário, mostrando a correspondência das características que em alta quantidade reconheceu qual é o objeto que está na cena (LOWE, 1999).

Esta técnica fará parte dos experimentos deste trabalho, para alcançar os mesmos resultados que D. Lowe (1999) obteve ao desenvolver-lá. 
Figura 4 - Características SIFT do cenário correspondendo com as do treinamento.
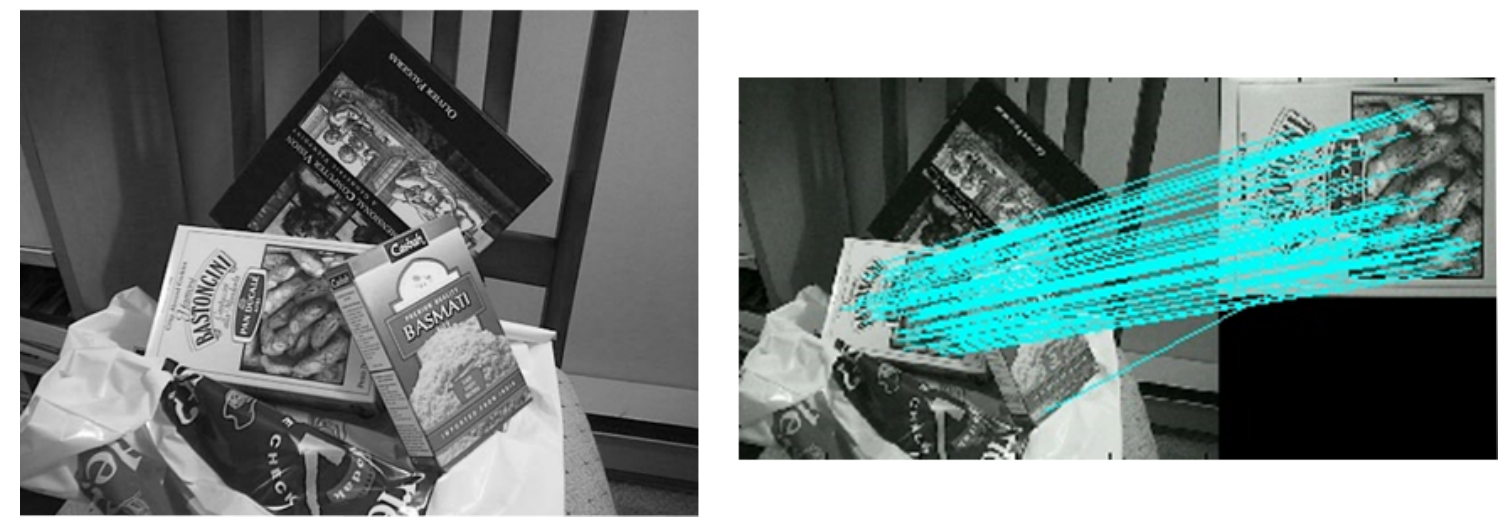

Fonte: Autor "adaptado de"Lowe, 1999.

\subsubsection{HAAR}

HAAR (HAAR, 1910) foi um pesquisador matemático que propôs as ondaletas de HAAR (do inglês Haar Wavelets), sendo utilizado inicialmente no mundo de visão computacional por Viola e Jones (VIOLA; JONES, 2001). A ideia foi aplicar as ondaletas de HAAR para a detecção de pessoas e tentar, ao máximo, vencer os desafios simplificando as imagens digitais. O principal foco do método é rastrear por toda a imagem, utilizando as janelas de pixels, a procura por características HAAR que possam ser consideradas como partes de objetos de interesse. Para encontrar as características HAAR, é feita a soma dos pixels que estão em cada área das janelas e após, é feita a diferença de cada uma das áreas, a fim de encontrar um contorno ou áreas claras e escuras que possam representar alguma característica importante em uma imagem.

De início, quando Viola e Jones (VIOLA; JONES, 2001) utilizaram as características HAAR para encontrar os pontos de interesse, eles estipularam 4 formatos de características (Figura 5). Primeiro formato de característica foi o valor de características de 2 retângulos (Figura 5a e Figura 5b), no qual eles fazem a soma das diferenças das duas áreas do retângulo, sem que o retângulo sofra alterações na dimensão e em sua forma, fazendo com que todos os dados fossem calculados na vertical ou na horizontal. O segundo formato foi um pouco diferente dos outros dois, sendo o valor de características de 3 retângulos (Figura 5c), no qual é feita uma subtração da soma dos valores das extremidades do retângulo pela soma feita no quadrante interno do retângulo. E a terceira e última, foi o valor de características de 4 retângulos (Figura 5d) que efetua o cálculo da diferença da soma dos retângulos diagonais.

Com os retângulos propostos por Viola e Jones (VIOLA; JONES, 2001), percebeu-se uma falta na detecção dos pontos de interesse, na questão do objeto estar rotacionado, ou a borda ser uma curva. Com isso, Lienhart e Maydt (LIENHART; MAYDT, 2002) propuseram uma evolução no que Viola e Jones criaram, que seria a detecção de características com retân- 
Figura 5 - Retângulos para identificação de pontos HAAR.

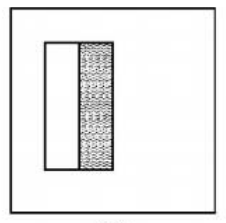

(a)

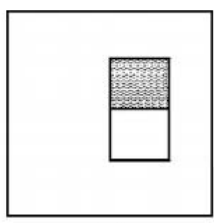

(b)

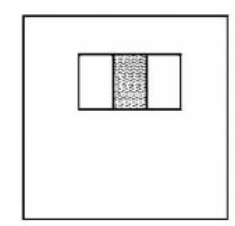

(c)

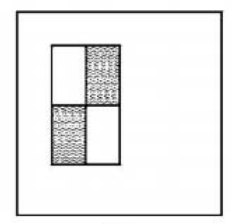

(d)

Fonte: Autor "adaptado de"Viola, Jones, 2001.

gulos com inclinação de $45^{\circ}$ (Figura 6), permitindo assim uma maior amplitude para detectar as características de possíveis objetos na imagem.

Figura 6 - Retângulos para identificação de pontos HAAR com adicionais inclinados.

1. Edge features

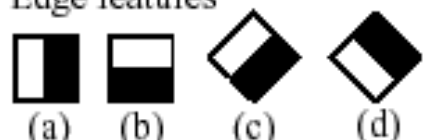

2. Line features

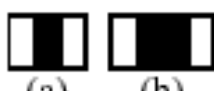

(a)

(b)

(c) (d)
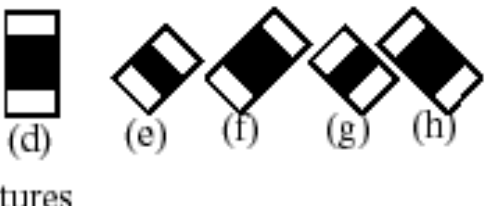

3. Center-surround features

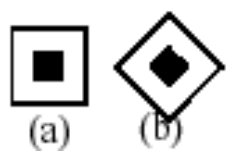

Fonte: Lienhart; Maydt, 2002.

Para ocorrer o reconhecimento de objeto, é necessário um treinamento prévio, conforme a maioria das técnicas de reconhecimento de objetos que serão consideradas neste trabalho. Para executar o treinamento são necessárias diversas imagens dos objetos alvos que deverão ser reconhecidos. Estas imagens são chamadas de "Imagens Positivas". É necessário também utilizar diversas imagens que são chamadas de "Imagens Negativas", e nelas não deve existir o objeto alvo que será reconhecido. Em um arquivo XML são gerados todos as características de HAAR das imagens negativas e positivas.

Quando já estiverem todas as características HAAR postas dentro do XML, o funcionamento do HAAR segue um padrão de espaço de escala dentro de uma janela de pixels testando todos as características salvas, para cada uma que for encontrada na imagem é acumulado a porcentagem dessa correspondência. Essa janela é passada por toda a imagem e, quando a porcentagem de características for $100 \%$, é marcada na imagem as linhas dessa janela informando onde provavelmente está o objeto alvo. Depois a janela é aumentada em escala e assim até que atinja um limiar estipulado. 
No final, quando todos os tamanhos de espaço de escala da janela forem passados, é feita a média das janelas marcadas com 100\% para informar a localidade provável do objeto alvo. Essa técnica é chamada de exposição exaustiva, que faz com que haja uma redução nas chances de a técnica encontrar falsos positivos e aumentam a velocidade com que a técnica faz a detecção do objeto alvo.

Esta técnica fará parte dos experimentos deste trabalho para que possa ser medido seu desempenho, comparando os resultados, com as demais técnicas que serão executadas nos experimentos.

\subsubsection{Histogram of Gradients (HOG)}

Histograma de Gradientes Orientados ou HOG (em inglês Histogram of Gradients) é uma técnica para o reconhecimento de objetos que utiliza uma forma diferente de extrair características de objetos. Sua principal diferença é que, ao invés de encontrar o ponto chave em uma imagem, ele descreve através da distribuição dos gradientes de intensidade dos pixels ou pelas direções das bordas, a aparência e forma de um objeto que esteja disposto na imagem (DALAL; TRIGGS, 2005).

Dalal e Triggs (2005) propuseram com o HOG conseguir identificar pessoas nas ruas. Eles tinham a preocupação com a variação de luminosidade dependendo da hora do dia e a existência de algum poste que esteja alterando a luminosidade na rua. Por conta dessa variação de luminosidade, pensaram na utilização dos gradientes ao invés de usar a intensidade de cada pixel. Utilizando a intensidade de cada pixel, um determinado ponto na imagem com incidência de luz e o mesmo ponto com uma sombra têm valores diferentes de intensidade o que causa uma confusão durante a comparação dos dois pontos. Utilizando gradientes ao invés de cálculos da intensidade de pixel, não é necessária a preocupação com a variação de luminosidade, pois o local que está sendo feito o cálculo dos gradientes tem correspondência dos dois pontos durante a comparação entre duas imagens. E para as pequenas variações que pudessem ocorrer em regiões da imagem, eles pensaram na utilização de histogramas dos gradientes, o que tornou o sistema muito mais robusto e invariante às mudanças durante o processo de extração dos gradientes.

Figura 7 - Sequência para identificação de pessoas na rua.

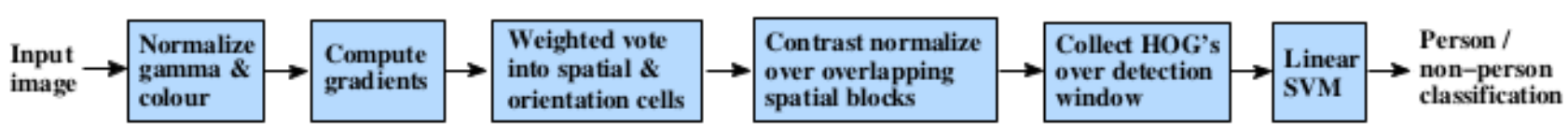

Fonte: Dalal; Triggs, 2005.

Segundo Dalal e Triggs (2005), para a produção dos descritores, o processo deverá ser seguido em cinco etapas, ao final de cada etapa é feita a normalização, como pode ser visto na Figura 7. Primeiro é feito o pré-processamento para a normalização da imagem com o 
objetivo de diminuir a influência dos efeitos de iluminação. Podendo ser opcional esse passo ou até ser substituído, segundo o autor, por outras técnicas como compressão gama, cálculo de raiz quadrada ou o registro de cada canal de cor, tudo de acordo com a necessidade da imagem de entrada. Na segunda etapa, é feito o cálculo dos gradientes de primeira ordem da imagem, capturando os contornos dos objetos, silhuetas e algumas informações de textura, neste ponto aumentando a tolerância a variação de iluminação. Na terceira etapa são construídos os histogramas locais utilizando janelas de pixels para detecção, que são de tamanhos fixos e são movimentadas por toda a imagem executando o cálculo para cada grupo de pixel. Essa janela é dividida em uma grelha de células, de $4 \times 4$ ou $8 \times 8$ pixels, fazendo o cálculo para que cada célula da janela forme um histograma de orientação de gradientes. Em seguida, os blocos de células de 2 x 2 são combinados para normalização do contraste da imagem, assim regulando a luminosidade que o objeto contém e ruídos que possam atrapalhar na quantização de magnitude do gradiente de cada pixel. Magnitude essa calculada para a seleção das melhores orientações por eleição, sendo a orientação de maior magnitude a orientação do ponto. Na quarta etapa, são feitas todas as normalizações para refinar os locais de células e de contrastes para melhorar a invariância à luminosidade, sombras e bordas. Com o agrupamento das células são formados os blocos, e analisando a energia local das vizinhanças dos blocos o resultado será a normalização de cada célula. Os blocos normalizados são definidos como descritores de HOG. Por fim, todos os blocos que estavam na janela são unidos em um único vetor que também está normalizado, formando um descritor da imagem resultante (DALAL; TRIGGS, 2005).

Portanto, Dalal e Triggs (2005) propuseram uma técnica para identificar pedestres. O primeiro passo é a aquisição da imagem; ela é passada por um pré-processamento no qual é feita a normalização do gamma e das cores para que não hajam ruídos e também, para que as bordas e cores estejam bem definidas. Efetuando o cálculo dos gradientes na imagem é realizada a eleição para escolher a melhor orientação e, após definido, aplica-se a normalização do contraste com a sobreposição dos blocos para os cálculos dos histogramas locais. E por último, é feita a utilização da janela em blocos normalizados para definição dos descritores de HOG e aplicando na SVM (CORTES; VAPNIK, 1995) (que será explicada na Seção 2.1.4) para efetuar a classificação e poder dizer se na janela de detecção há um pedestre ou não.

Serão executados testes com essa técnica neste trabalho, para medição da precisão em reconhecer objetos que contém formas diferentes, podendo assim, comparar os resultados e poder rotular se esta técnica é boa no reconhecimento de quais objetos (cilíndricos, irregulares e retangulares) que serão apresentados neste trabalho.

\subsubsection{Speeded-Up Robust Features (SURF)}

SURF (BAY et al., 2008), é uma técnica de extração de pontos chaves de imagens. Ele é muito semelhante ao SIFT, porém, segundo Bay et al. (2008), SURF é muito mais rápido que 
o SIFT e utiliza muito menos recursos computacionais. A proposta da técnica é melhorar as extrações das características sendo mais robusto, tendo repetibilidade e distintividade.

Na detecção de pontos chaves, o principal cálculo que a técnica executa é baseado na matriz Hessiana (Equação 8). A matriz foi escolhida por conter uma elevada precisão em seus resultados. Durante o processo de extração dos pontos chaves da imagem, utilizando a matriz Hessiana, a técnica utiliza os pontos onde o determinante da matriz é máximo. Em uma imagem no ponto $x=(x, y)$, a matriz Hessiana $H(x, \sigma)$ terá $x$ definido utilizando uma escala de $\sigma$. Logo a matriz será:

$$
H(x, \sigma)=\left[\begin{array}{ll}
L_{x x}(x, \sigma) & L_{x y}(x, \sigma) \\
L_{x y}(x, \sigma) & L_{y y}(x, \sigma)
\end{array}\right]
$$

onde $L_{x x}(x, \sigma)$ representa a convolução da derivada gaussiana de segunda ordem $\frac{\partial^{2}}{\partial x^{2}} g(\sigma)$ com a imagem em um ponto $x$, e similarmente para $L_{x y}(x, \sigma)$ e $L_{y y}(x, \sigma)$.

É feita uma aproximação à Matriz Hessiana para verificar se aquele ponto é ou não um ponto chave da imagem. Para isso, são utilizadas derivadas parciais das intensidades dos pixels da imagem. Na detecção do ponto chave, são usados os valores máximos e mínimos do determinante da matriz Hessiana. Para fazer o processamento das derivadas de segunda ordem de Gauss é necessária a utilização de muito processamento computacional, tornando o processo demorado quando aplicado a imagem toda. Pensando nisso, Bay et al. (2008) tendeu a simplificar o processo derivativo utilizando filtragem da imagem, que seria dividir em retângulos, como mostra Figura 8.

Figura 8 - Retângulos para detecção dos pontos chaves.

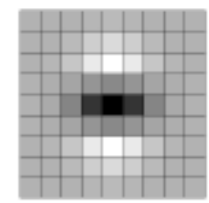

a)

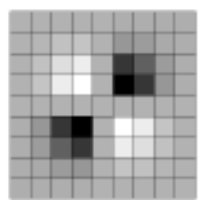

b)

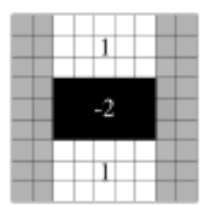

c)

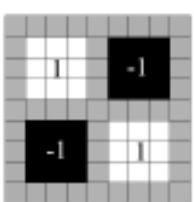

d)

Fonte: Bay et al., 2008.

O funcionamento da técnica SURF é percebido pela ordem das imagens, da esquerda para a direita. Primeiro ele utiliza uma máscara discretizada e cortada da derivada parcial de segunda ordem no ponto $y,\left(L_{y y}\right)$ e $x y,\left(L_{x y}\right)$ (Figura 8 a e b). No segundo passo é feita a aproximação à derivada parcial gaussiana de segunda ordem em $y,\left(D_{y y}\right)$, em $x\left(D_{x x}\right)$ e na direção $x y,\left(D_{x y}\right)$ (Figura $8 \mathrm{c}$ e d). Os quadrados em cinza tem o valor zero.

Supondo um ponto qualquer e utilizando os filtros da Figura 8 , ponto $x=(x, y, \sigma)$, a execução do cálculo do determinante da Matriz Hessiana é feito da seguinte forma:

$$
\operatorname{det}\left(H_{\text {aprox }}\right)=D_{x x} D_{y y}-\left(0.9 D_{x y}\right)^{2}
$$


Com o resultado da Equação 9, é possível utilizá-los nos cálculos para encontrar o determinante da matriz Hessiana para cada pixel da imagem.

Durante a extração dos pontos chaves da imagem, a técnica deverá se comportar invariante a escala, conforme explicado na Subseção 2.1.3.2. A invariação de escala é a deformação que o objeto sofre tendo distância focal em relação a imagem original alterada. No SURF a invariação de escala é feita com espaço de escala e ela é implementada sob a forma de pirâmide invertida, conforme Figura 9.

Figura 9 - Pirâmide invertida.
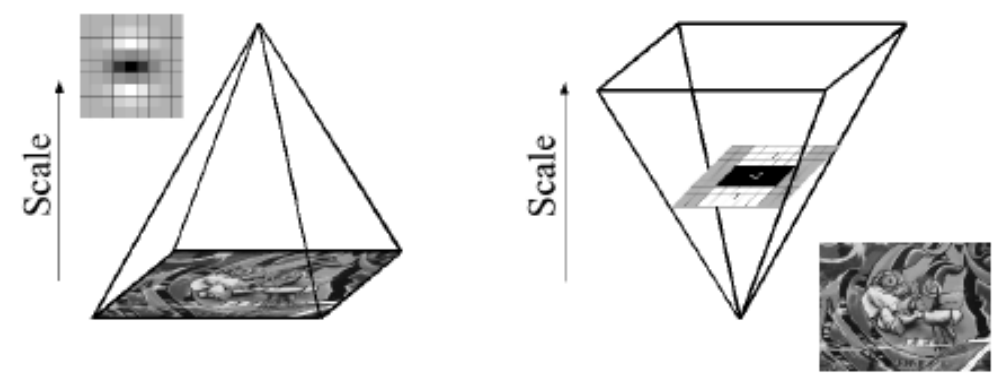

Fonte: Bay et al., 2008.

A utilização de uma pirâmide invertida é muito interessante por não usar apenas a redução do tamanho da imagem para encontrar os pontos chaves, e sim usar imagens integrais que fazem com que tenham uma expansão no filtro sem obter aumento nem diminuição do custo, mantendo constante. Como a escala será diferente por conta da pirâmide, para encontrar os pontos chaves é necessário determinar os máximos e mínimos no mapa de resposta, resultantes dos determinantes calculados da matriz Hessiana (Equação 9), para cada um dos pixels da imagem.

Na Figura 10 pode ser visto uma imagem de um campo de flores onde os círculos são os pontos de interesse encontrados na imagem com base nos máximos encontrados através do determinante da matriz hessiana, e a diferença dos tamanhos dos círculos, põe em prática a funcionalidade do espaço de escala. Para cada medida de diâmetro dos círculos correspondem a um ponto de interesse encontrado em cada patamar do espaço de escala.

E para a última etapa para a detecção dos pontos chaves da imagem, a técnica determina a orientação de cada ponto utilizando filtros HAAR, como explicado na Seção 2.1.3.3, fazendo o mapeamento da variação direcional do ponto em $x$ ou em $y$. Na Figura 11 é mostrado quais são os retângulos de HAAR utilizados.

O retângulo de HAAR identifica todos os pontos que estão ao redor do ponto chave e calcula para cada ponto a direção em $x$ e $y$, utilizando uma ponderação baseada nas distâncias do ponto para o vizinho, tendo como principal resposta os cálculos de uma função Gaussiana. Após, é feita uma soma de todas as orientações que foram estimadas, formando assim, um novo vetor tendendo a proximidade do ponto chave, que poderemos entender melhor ao observarmos 
Figura 10 - Pontos de interesse encontrados em espaços de escalas diferentes.

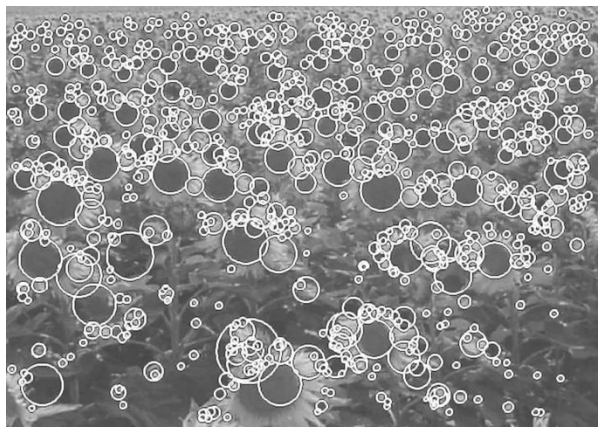

Fonte: Bay et al., 2008.

Figura 11 - Filtros ondaletas de HAAR nas direções $x$ e $y$, respectivamente.
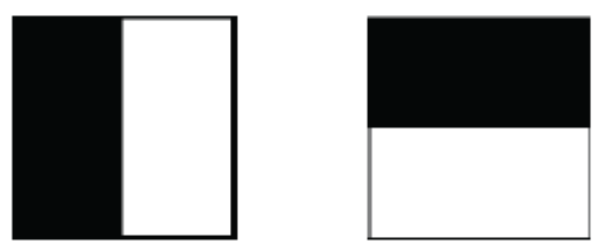

Fonte: Bay et al., 2008.

a Figura 12, que contém os pontos que foram encontrados das orientações em um plano de 360 graus. O maior gradiente é criado pela média da quantidade de pontos existentes na região.

Figura 12 - Determinando orientação do vetor dos pontos chaves.

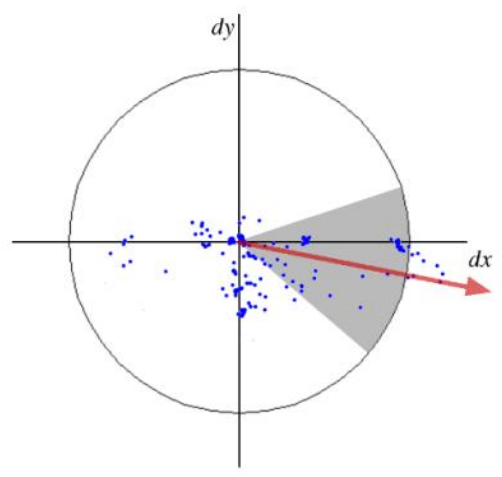

Fonte: Bay et al., 2008.

Na Figura 13 é possível perceber a funcionalidade do SURF encontrando os pontos de interesse em diversos espaços de escala, representados pelos quadrados de diferentes tamanhos e no interior um traço indicando para qual lado os retângulos de HAAR encontraram a maior orientação, representando dessa forma na imagem a orientação do ponto.

O último passo da técnica é extrair os pontos do cenário, utilizando como base os pontos chaves já encontrados do objeto. A técnica encontra os pontos chaves do ambiente e é criado a partir do centro desse ponto encontrado um quadrado onde ele verifica as respostas das mesmas 
Figura 13 - Ponto de interesse com a orientação.

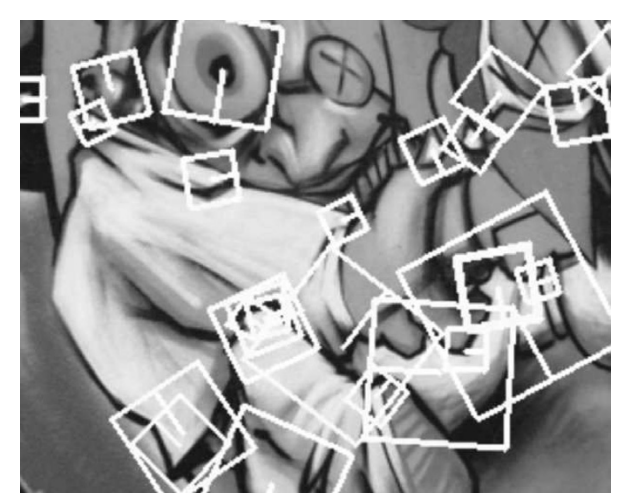

Fonte: Bay et al., 2008.

Ondaletas de HAAR utilizados no treinamento, encontrando também os vetores de cada ponto. Em seguida, é feita uma comparação com os vetores dos pontos chaves que existem da base treinada com a imagem da cena, possibilitando afirmar se aquele é um objeto conhecido ou não. Podemos verificar na Figura 14 como é feita a soma dos vetores dos vizinhos e como é gerado um vetor maior que servirá para as devidas comparações.

Figura 14 - Orientação dos vetores dos pontos chaves do cenário.

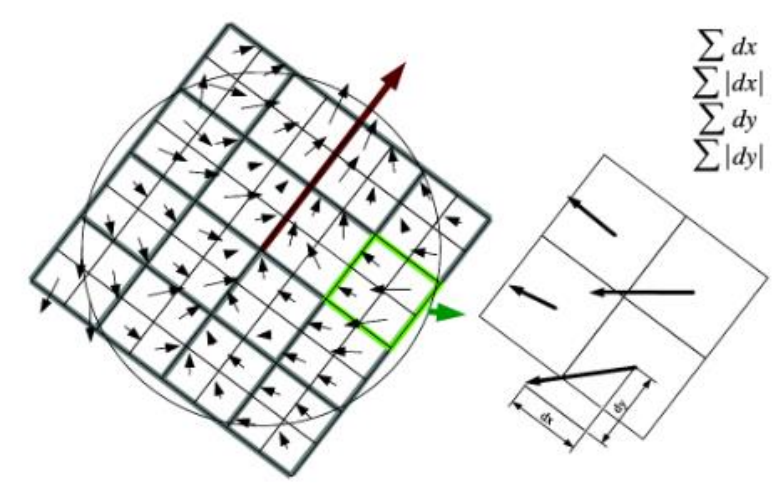

Fonte: Bay et al., 2008.

Finalizando assim o processo de identificação e descrição dos pontos chaves encontrados na imagem, para que sejam utilizadas para treinamento de classificadores e, após o classificador treinado, sejam utilizados para extrair os pontos chaves de novas imagens para que sejam executados os testes no classificador.

Está técnica também fará parte dos experimentos deste trabalho. Utilizado para comparação com as outras técnicas durante o reconhecimento de objetos de diferentes formas, sendo os cilíndricos, retangulares e irregulares. 


\subsubsection{Oriented FAST and Rotated BRIEF (ORB)}

ORB (2011) tem uma proposta muito interessante, ele foi elaborado para superar as técnicas SIFT (Seção 2.1.3.2) e SURF (Seção 2.1.3.5). Essa superação seria na velocidade em extrair pontos chaves da imagem e também em poder ser acessível para qualquer dispositivo móvel, portanto, sendo possível execução em dispositivos com baixa capacidade de processamento. ORB é quase duas ordens de magnitude mais rápido que SIFT e uma ordem mais rápida do que o SURF, produzindo também resultados similares no reconhecimento de objetos (RUBLEE et al., 2011).

Na extração de pontos chaves, ORB foi desenvolvido, utilizando dois principais conteúdos da literatura que seriam o FAST (TUYTELAARS et al., 2008), para a detecção dos pontos de interesse, e o descritor BRIEF (CALONDER et al., 2010).

Os pontos de interesse encontrados por FAST utilizam a medida de canto de Harris (descrito na Seção 2.1.3.1), e não possui a representação da orientação do ponto chave, e com isso, surgiu a necessidade de Rublee et al. (2011) encontrassem uma alternativa para o problema, implementando então a utilização da intensidade do centroide (ROSIN, 1999). Este método assume que a intensidade do canto é deslocada de seu centro, e portanto, poderá ser descrita por um vetor que vai do centro do ponto para o centroide (RUBLEE et al., 2011).

Com o ponto de interesse identificado, a técnica então aplica o descritor BRIEF que constrói uma sequência binária que representa um patch de imagem. Para a construção da sequência binária é utilizada uma série de testes binários os quais passam por avaliação de cada patch da imagem, e depois, estas passam por uma função que soma todas as avaliações. Porém, BRIEF não é invariante a rotações dos planos e o ORB veio com uma alteração no BRIEF fazendo com que ele seja guiado pela orientação dos pontos chaves (Equação 10), tornando assim, invariante à rotação (RUBLEE et al., 2011).

$$
\Theta=\arctan 2\left(m_{01}, m_{10}\right)
$$

onde $\Theta$ é a orientação que será aplicada ao ponto junto com BRIEF.

O ORB funciona da seguinte forma: com os patchs criados pelo modelo alterado de BRIEF, chamado de BRIEF dirigido, é construída uma tabela de pesquisas padrões, e após, são utilizados os testes binários para ter uma alta variação nos padrões gaussianos de bits nas características. Cada teste é executado com todos os patches, ordenando os testes por uma distância média de 0,5 , formando assim, o vetor $\mathrm{T}$. Depois de feita a pesquisa no vetor $\mathrm{T}$, cada resultado é posto no vetor $\mathrm{R}$ e removido de $\mathrm{T}$. A última parte é executar novamente um teste no vetor $\mathrm{T}$ e comparado com todos os resultados que já estão em $\mathrm{R}$, se a correlação for inferior a um limiar, este valor é posto no vetor $\mathrm{R}$, se os valores forem excedentes desse limiar então são descartados. Esse processo é feito até que alcance um valor de 256 teste e o limiar seja reajustado. Caso não alcance a quantidade de testes estipulada como aceitável (RUBLEE et al., 2011). 
Figura 15 - Correspondência dos pontos utilizando ORB.

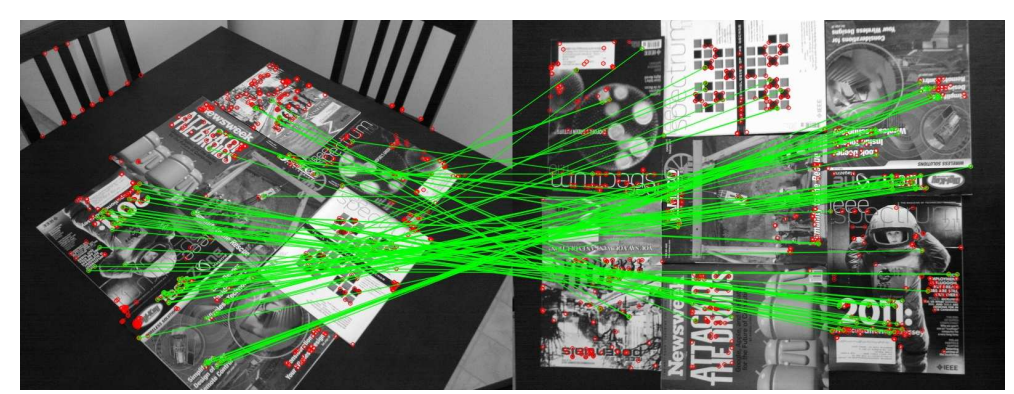

Fonte: Rublee et al., 2011.

Na Figura 15 a execução da técnica em um cenário à esquerda e o objeto que mais teve correspondência à direita. Os pontos vermelhos significam os pontos encontrados pela técnica e os que tiveram correspondência são os que estão com as linhas em verde, mostrando qual ponto do cenário foi correspondente com o ponto do objeto.

\subsubsection{Classificadores}

Existem diversos classificadores na literatura. Dentre eles, existem os que utilizam árvores de decisão, e até cascata de classificadores (FREUND; SCHAPIRE, 1995). Será apresentado neste trabalho o SVM - Support Vector Machine (CORTES; VAPNIK, 1995). Sua escolha deve-se a Dalal e Triggs (2005), que utilizaram o SVM na classificação dos gradientes para identificar pedestres, por ter boa generalização e flexibilidade em separar hiperplano em diversas dimensões (RUSSELL; NORVIG, 1995).

\subsubsection{Support Vector Machine (SVM)}

Máquina de Vetores de Suporte (em inglês Support Vector Machine - SVM) é uma técnica de aprendizado de máquina supervisionado e que foi desenvolvida por Cortes; Vapnik (1995) para análise de dados e reconhecimento de padrões (estimar funções indicadores). Muito utilizado para classificação e análise de regressão (estimar funções de valores reais), com base na teoria de aprendizado estático. Aprendizado estático busca encontrar um bom classificador, com bom desempenho, para manusear um conjunto de dados (LORENA; CARVALHO, 2003).

Existem três propriedades principais que incentivam a utilização das SVM's. A primeira delas é que as SVM's proporcionam uma boa generalização, fazendo o uso de separadores de margem máximos que são fronteiras de decisão. Fronteira essa que abrange a maior distância possível com relação aos pontos de uma amostra. A segunda propriedade é que as SVM's criam uma separação linear em hiperplano, pode-se também, introduzir os dados em um espaço de dimensão superior com a utilização do truque de kernel. Com ele é possível fazer com que os dados sejam separados facilmente no espaço de dimensão superior, quando não são separados 
linearmente no espaço original. E por fim, a última propriedade, a SVM é um método não paramétrico na qual todas as amostras de treinamento deveriam ser armazenadas, porém, durante a execução não são todas as amostras que são armazenadas, apenas uma pequena fração. Portanto, as SVM's mesmo assumindo serem não paramétricas combinam partes das paramétricas, tornando flexíveis na representação de funções complexas e sendo resistentes às superadaptações (RUSSELL; NORVIG, 1995).

A Figura 16 mostra como é o funcionamento de uma SVM com duas classes espalhadas pelo gráfico (pontos preenchidos e pontos não preenchidos). A linha mais escura é denominada separador máximo de margem, já citada anteriormente. Cada uma das linhas tracejadas são os vetores de suporte que se baseiam pelos pontos com círculos maiores ao redor (RUSSELL; NORVIG, 1995).

Figura 16 - Exemplo de classificação do SVM.

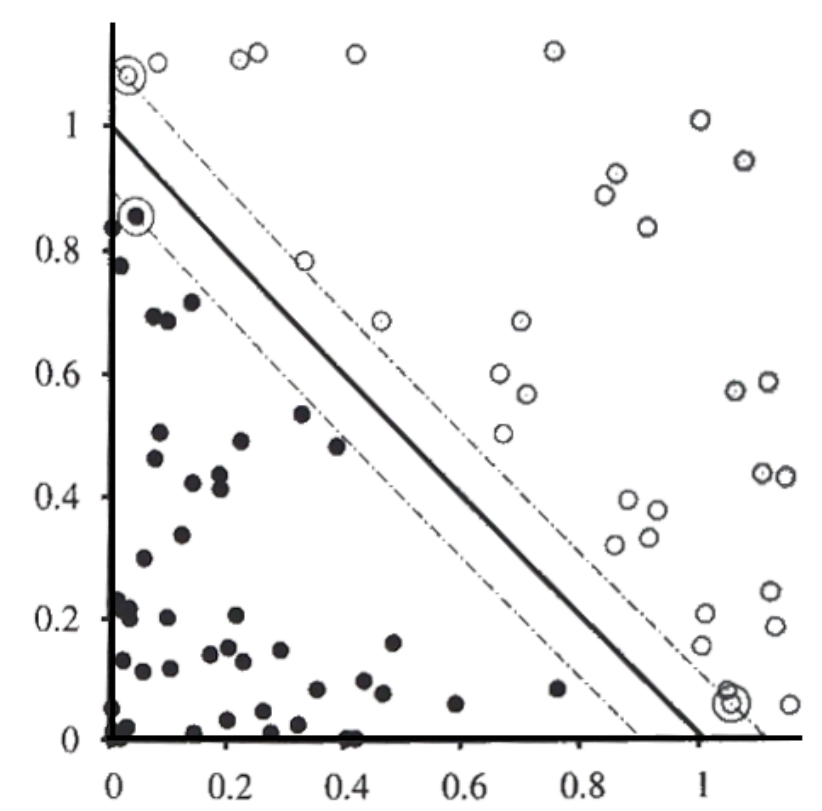

Fonte: Russell; Norvig; Intelligence, 1995.

Nem sempre os dados de entrada de uma SVM poderão ser separados linearmente. Para que a SVM consiga fazer a separação, os dados de entrada poderão ser mapeados e ir para um espaço de dimensões superiores. Assim, eles quase sempre poderão ser separados linearmente. O mapeamento é feito por uma função específica denominada de função truque de kernel, sendo aplicada aos pares dos dados de entrada para que os produtos escalares sejam avaliados em algum espaço de características de interesse. Porém, a utilização de espaços de dimensões superiores são computacionalmente custosos e se forem muito superiores podem tornar o processo inviável para computadores de uso convencional (RUSSELL; NORVIG, 1995).

Para que a SVM tenha precisão na separação, existe um parâmetro que permite maior flexibilidade na classificação, um Parâmetro de Custo (C). Sua função é executar a melhor separação das classes, podendo até aceitar dados que estavam em outra classe. Com isso, a alteração 
neste parâmetro pode causar tanto uma classificação específica como genérica. Sendo um parâmetro muito determinante para a funcionalidade do classificador. Por causa disso, existem dois métodos para encontrar o melhor valor deste parâmetro no exato momento onde os vetores de dados para classificação são enviados a SVM, sendo eles os que utilizam pesquisa de grade e o padrão de busca (ANDREW, 2000). Pesquisa de grade utiliza passos geométricos para testar todos os valores do parâmetro em toda a faixa de busca e a busca padrão que começa no centro da faixa de busca, executando experimentos em cada sentido. Assim, analisando os vetores de entrada e ajustando o parâmetro para uma melhor classificação dos dados.

Durante a execução do treinamento foi gerado um vetor de característica, sendo um vetor com todas as características das imagens de todos os objetos, separando este vetor em uma porcentagem para treino e outra para teste. O que o classificador SVM executará é a criação de um hiperplano maximizando a separação entre esse vetor de treino, encontrando a melhor separação dos dados para o vetor de teste ser inserido. As imagens, em um processo anterior, são embaralhadas, para assim, tornar o treino da SVM mais robusto e não tornar-se viciado os valores de entrada. E em seguida, na execução do teste com o restante do vetor, foram enviadas ao classificador SVM para que faça a classificação e a geração da matriz de confusão dos resultados obtidos.

Portanto, o processo que foi utilizado neste trabalho para inserir os dados no SVM foi feito da seguinte forma: Os dados para inserção no classificador teve que conter tanto um vetor com as características do objeto como outro vetor com a classe que essas características pertencem. Todos os dados estavam em vetores numéricos inteiros. Em seguida, foi utilizada a verificação para adequação dos parâmetros de separação dos valores de entrada, por pesquisa de grade.

Para validação do classificador, foi utilizado o método de validação cruzada (KOHAVI et al., 1995), garantindo assim, a confiabilidade dos resultados obtidos. Depois, com o restante do vetor separado para teste, foram inserido novamente na SVM sem o vetor com as classes esperadas, finalizando todo o processo na geração das matrizes de confusão onde foi notável a eficiência de cada técnica.

Finalizando o entendimento, o classificador SVM é de extrema importância para o processo de reconhecimento de objeto. É nele que foi possível dizer se em uma determinada imagem há um objeto específico. Para isso, foi executado o treino passando "quais características são"junto de "qual objeto é", demonstrando o porque a técnica é classificada como aprendizado de máquina supervisionado, para que o classificador separe de acordo com cada objeto. E para o teste, foi entregue o vetor com novas características, sem dizer de qual objeto é, para que ele, em sua separação de treino, diga qual é o objeto. 


\section{TRABALHOS RELACIONADOS}

O principal foco do trabalho de Lowe $(1999,2004)$ foi a criação de uma nova técnica onde pudesse, através de pontos chaves encontrados em imagens, reconhecer objetos que possam estar em diversas condições em ambientes. As preocupações para reconhecer objetos seriam a de que o objeto está em diferentes tamanhos em escala, com muita ou pouca luminosidade, o objeto em outra posição e as possíveis obstruções que podem ocorrer ou por outros objetos ou móveis. Com todas essas variáveis, Lowe (1999) criou a técnica SIFT em 1999 para superar essas dificuldades durante o reconhecimento de objetos (técnica foi explicada na Seção 2.1.3.2). Está técnica é muito utilizada pela comunidade para o reconhecimento de objetos em ambientes com essas dificuldades citadas. Lowe (2004) na criação da técnica utilizou Best-Bin-First (BBF) para aproximar os pontos positivos do objeto pelo pontos negativos que não eram do objeto. Com essa abordagem BBF encontra com mais probabilidade os pontos da vizinhança, aglomerando os pontos positivos. Com isso ele conseguiu encontrar objetos mesmo com obstrução parcial ou com problemas de ambiente (iluminação, rotação e escala), com uma quantidade pequena de pontos chaves foi possível estimar sua posição e reconhecer. A semelhança para este trabalho é a da utilização da técnica para o auxílio no reconhecimento de objetos e a principal diferença é a utilização da SVM ao invés do classificador mínimos quadrados

Bay et. al (2008) criaram a técnica SURF de detecção de pontos chaves em imagens, seguindo a ideia de Lowe (1999) e aperfeiçoando o método na utilização para reconhecimento de objetos. A principal diferença foi na utilização da matriz Hessiana e todos os passos que foram explicados na Seção 2.1.3.5. Eles fizeram um comparativo de qual técnica conseguiu executar melhor o reconhecimento, sendo as técnicas SURF, SIFT e GLOH (LIANG et al., 2011). Bay et. al (2008) conseguiu mostrar que o SURF foi superior em Detecção por Alarme Falso, sendo mais eficiente e mais rápido para detectar objetos que as outras duas técnicas, como pode ser visto na Figura 17 superior a curva gerada. E utilizando o comparativo de quantidade de pontos chaves encontrados que sejam do objeto alvo, SURF também demonstrou ser melhor, podendo ser observado na Figura 17 inferior. A principal semelhança dessa pesquisa para este trabalho é a comparação das técnicas para conseguir diversificar qual é melhor em reconhecer objetos e as diferenças são na utilização de outras técnicas, ao invés do GLOH, serão utilizados SIFT, SURF, ORB, HAAR e HOG. E outro será a diferença da técnica de classificação, que será utilizado a SVM.

O artigo de Silva et al. (2013) propõem um estudo de comparação das técnicas de detecção de ponto chaves com descritores. Ele utiliza as técnicas SIFT, SURF, FAST, STAR (um derivado da técnica CenSurE (AGRAWAL; KONOLIGE; BLAS, 2008)), MSER (MATAS et al., 2004), GFTT (Com Harris) proposto pelo autor (SILVA et al., 2013), GFTT (SHI et al., 1994) e ORB, e os descritores: SIFT, SURF, BRIEF e ORB. Aplicando eles em uma imagem para testar o tempo de processamento (TP), o número de pontos chaves correspondentes (NIn) 
Figura 17 - Gráfico de comparativo da execução das técnicas.
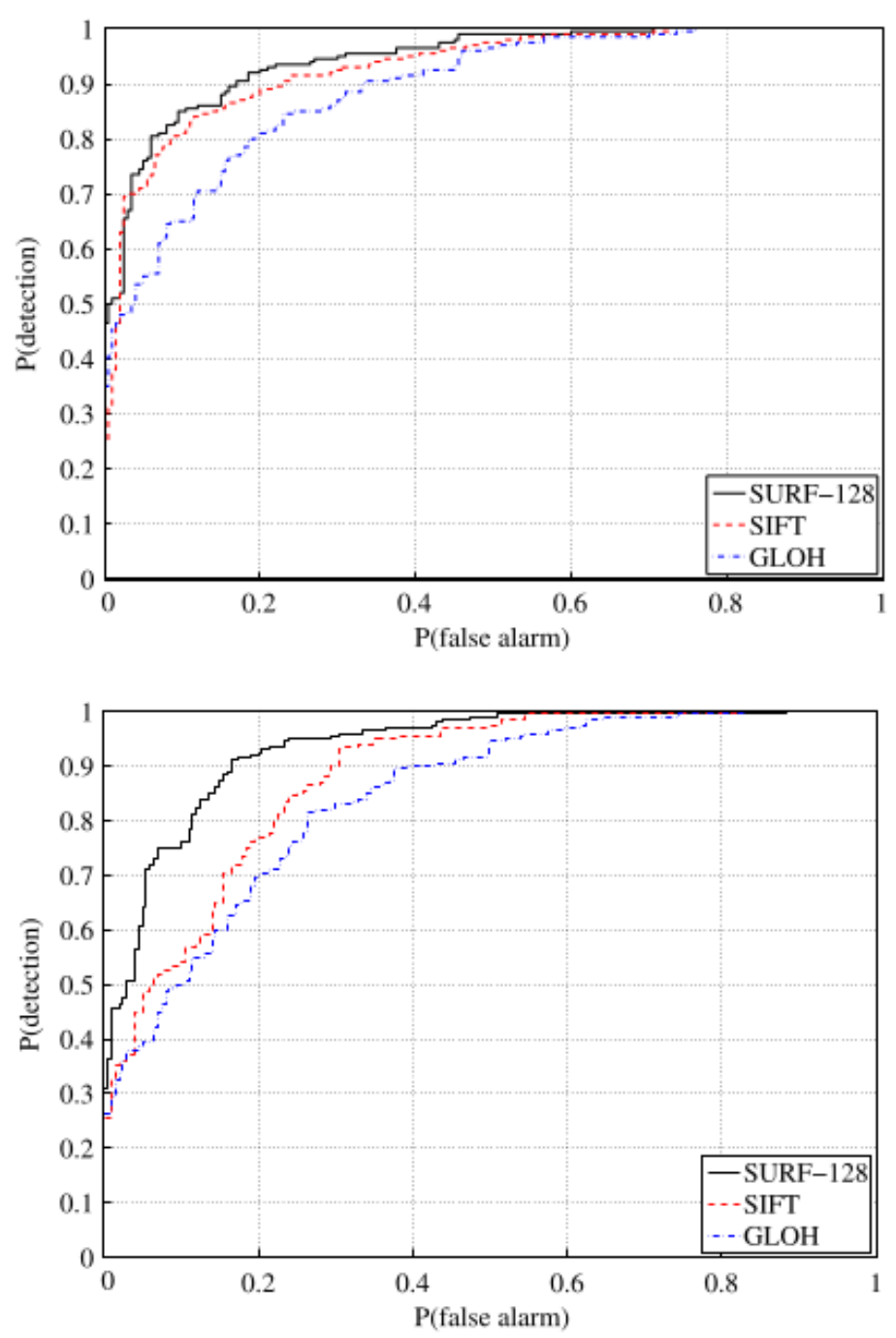

Fonte: Bay et al., 2008.

e geração de matriz homográfica. Foram feitas alterações na imagem com borramentos, escala, iluminação, rotação, ruído em imagens separadas e, colocando todas essas alterações juntas em uma nova imagem. Concluindo que as melhores técnicas foram utilizando o detector SIFT e descritor SIFT, detector ORB com o descritor ORB. O que se assemelha a este trabalho é o comparativo entre as técnicas SIFT, SURF e ORB. O que difere da aplicação com o que será proposto neste trabalho, é o uso das técnicas de detecção e na análise de desempenho no reconhecimento de objetos. E serão utilizados os descritores SIFT, SURF, ORB, HAAR e HOG; Com o classificador SVM.

Na pesquisa de Vilão e Bianchi (2016), Vilão et al. (2014) e Vilão Jr et al. (2016) foi feito o estudo de visão computacional para reconhecimento da bola, trave e adversários em robôs autônomos monoculares para a competição de futebol de robôs Kid-Size, da RoboCup. Durante o estudo foram abordadas duas técnicas de descrição e duas de classificação. Foi feito o comparativo de HOG utilizando o classificador SVM e o HAAR com o classificador AdaBoost 
(FREUND; SCHAPIRE, 1995). Notou-se que, como a exigência para o futebol de robô é a velocidade de processamento, o HAAR com AdaBoost tiveram um desempenho melhor; porém, observou-se que a luminosidade do ambiente real foi o principal problema. No caso do HOG com SVM, foi descoberto que a resolução melhor para alcançar o resultado desejado teria que ser menor que HD (720x1080) e foi utilizada a resolução 640x480. Na proposta deste trabalho será aplicado o HAAR e HOG, com as seguintes diferenças: a primeira, o tempo de resposta não será o diferencial, devido na competição @ Home o robô estará parado de frente a uma prateleira e poderá esperar mais tempo para processar a imagem; e segunda, serão aplicadas as técnicas para vários tipos e formas de objetos.

Na competição de futebol de robôs small size da RoboCup, o trabalho de Silva Barros et al. (2016) utiliza a técnica SIFT para encontrar os símbolos (Figura 18, (a) Deus, (b) Amor, (c) Alegria e (d) Fé) que ficam em cima de cada robô para que sejam tomadas as decisões do jogo. Silva Barros et al. (2016) fizeram essa pesquisa, utilizaram como comparativo as técnicas SIFT e ORB para saber qual delas tinha melhor tempo de resposta e qual conseguiria reconhecer os símbolos. Aplicaram as técnicas SIFT e ORB juntamente com RANSAC (FISCHLER; BOLLES, 1981) para conseguir delimitar onde estavam os símbolos, eliminando os pontos não úteis, chamados de outliers e deixando apenas os pontos úteis, chamados de inliers. À princípio, fizeram os testes para saber qual das duas técnicas, escolhidas por conta da pesquisa de Silva et al. (2013), iriam reconhecer melhor os símbolos e chegaram a conclusão que o SIFT se comportou melhor que o ORB, porém o tempo de processamento não agradou, por se tratar de um jogo de futebol onde o tempo é crucial para alcançar o objetivo, o gol. Com essa dificuldade eles aplicaram a técnica, não em uma CPU (computadores convencionais) e sim, em uma GPU (GPUs são os processadores programáveis de placas de vídeos), tendo ao final a melhora no desempenho, como pode ser visto na Figura 19, para cada imagem de símbolo foi calculado o tempo de processamento para o reconhecimento e utilizando GPU o tempo de todos foram abaixo de 500 milissegundos. A principal semelhança para este trabalho é a utilização das técnicas SIFT e SURF e a principal diferença é a não comparação dos dados com o processamento da CPU e GPU, sendo utilizado apenas com a CPU de computadores convencionais.

Figura 18 - Símbolos utilizados para diferenciar jogadores no campo de futebol de robôs.

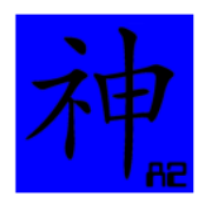

(a)

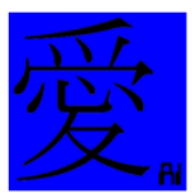

(b)

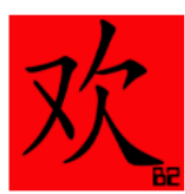

(c)

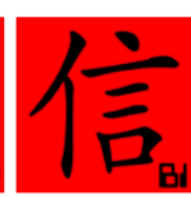

(d)

Fonte: Barros et al., 2016.

No artigo de Macedo et al. (2015) e Macedo e Fernandes (2015) foi proposto a utilização de técnicas de extração de pontos chaves, SURF, para o reconhecimento de logomarcas de 
Figura 19 - Desempenho do algoritmo SIFT com CPU e GPU.

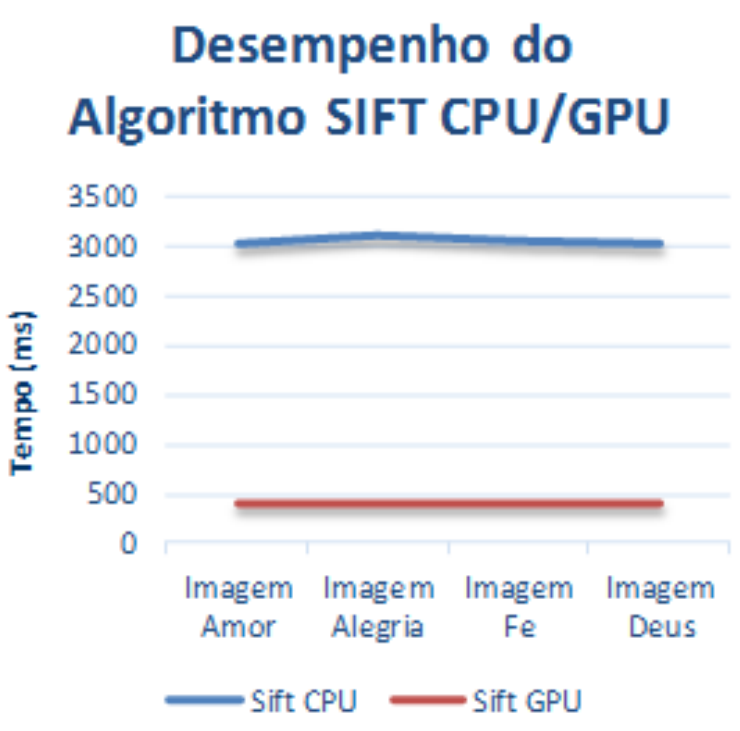

Fonte: Barros et al., 2016.

carros. Utilizaram técnicas de segmentação de médio nível para encontrar a placa do veículo e após marcar uma região acima da placa onde provavelmente está a logo marca do veículo. Com a região demarcada do restante do veículo, o autor aplica a técnica SURF para fazer a extração dos pontos da imagem cortada. Após a extração, são gerados os pontos que são da logomarca (inliers) e os pontos que não são da logomarca (outliers), com isso é necessário a aplicação de um método que faça a separação desses pontos e sejam apenas escolhidos os pontos da logomarca, os autores utilizando o método RANSAC. A principal semelhança dessa aplicação para este trabalho é a utilização do SURF no reconhecimento e a diferença é na utilização do classificador SVM e não pelo método RANSAC.

Na competição da RoboCup todas as equipes fazem o uso de técnicas para reconhecimento de objeto. Entre as três primeiras colocadas da última edição que ocorreu na Alemanha em Liepezig, a campeã foi a equipe ToBi (Team of Bielefeld) (MEYER ZU BORGSEN; KORTHALS; WACHSMUTH, 2016), que utilizou para o reconhecimento dos objetos o PCL (Point Cloud Libary) (RUSU; COUSINS, 2011), para estimar todos os objetos da cena e criou um cenário 3D, aplicando como técnicas de descritores o GIST (OLIVA; TORRALBA, 2001), ColorSHOT e FPFH (RUSU; BLODOW; BEETZ, 2009); e como classificador utilizaram SVM e Árvore de Decisão.

O segundo colocado foi o Tech United Eindhoven (LUNENBURG et al., 2016), no qual também fizeram a utilização do PCL (RUSU; COUSINS, 2011) para estimar os objetos criando o cenário 3D.

O terceiro colocado foi a equipe do WrightEagle@HOME (SHUAI et al., 2016) com uma abordagem um pouco diferente. Eles utilizaram PCL com SURF para fazer o reconhecimento de objetos e tiveram diversas dificuldades com a luminosidade do ambiente, mas, o 
PCL segmentando a imagem e depois a utilização do SURF foram suficientes para extrair as características do objeto.

Neste trabalho não serão aplicadas técnicas que precisam da utilização de sensores infravermelhos, como o kinect Zhang (2012), que permitem a modelagem dos objetos da imagem em 3 dimensões. Será utilizada uma câmera full HD para a extração das imagens para processamento.

A Tabela 1 é um demonstrativo das técnicas utilizadas para encontrar os objetos e os classificadores utilizados. Muitas informações não são disponibilizadas devido à competição, portanto existem os dados "N/A"na tabela por não constarem informações sobre o classificador utilizado.

Tabela 1 - Tabela das técnicas utilizadas pelas equipes na competição RoboCup

\begin{tabular}{r|r|r} 
Equipe & Técnica & Classificador \\
\hline ToBi & PCL/GIST/ColorSHOT/FPFH & SVM/Árvore de Decisão \\
Tech United & PCL & N/A \\
WrightEagle@HOME & PCL/SURF & N/A \\
Fonte: Autor &
\end{tabular}

A utilização de técnicas de extração de característica em reconhecimento de objetos pode ter sucesso em campos diferentes, como na área de segurança. No artigo de Flitton, Breckon e Bouallagu (2010) foi utilizado o SIFT para reconhecimento de armas em ultrassom de aeroportos. O ultrassom extrai uma imagem 3D; neste caso, foi preciso uma alteração na técnica para que as informações dos pixels processassem na terceira dimensão. Todos os passos que o SIFT 2D executa, desde a filtragem usando a DoG, foram alteradas aumentando uma dimensão utilizando a variável " $z$ ". Portanto, no cálculo da diferença de Gaussianas ficou $\operatorname{DoG}(x, y, z, k)$. Na matriz Hessiana para encontrar o canto do objeto também sofreu o aumento de uma dimensão tornando a matriz 3 x 3 . Para considerar a orientação de cada ponto, foi feita a adição de 3 ângulos, sendo azimute, elevação e inclinação. Com isso, a arma poderá estar apontada para a mesma região, porém, em três diferentes possibilidades de posição.

Depois, durante a execução da classificação dos dados da cena, eles utilizaram primeiramente a distância Euclidiana, e após, foi feita a classificação novamente utilizando o modelo de regressão RANSAC de Fischler e Bolles (1981), assim, conseguiram com mais rapidez encontrar o objeto dentro de uma mala.

A utilização do SIFT foi útil para o projeto por conta da robustez que a técnica contém com relação à invariância à obstrução parcial de objetos dentro de uma mala de viagem. Obstruções não podem atrapalhar durante a fase de reconhecimento de objetos. Por isso, SIFT é um grande candidato a ser utilizado em ambientes residenciais. A principal diferença deste artigo para o que será feito neste trabalho é a utilização de uma câmera e SIFT 2D e o classificador SVM. 
No trabalho de Leonardo Almeida Rodrigues et al. (2014) a proposta foi criar uma junção entre as técnicas SIFT e o detector de canto de Harris. O principal motivo é a execução da detecção da técnica de Harris ser mais rápida e eficaz porque ele encontra os autovetores da matriz de segundo momento e adicionado ao descritor SIFT, contendo alta repetibilidade e boa propriedade de correspondência. Também foi utilizada a técnica SURF servindo de comparativo por ser mais rápido em tempo de execução do que o SIFT (BAY et al., 2008), e o regressão foi o RANSAC (FISCHLER; BOLLES, 1981), com a proposta de comparar os pontos chaves que tiveram correspondência com os que não tiveram. O estudo concluiu que o SIFT conseguiu ser melhor que todos os outros, porém, o Harris-SIFT obteve bons resultados com relação ao tempo de processamento e quantidade de pontos que foram correspondentes. $\mathrm{O}$ diferencial que pode ser visto deste projeto para o que será apresentado neste trabalho é que o classificador é diferente e a proposta de junção não será feita unificando duas técnicas em apenas uma e, sim, utilizar técnicas que executem melhor as funções para cada tipo de objeto em paralelo. 


\section{ANÁLISE DE ALGORITMOS PARA RECONHECIMENTO DE OBJETOS}

Este capítulo está dividido nas seções materiais e métodos e domínio. Na primeira seção serão apresentados os materiais e métodos utilizados neste trabalho, qual será a arquitetura utilizada neste projeto, a base de imagem que comportará os testes, a metodologia aplicada e a coleta de informações. Na segunda seção será apresentado o domínio da RoboCup, como é feita a etapa de reconhecimento de objetos e a descrição da arena que é montada para a competição.

\subsection{MATERIAIS E MÉTODOS}

Este trabalho realiza a comparação de técnicas utilizadas para reconhecimento de objetos (técnicas apresentadas na Seção 2.1.3) e avalia qual é a melhor em reconhecer três formatos de objetos que podem ser encontrados em ambientes residenciais. O principal foco foi a análise do desempenho das técnicas durante o reconhecimento de tipos de objetos que contém formas diferentes, sendo eles objetos cilíndricos, retangulares e irregulares. Classificando cada técnica com sua melhor capacidade atrelado ao tipo de objeto.

Inicialmente foram realizados testes das técnicas de reconhecimento de objetos em imagens da base de imagens da ALOI (Amsterdam Library of Object Images (GEUSEBROEK et al., 2005)) que contém variações de luminosidade e de posição e após, foram executados testes no laboratório em ambiente com variações que são encontradas em qualquer residência. Também foi utilizado a biblioteca OpenCV (BRADSKI; KAEHLER, 2008) criada para a área de visão computacional, que suporta todo conteúdo necessário para o desenvolvimento deste trabalho, como também o suporte da linguagem Python que foi utilizada (será explicada melhor na Seção 4.2). As técnicas que foram testadas foram SIFT; HAAR; HOG; SURF; ORB; com classificador SVM.

As técnicas foram escolhidas com base nas equipes do RoboFEI. As técnicas SIFT, SURF e ORB estão implementadas no robô da equipe @Home e as técnicas HOG e HAAR foram escolhidas por terem sido testadas na equipe Futebol de Robô. O classificador utilizado foi o SVM que também foi utilizado pela equipe do Futebol de Robô juntamente com a técnica HOG (igual Dalal e Triggs (2005) utilizaram). Formando assim, a base de técnicas para a aplicação e comparação.

Todas as técnicas foram executadas com os objetos colhendo resultados em matrizes de confusão, cujas médias das precisões serão usadas nos cálculos de Desvio Padrão e Padrão de Erro, como sendo os principais métodos para a avaliação das técnicas.

\subsection{ARQUITETURA}

Para a arquitetura foi utilizada a biblioteca OpenCv (Open Source Computer Vision Library) Bradski e Kaehler (2008), uma biblioteca multiplataforma aberta e gratuita feita es- 
pecialmente para a manipulação de imagens e que nos permite a utilização dos recursos para efetuarmos o reconhecimento de objetos. Essa biblioteca possui diversas funcionalidades, como por exemplo, a aplicação de filtros na imagem, calibração de câmeras, segmentação da imagem, vasta biblioteca de técnicas que são utilizadas para efetuar o reconhecimento de objetos, entre outras. Ela foi desenvolvida pela Intel Corporation com a finalidade de fornecer a base para o desenvolvimento de aplicações que utilizam visão computacional.

A biblioteca OpenCV foi utilizada neste trabalho para fazer a captura de imagem, via câmera, para a extração das características e efetuação das comparações dos padrões colhidos. Ela permite a utilização de diversas linguagens de programação, entre elas C++, Java, Python, entre outras.

Foi utilizado também a biblioteca SCIKIT-LEARN... (2017) que está em Python. Uma biblioteca que tem todo o suporte para as técnicas de aprendizado, por exemplo o SVM (Subseção 2.1.4.1), entre outras que executam classificação ou regressão de dados. Tendo também formas de apresentação dos resultados bem elaboradas, já vinculadas a biblioteca, facilitando assim, o processo de extração e visualização dos resultados.

O sistema todo foi desenvolvido na linguagem Python, por ser uma linguagem interpretada, com diversas bibliotecas e métodos implementados para os fins de utilização na visão computacional e por ser uma linguagem utilizada no grupo de estudo do RoboFEI. Todos as técnicas para reconhecimento de objetos que foram usadas nesse trabalho estão disponíveis nessas bibliotecas.

Para a captura de imagem foi utilizado uma câmera da marca Logitech C920 Pro 15 mega pixel (Figura 20), essa câmera grava as imagens em full HD (high definition, em português Alta Definição) sendo 1920x1080 pixels com 30 quadros por segundo.

Figura 20 - Câmera Logitech C920 PRO 15MP Full HD.

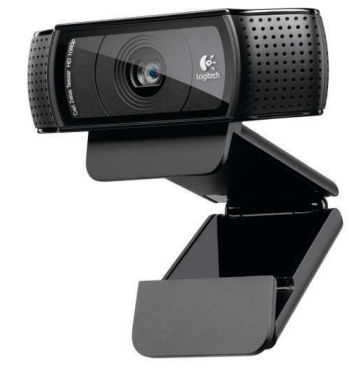

Fonte: https://www.logitech.com/pt-br/product/hd-pro-webcam-c920 acessado 09/04/2017.

Na Tabela 2 está descrito qual foi a arquitetura do computador utilizado para este trabalho.

A Figura 21 mostra um diagrama de bloco, destacando todos os processos que foram executados no bloco do python, tendo como entrada a imagem, utilizando os recursos do 
Tabela 2 - Tabela da arquitetura do computador utilizado.

\begin{tabular}{r|l} 
Processador & Intel Core i3 CPU M 370 @ 2.40GHZ x4 \\
\hline Placa de Vídeo & Intel Corporation Core Processor Integrated Graphics Controller \\
\hline Memória RAM & 4 GB \\
\hline HD Particionado & $95 \mathrm{~GB}$ \\
\hline Sistema Operacional & Linux Ubuntu \\
Fonte: Autor
\end{tabular}

OpenCV e do Scikit-Learn para ter na saída o resultado da matriz de confusão, que mostrou qual foi a melhor técnica para cada tipo de objeto.

Figura 21 - Diagrama de bloco da arquitetura utilizada neste trabalho.

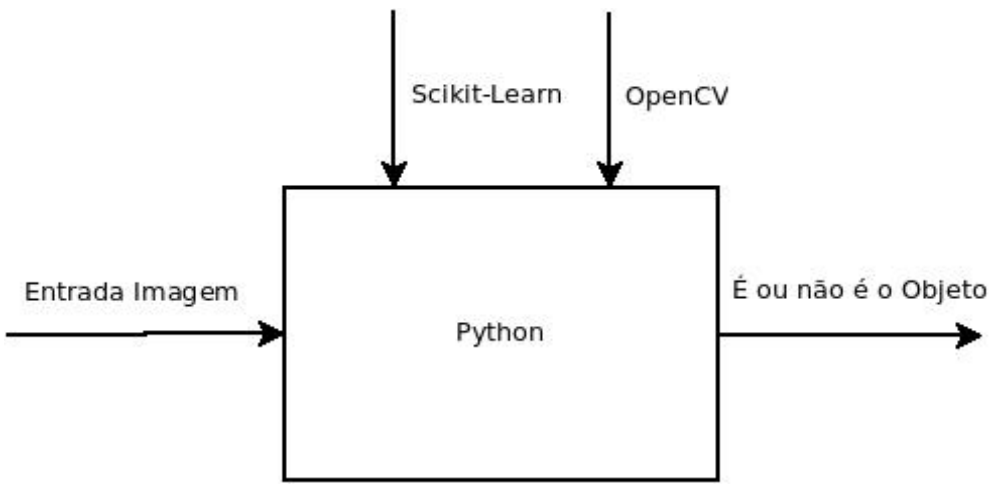

Fonte: Autor.

\subsection{BASE DE IMAGEM}

A primeira etapa do estudo foi feita utilizando a base de imagem ALOI (GEUSEBROEK et al., 2005). Ela contém vasto conteúdo de imagens com variações de luminosidade, variação de angulação do objeto e perspectivas, como pode ser visto na Figura 22. Contendo uma base com mil objetos, sendo que para cada objeto tem-se 72 imagens em ângulos diferentes, totalizando em 360 graus do objeto, é uma base importante para análise do desempenho das técnicas de reconhecimento de objetos em condições onde há diversas variações, tanto de rotação quanto de iluminação. A Figura 23 mostra a configuração do ambiente para extrações das imagens da base de imagem ALOI.

Durante a extração das imagens, a equipe da ALOI utilizou 5 luzes em posições diferentes e, para cada imagem que foi tirada do objeto, uma luz foi acesa individualmente gerando 5 imagens cada uma com um ponto de luz. Na próxima etapa, as luzes foram acesas aos pares formando mais 2 imagens com efeitos oblíquos de luminosidade, até que a última imagem, todas as luzes estavam acesas formando assim, a base de imagem com 8 imagens com variação da incidência de luz sobre o objeto. 
Figura 22 - Imagem de um objeto da base de dados ALOI com variação de Luminosidade.

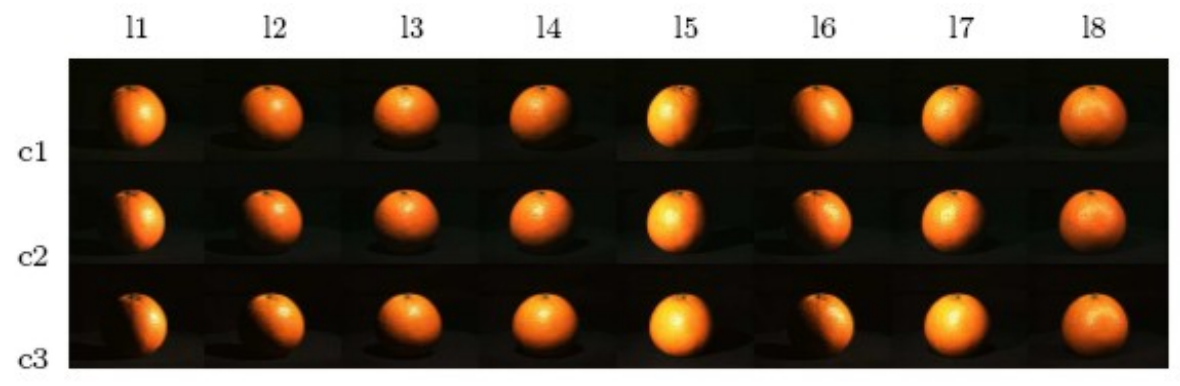

Fonte: Geusbroek et al., 2005.

Figura 23 - Configuração do ambiente da ALOI para extração das imagens.

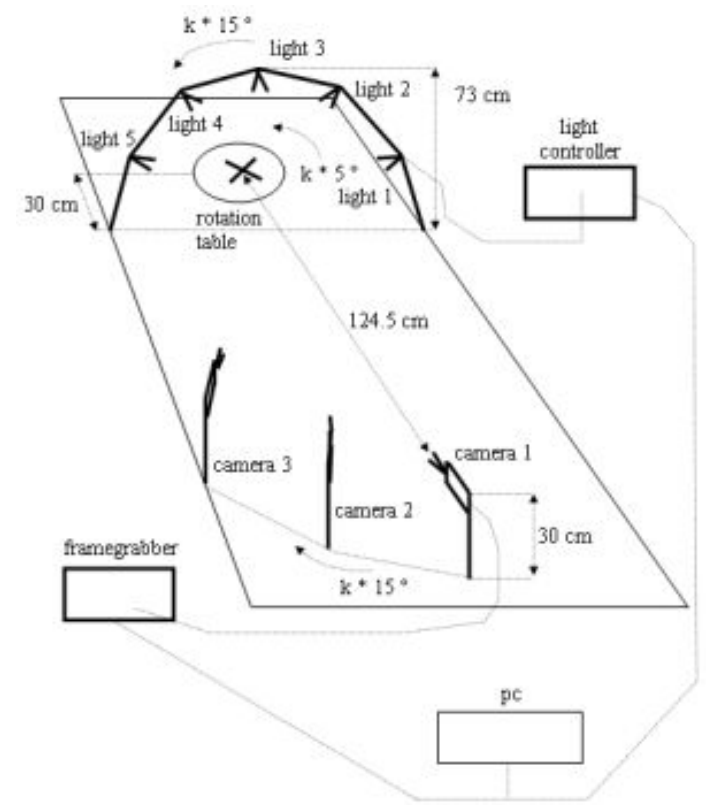

Fonte: Geusbroek et al., 2005.

Cada luz está em uma angulação diferente para fazer os efeitos que podemos ver na Figura 22. Como exemplo, nas condições de 11 - 15 é possível ver cada luz sendo acesa, iluminando o objeto em ângulos diferentes.

A coluna 16 e 17 contém duas luzes ligadas para cada objeto, sendo que a 16 possui duas luzes do lado direito e na 17 possui duas luzes do lado esquerdo do objeto, causando um efeito oblíquo de luminosidade. E por fim, na coluna 18 todas as luzes estão acesas.

Foram utilizadas 3 câmeras para a captura e estas também estão dispostas sobre o cenário com uma variação em graus. A c2 está a 15 graus de diferença de c1 e este está à 30 graus de diferença de c3, transparecendo o efeito não de alteração na forma e cor do objeto, mas sim, na diferença de iluminação que o objeto recebe em cada ângulo. 


\subsection{METODOLOGIA}

Foi feita a avaliação do desempenho de cada técnica conforme o tipo de objeto e as variações do ambiente, calculando qual técnica teve melhor desempenho para cada tipo de objeto. A avaliação foi feita utilizando objetos de tipos diferentes de classificação (cilindros, retangulares e irregulares), na qual cada técnica teve que reconhecer a maior quantidade de imagens do mesmo objeto com ou sem variações de ambiente, e para cada resultado de técnica aplicada foi gerada a matriz de confusão.

Foram escolhidos três tipos de objetos para os experimentos: o cilíndrico (lata), o retangular (caixa) e o irregular (saco de biscoito).

As técnicas SIFT, SURF e ORB foram testadas através de dois tipos de desempenho: pela Divisão (com Validação Cruzada) e com Alteração de Luminosidade (sem Validação Cruzada).

\subsubsection{Desempenho pela Divisão}

a) O objetivo foi encontrar qual a porcentagem do vetor de característica para Treino necessária para obter os melhores resultados de cada técnica.

Todas as imagens de todos os objetos, tanto as imagens em $360^{\circ}$, como as imagens com variação de luminosidade, foram reunidas em um só local para o embaralhamento. Após este embaralhamento, foram aplicadas as técnicas (SIFT, SURF e ORB) gerando os pontos característicos de cada imagem. Em seguida, foi elaborada uma divisão em porcentagem do vetor de característica ficando uma parte para Treino e outra, para Teste. Foram utilizadas diferentes porcentagens de Treino e Teste durante a aplicação da Validação Cruzada no classificador SVM. Por fim, foram geradas as Matrizes de Confusão, para cada porcentagem diferente de Treino e Teste, e, também, foram apresentadas as quantidades de acertos pelos falsos positivos. Todo o processo pode ser visto no fluxograma da Figura 24a.

\subsubsection{Desempenho com Alteração de Luminosidade}

b) Tem como objetivo encontrar, simulando um ambiente real, qual técnica dará melhor resultado.

Nesse segundo experimento, como principal diferença do experimento anterior, a validação cruzada e o embaralhamento das imagens foram removidas para gerar os testes simulando o ambiente real de competição. As características das imagens em $360^{\circ}$ dos objetos foram utilizadas para o treino do classificador e as características das imagens com variações de luminosidade foram utilizadas para testar o classificador, gerando as matrizes de confusão. Conforme pode ser visto o processo, diferente do anterior, na Figura 24b. 
Figura 24 - Fluxograma das metodologias aplicadas nos experimentos.

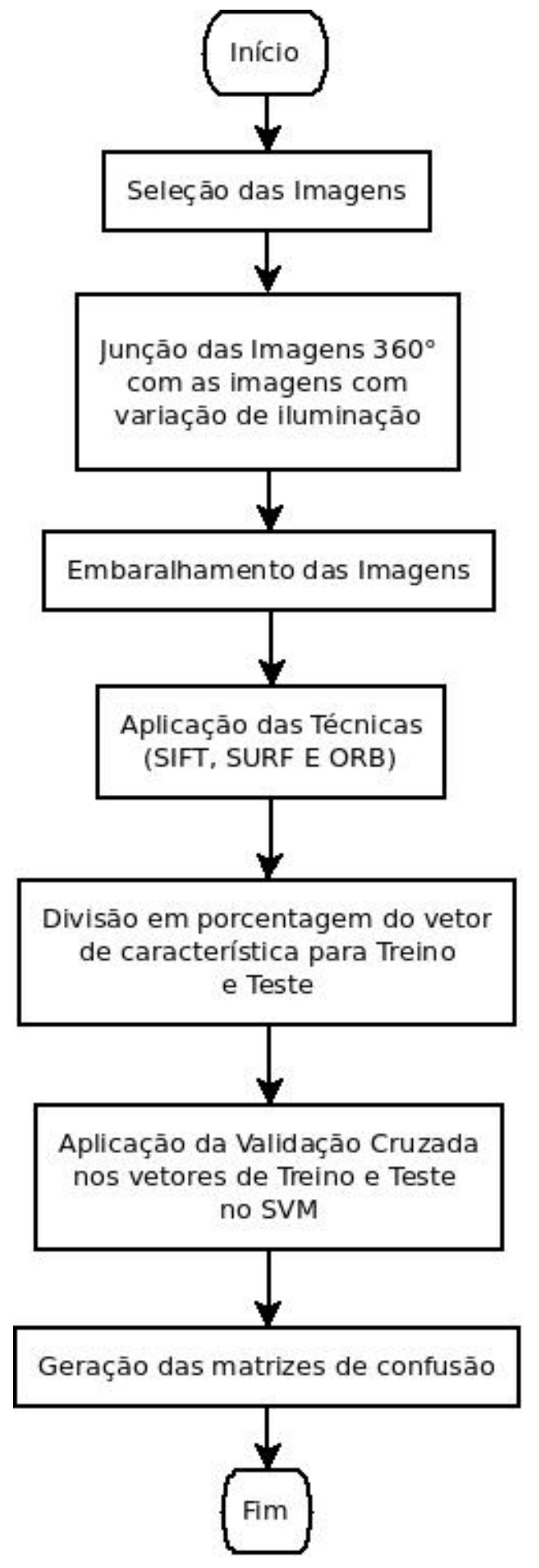

(a) Desempenho Pela Divisão

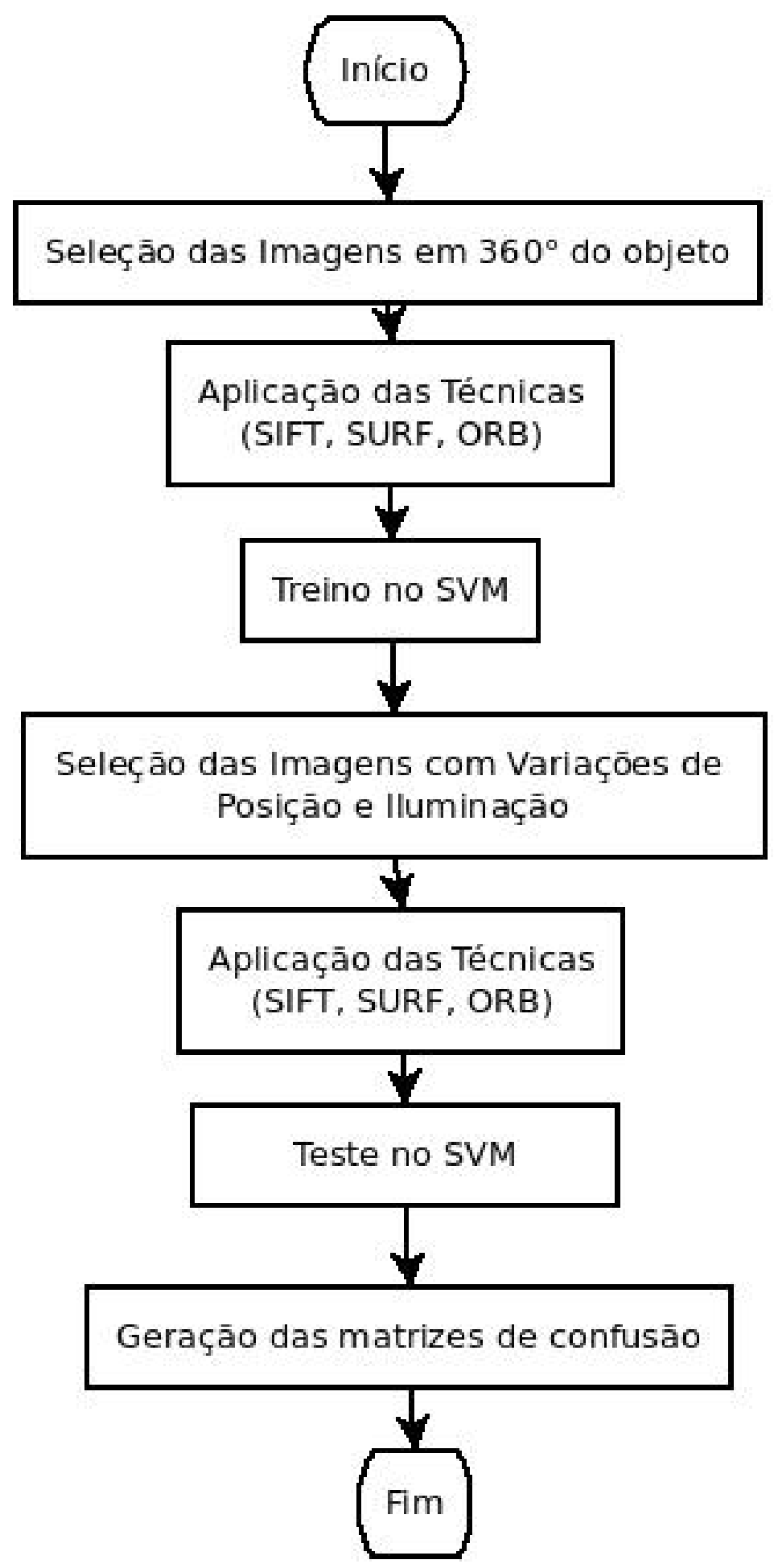

(b) Desempenho com Alteração de Luminosidade

Fonte: Autor.

Para a extração das imagens do cenário do laboratório, segundo experimento executado deste trabalho, foi feito utilizando os seguintes passos da Figura 25, a cada novo objeto posto no cenário foi retirada uma imagem, após foi feita a variação de luminosidade e uma nova 
extração da imagem. Somente no passo 3 não foi feita a extração da imagem e, sim, a remoção da variação de luminosidade para colocar o objeto em outra posição, rotacionando o objeto em $30^{\circ}$ graus no eixo $y$. Nos últimos passos são extraídas imagens na nova posição e outra com a variação de luminosidade. Fazendo assim a base de imagens do ambiente onde o robô estará para reconhecer os objetos.

Figura 25 - Diagrama de atividade para extração de imagens.

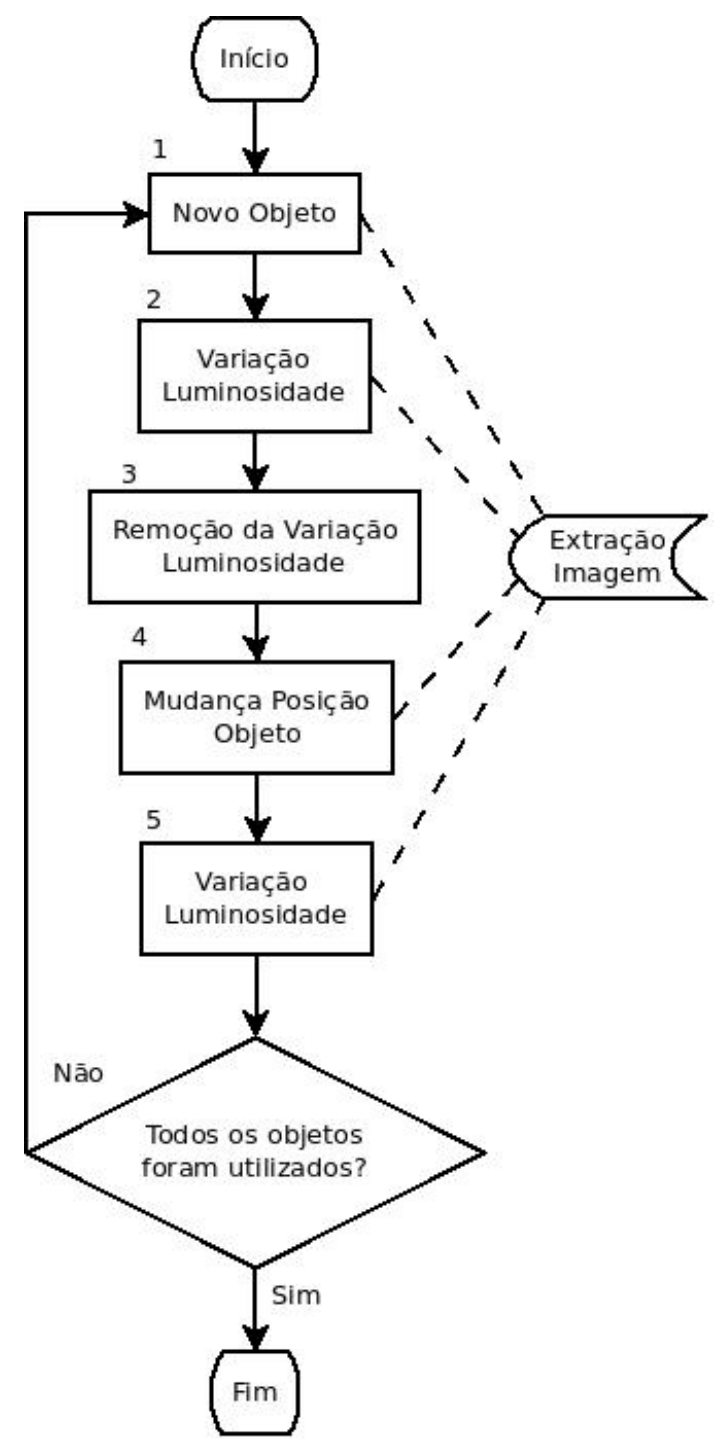

Fonte: Autor.

Para cada objeto foi extraída uma imagem utilizando luz de duas lâmpadas dicróicas no teto do ambiente, condição considerada para simular um ambiente residencial onde não há controle sobre a luminosidade que os objetos possam ter. 


\subsection{DOMÍNIO}

O domínio deste trabalho é com base na RoboCup@Home, para qual o robô irá trabalhar. As informações sobre essa seção estão de acordo com as regras da RoboCup 2017 categoria @Home (BEEK et al., 2017). A arena é uma residência comum onde há uma sala de estar, cozinha, banheiro, quarto e outros cômodos, conforme a Figura 26. Além dos cômodos, existem diversos móveis espalhados aleatoriamente pela arena como mesas, sofá, estantes, prateleiras, vasos de plantas, cadeiras, entre outros.

Figura 26 - Arena RoboCup@Home.

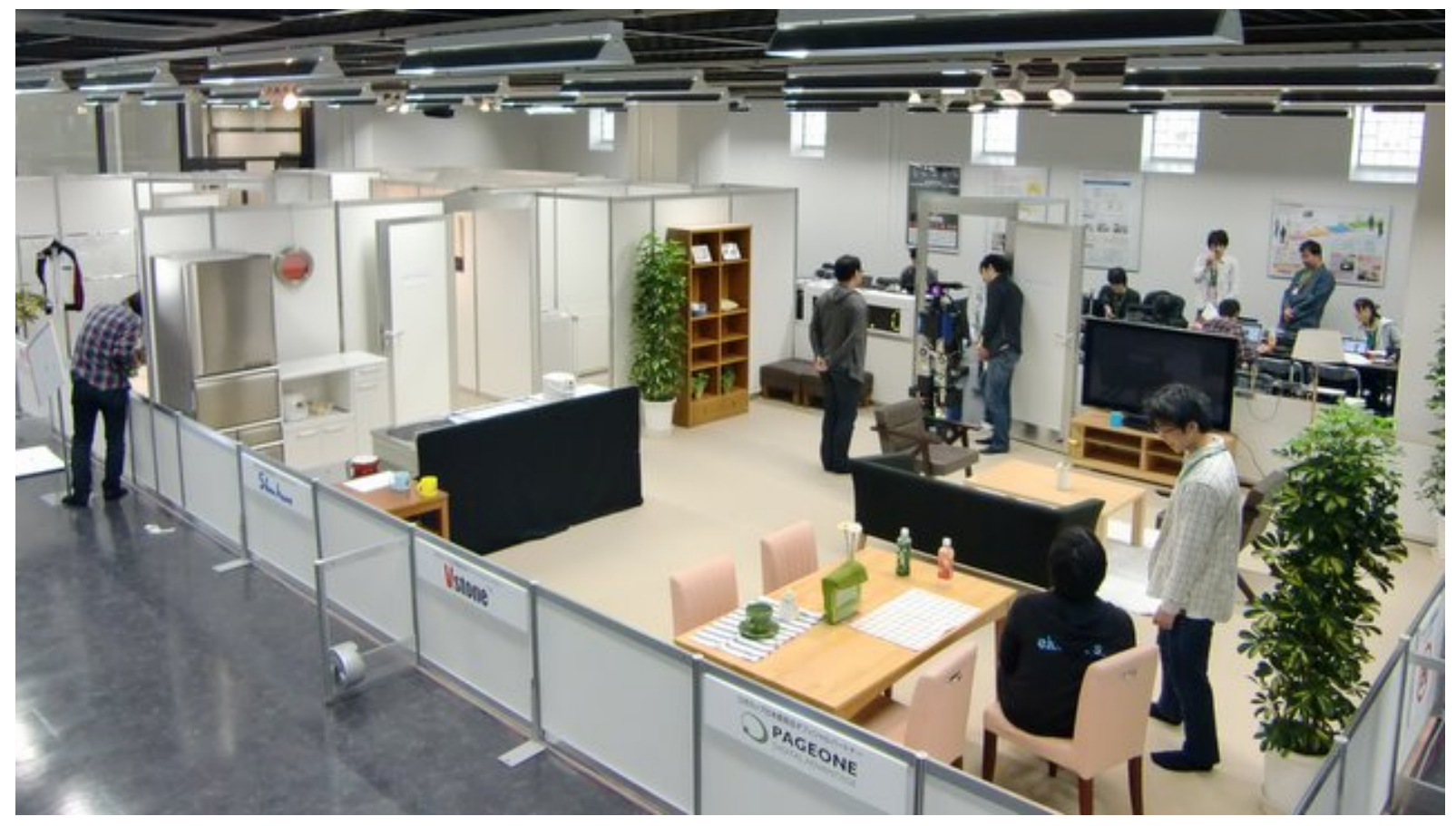

Fonte: Robocup@home, 2017.

\subsubsection{Reconhecimento de Objetos}

Na seção de reconhecimento de objetos, uma das tarefas da competição, tem-se uma prateleira com os objetos distribuídos sobre cada andar. Conforme mostra a Figura 27, tem-se um exemplo com apenas duas prateleiras e todos os possíveis objetos que farão parte do processo de reconhecimento de objeto. Todos os objetos são disponibilizados, antes da competição, para que as equipes façam os devidos treinamentos.

Cada objeto tem sua categoria. Um exemplo são os objetos da categoria "frutas"serem banana e maçã, e a sua localidade na arena também é definida como no caso das "frutas"deverão estar na "cozinha". Durante o reconhecimento desses objetos é necessário anexar essas informações ao documento que é entregue ao final da tarefa para os jurados. Na prateleira os objetos são dispostos à 15 centímetros da beira da superfície e a distância entre cada objeto disposto 
Figura 27 - Prateleira com os objetos.

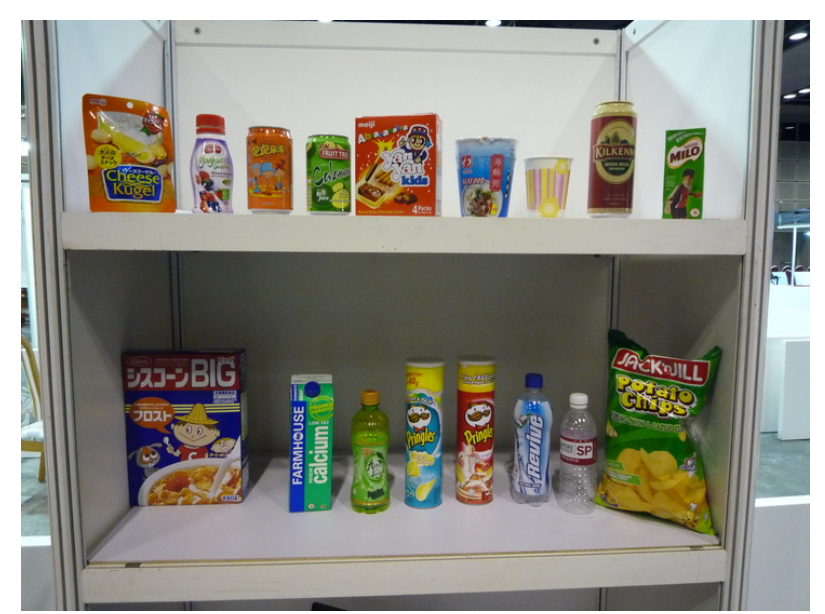

Fonte: Robocup@home, 2017.

é de 5 centímetros. Os objetos para serem reconhecidos são escolhidos antes da competição, facilitando assim, em tempo para extração das imagens e treinamento do classificador. 



\section{EXPERIMENTOS E RESULTADOS}

Este capítulo apresenta os testes efetuados tanto na base de dados da ALOI quanto no laboratório. Como primeira etapa foram executados testes junto a base da ALOI para eleger as melhores técnicas, para que posteriormente, as melhores sejam aplicadas no ambiente não controlável do laboratório. O objetivo principal destes testes foi encontrar as melhores técnicas e propor a utilização delas juntas para alcançar com êxito o reconhecimento de toda gama de objetos possíveis na competição ou em qualquer residência.

\subsection{EXPERIMENTO 1 - BASE DA ALOI}

A primeira etapa é o experimento com a base de imagem da ALOI. Para efetuar o experimento foram utilizados 1080 imagens de $360^{\circ}$ de 5 objetos de cada classe, de resolução de $768 \times 576$ pixels, sendo 3 classes que se referem aos objetos retangulares, cilíndricos e irregulares, conforme exemplo das classes utilizadas na Figura 28. O primeiro é o objeto cilíndrico (Figura 28 (a)); em segundo o retangular (Figura 28 (b)); e, por último, o objeto irregular (Figura 28 (c)). Todas as imagens são em preto e branco, de apenas um canal.

Figura 28 - Imagem dos objetos da base de dados ALOI escolhidos para os testes.

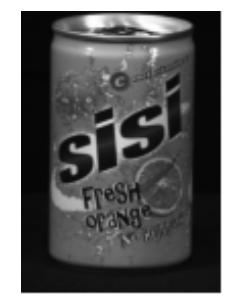

(a)

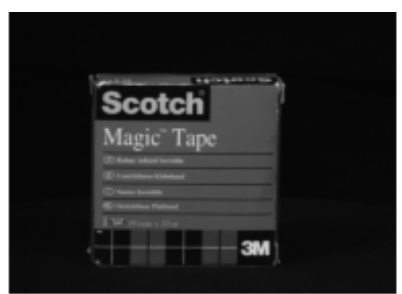

(b)

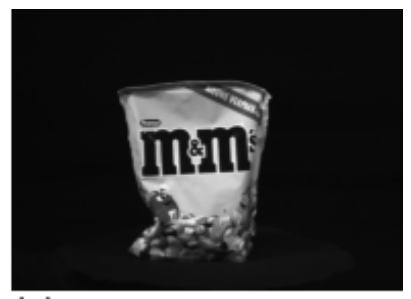

(c)

Fonte: Geusbroek et al., 2005.

A segunda etapa é a utilização de imagens com variação de luminosidade. Para isso foram utilizadas as imagens da base de imagens da ALOI a qual foram feitas as variações de luminosidade (Figuras 29, 30 e 31) e de angulação dos objetos.

Primeiramente as imagens passaram por um embaralhamento para que possam garantir o funcionamento adequado do classificado, se caso as imagens mantivessem o mesmo padrão de entrada, o classificador viciaria na separação, resultando em uma má classificação.

Depois, as técnicas foram aplicadas para que fizessem as extrações necessárias na imagem gerando assim os vetores de características. Cada vetor passou pelo método de Pesquisa de Grade (explicado na Subseção 2.1.4.1) utilizando da biblioteca Scikit-Learn o método GridSearchCV, para encontrar os melhores parâmetros do SVM e conseguir separar os dados da melhor forma possível. Os parâmetros que foram testados durante a Pesquisa de Grade foram o kernel, Gamma e Parâmetro C (Custo). No GridSearchCV é passado como parâmetro o tipo de classificação, sendo no caso a multi-classificação, que utiliza o método um-contra-um, e os 
Figura 29 - Imagem do objeto cilíndrico com pouca e muita luminosidade para reconhecimento.

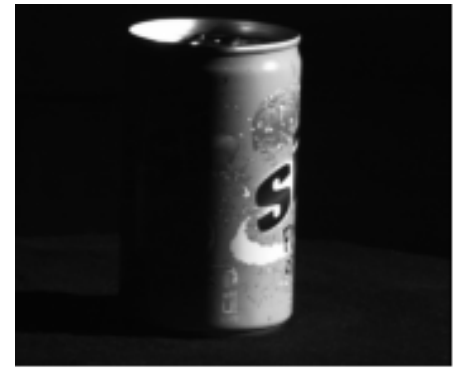

(a)

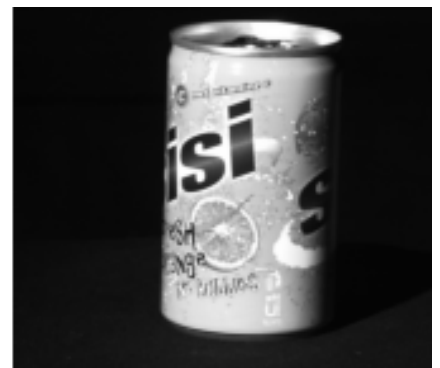

(b)

Fonte: Geusbroek et al., 2005.

Figura 30 - Imagem do objeto retangular com pouca e muita luminosidade para reconhecimento.

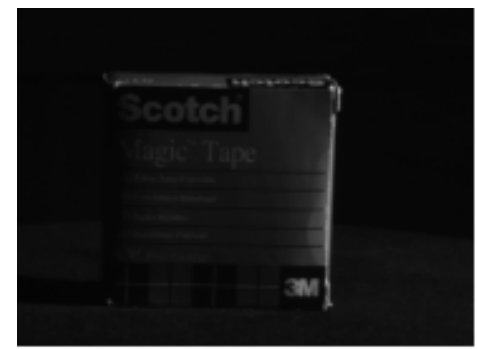

(a)

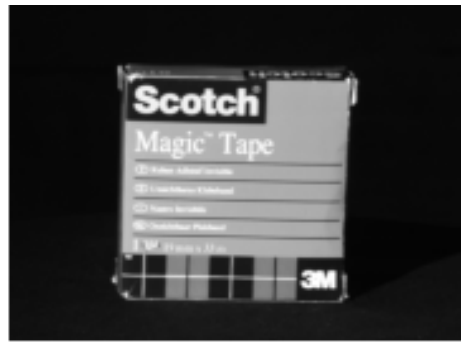

(b)

Fonte: Geusbroek et al., 2005.

Figura 31 - Imagem do objeto irregular com pouca e muita luminosidade para reconhecimento.

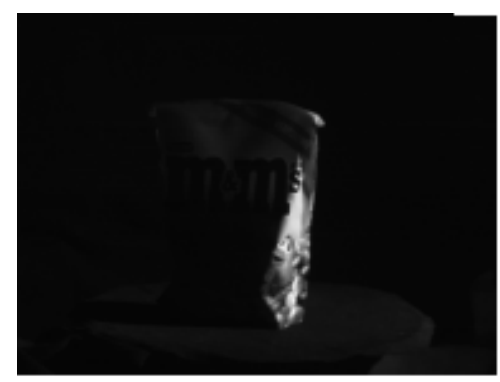

(a)

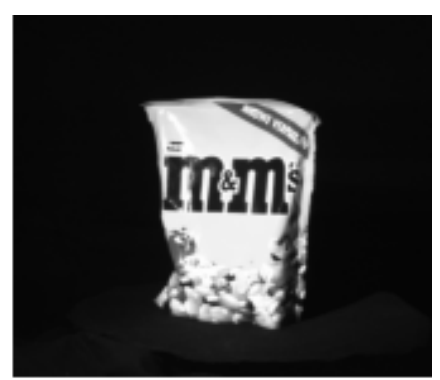

(b)

Fonte: Geusbroek et al., 2005.

parâmetros para separação que foram testados. Foram efetuados 10 testes para ter a média dos melhores resultados encontrados pela pesquisa de grade e inseridos na SVM durante o treino de cada técnica.

Os parâmetros testados foram: para o kernel foram o Linear e o RBF (do inglês: "Radial Basis Function"), para o Gamma foram de 0,0001; 0,0005; 0,001; 0,005; 0,01 e 0,1, e por fim o 
parâmetro $C$ de 0,$001 ; 1 ; 10 ; 100$ e 1000 . Tornando um processo bem custoso por fazer diversos testes para cada um dos itens até que alcance um valor de acurácia mais próximo de 100, que é o máximo. Após todo esse processo de encontrar quais são os melhores valores para a separação mais correta dos dados de entrada, gerando um valor para cada parâmetro por exemplo: kernel é Linear, Gamma de 0,0001 e $C$ seja 1. Foram aplicados durante o treinamento da SVM.

Para o treinamento do classificador não ser superficial, foi utilizada a validação cruzada dos dados para que garanta tanto a validade do classificador quanto evitar torná-lo viciado com os dados de entrada. Na utilização da validação cruzada foi possível alterar a quantidade de dados desse vetor que serão utilizados para Treino e Teste. Alterando o parâmetro de porcentagem que foi utilizada para Teste e o restante para Treino, utilizado da biblioteca Scikit-Learn o Train Test Split (Divisão de Teste e Treino) onde pode ser inserido os valores no parâmetro test size (tamanho do Teste). Assim, foi utilizada as variações em porcentagem, fazendo 30 testes para cada região para ter a média das precisões geradas. Começando o testes com o valor de $20 \%$ para Teste e $80 \%$ para Treino, após, $40 \%$, 70\% e, ao final, em 90\% para Teste e o restante para Treino.

Com esse teste foi possível verificar qual técnica necessita de qual porcentagem de imagem para efetuar uma boa classificação, fator muito decisivo, por conta que, futuramente a melhor técnica será aplicada no robô para competição e, o conhecimento da quantidade de imagens necessárias para Treino, torna-se essencial para a execução do pré-treino na competição.

Para obter outro fator muito importante para o teste de cada técnica, um segundo teste foi aplicado sem a utilização da validação cruzada e o embaralhamento dos dados de entrada, simulando o momento exato da competição. Foram utilizados, separados, os vetores de Treino com as imagens de $360^{\circ}$ do objeto e para o Teste foram utilizados as imagens com variações de luminosidade. Para encontrar qual técnica é mais estável mediante a variação de luminosidade, treinando sem variação e testando com imagens com variações de posição e luminosidade.

Para cada teste no classificador foi gerada uma matriz de confusão com os dados de precisão, valores de F1 score, valores de precisão pela revocação (como pode ser visto no Apêndice A e B). Com a precisão dos valores gerados nas matrizes de confusão, extraídas em cada estágio, foram calculadas as médias de acertos para cada objeto.

Para os cálculos de desempenho com alteração de luminosidade foi medido o Desvio Padrão e Erro Padrão de cada técnica, levando em conta a média das precisões de cada técnica aplicada a cada tipo de objeto. Sendo utilizado como comparativo entre as técnicas para determinar qual técnica conseguiu ser mais estável e conseguiu reconhecer melhor cada tipo de objeto. Sendo assim, as técnicas que obtiverem melhores resultados de média de precisão, baixo valor de desvio padrão e baixo valor em padrão de erro, foram rotulados com o tipo de objeto.

A seguir serão apresentados os resultados encontrados levando em consideração os critérios citados anteriormente. 


\subsubsection{Experimento - SIFT}

Os parâmetros utilizados inicialmente para extração dos pontos característicos foram os mesmo utilizados por D. Lowe (1999). Como o foco de D. Lowe (1999) foi o reconhecimento de objeto, nada mais justo que utilizar os mesmo parâmetros para o teste.

Com a busca por grade aplicado ao vetor criado, foi notado que o kernel da SVM que melhor separaria os dados de entrada foi o RBF, junto com o valor de gamma igual a 0,01 e o parâmetro de Custo em 1000.

\subsubsection{Desempenho Pela Divisão}

A Figura 32 mostra todos os valores que foram coletados das precisões em cada estágio de separação dos dados de entrada, mostrando onde foram os máximos e mínimos encontrados e, no quadrante central, está no intervalo de $25 \%$ à $75 \%$ da maioria dos valores encontrados. Em alguns deles consta um traço indicando onde está a mediana desses dados, em alguns não foi possível encontrar o traço por estar fora desse intervalo.

Figura 32 - Gráfico dos valores da precisão pela divisão dos dados em porcentagem do vetor de Teste - SIFT ALOI.

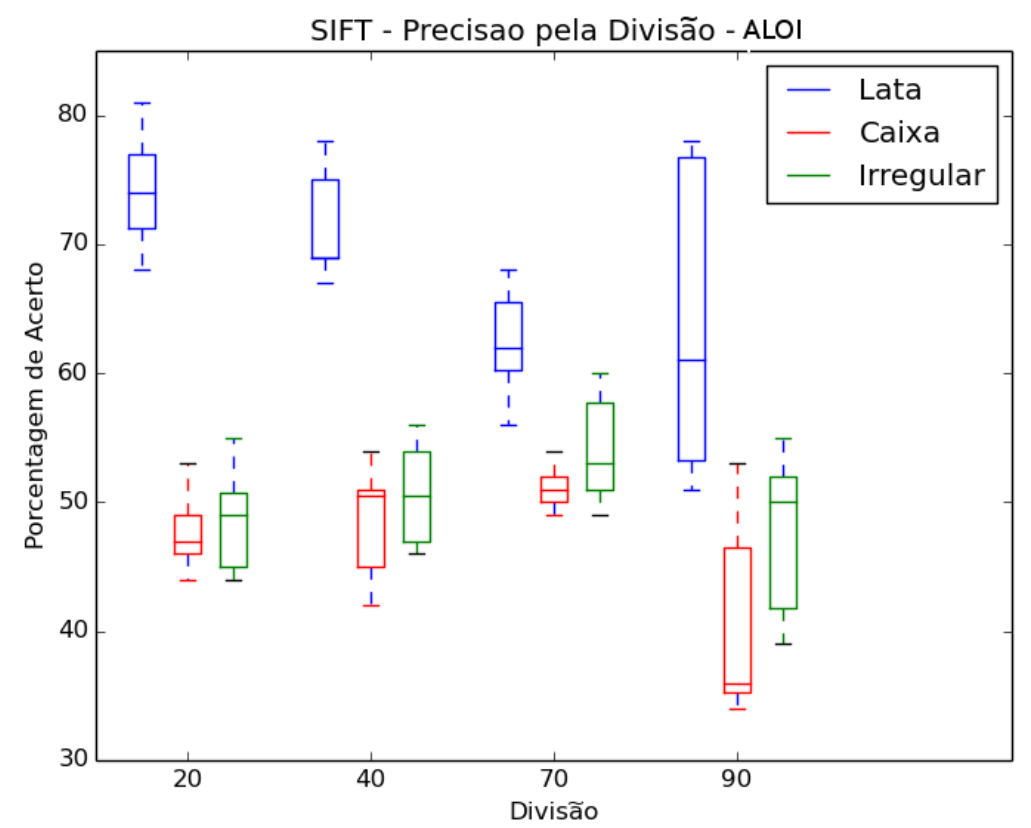

Fonte: Autor.

Com o gráfico da Figura 32 é notável que, para que a técnica SIFT obtenha um bom resultado, levando em consideração o menor valor do intervalo, a técnica precisa de no mínimo $30 \%$ dos dados para Treino, conforme pode ser visto que na divisão por 90, o intervalo é grande 
mostrando que com $90 \%$ para Teste e $10 \%$ para treino a técnica variou muito nos resultados. Nos demais valores para Treino a técnica teve uma variação menor.

Concluindo assim, para o objeto lata é necessário mais de $30 \%$ de dados para Treino para ter bons resultados, no caso do objeto caixa e irregular, o melhor foi na faixa de divisão de $70 \%$ de Teste.

\subsubsection{Desempenho com Alteração de Luminosidade}

Foram executados 10 testes com base sem a unificação das imagens tanto de $360^{\circ}$ do objeto como as com variações de luminosidade. A quantidade de imagens por classe de objeto para teste foi de 120. Coletados os resultados de desempenho das matrizes de confusão geradas, obteve a média em porcentagem de acerto na Figura 33. Para o objeto Lata obteve média de $49,1 \%$ de acerto, para o objeto Caixa teve média de $25,1 \%$ e para o Irregular média de $18,1 \%$.

Figura 33 - Gráfico das médias das precisões geradas com a variação de luminosidade para cada classe - SIFT ALOI.

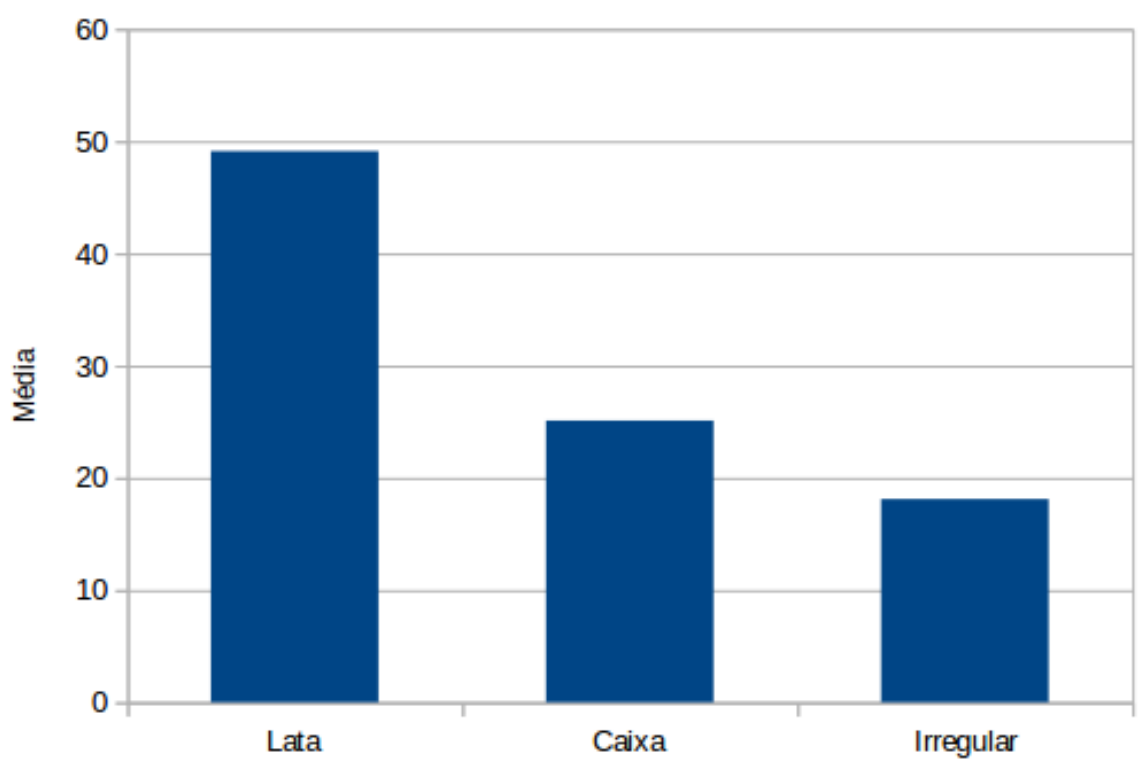

Fonte: Autor.

Com os valores de média, foi possível calcular o desvio padrão da amostra para cada objeto. Sendo para a Caixa valor de desvio padrão de 3,28, a Lata de 9,16 e o Irregular de 10,1. Gerando assim, um comparativo no gráfico da Figura 34a.

Utilizando como base os valores de Desvio Padrão divido pela raiz quadrada da média de precisão obtida, foi possível encontrar o Erro Padrão gerado pela média dos dados. Sendo para a Lata 1,3, para Caixa 0,65 e para o irregular 2,37, conforme pode ser visto o comparativo no gráfico da Figura 34b 
Figura 34 - Gráfico do desvio padrão e erro padrão - SIFT ALOI.
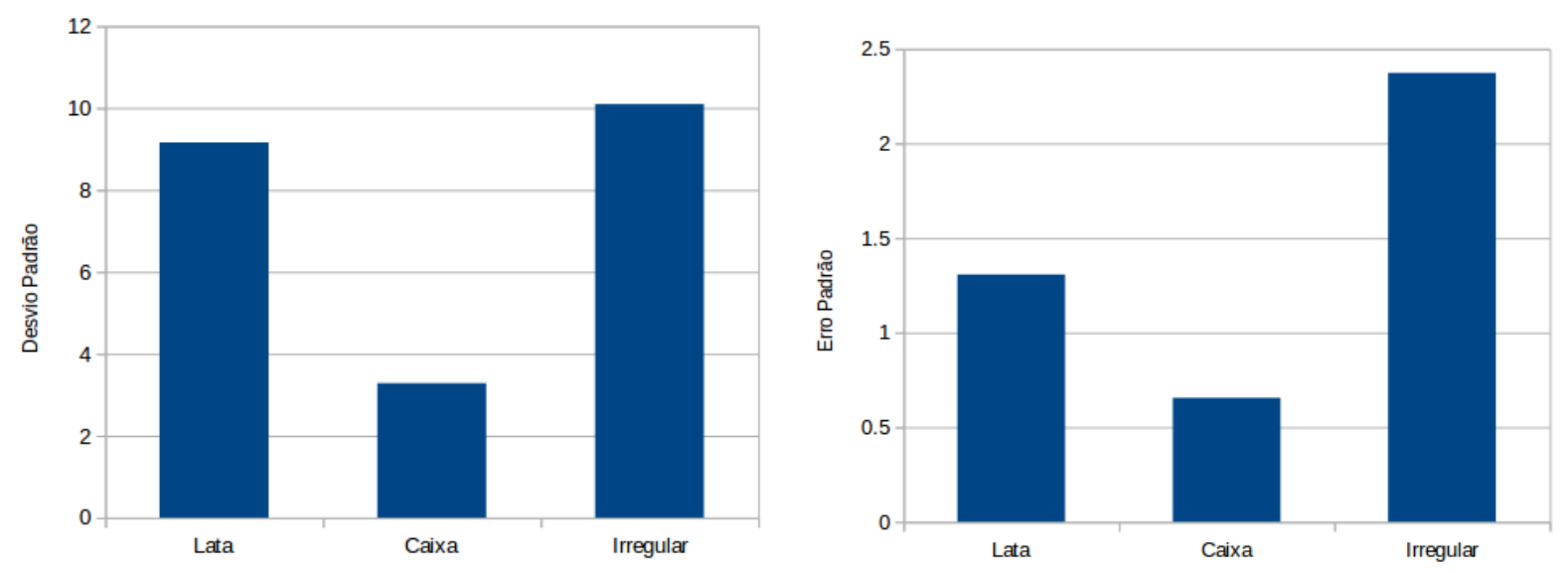

(a) Desvio padrão

(b) Erro Padrão

Fonte: Autor.

\subsubsection{Experimento - HAAR}

Durante a aplicação da técnica houve algumas descobertas que tornaram a utilização da técnica inviável para o cenário proposto neste trabalho. Umas das dificuldade foi em relação ao tempo de treino da técnica, Vilão (2016) comprovou que a técnica demora entre uma à cinco horas para concluir o treino de um objeto, tornando inviável a utilização na competição por conter diversos objetos para serem treinados. Os objetos são entregues antes da competição e com tempo curto para treino. Treinar vários objetos demoraria muito tempo, portanto, não será mais utilizada neste trabalho.

\subsubsection{Experimento - HOG}

A técnica foi criada para reconhecer apenas pedestres na rua (DALAL; TRIGGS, 2005), sua abordagem é deveras interessante por ser invariante a luminosidade, porém a utilização da técnica necessita de um redimensionamento na imagem para 128x64 pixels o que torna a imagem muito reduzida e processo muito custoso, fora do contexto para ser executado durante a competição. Cada imagem processada deverá ter essa dimensão, que resulta numa distorção e na perda das características dos objetos a serem reconhecidos.

Além dessa questão, a técnica não processa dados em full $H D$, logo, a imagem deverá ser de 640x480 (VILÃO; BIANCHI, 2016), perdendo informações cruciais para diferenciar os objetos, incapacitando a continuidade da execução da técnica por não se encaixar aos requisitos mínimos para este trabalho. 


\subsubsection{Experimento - SURF}

Os parâmetros utilizados inicialmente para extração dos pontos característicos foram os mesmo utilizados por Bay et al (2008). O foco do trabalho dele também foi o desenvolvimento da técnica para reconhecimento de objetos, portanto, foram utilizados os mesmo parâmetros para comparativo.

Com a busca por grade aplicado no vetor criado de característica, foi notado que o kernel da SVM que melhor separou foi o RBF, junto com o valor de gamma igual a 0,0001 e o parâmetro de Custo em 1000.

\subsubsection{Desempenho Pela Divisão}

A Figura 35 mostra todos os valores que foram coletados das precisões em cada estágio de separação dos dados de entrada, mostrando onde foram os máximos e mínimos encontrados e, no quadrante central, está no intervalo de $25 \%$ à $75 \%$ de todos os valores encontrados. Em alguns deles consta um traço indicando onde está a mediana desses dados, em alguns não foi possível encontrar o traço por estar fora do intervalo.

Figura 35 - Gráfico dos valores da precisão pela divisão dos dados em porcentagem de teste SURF ALOI.

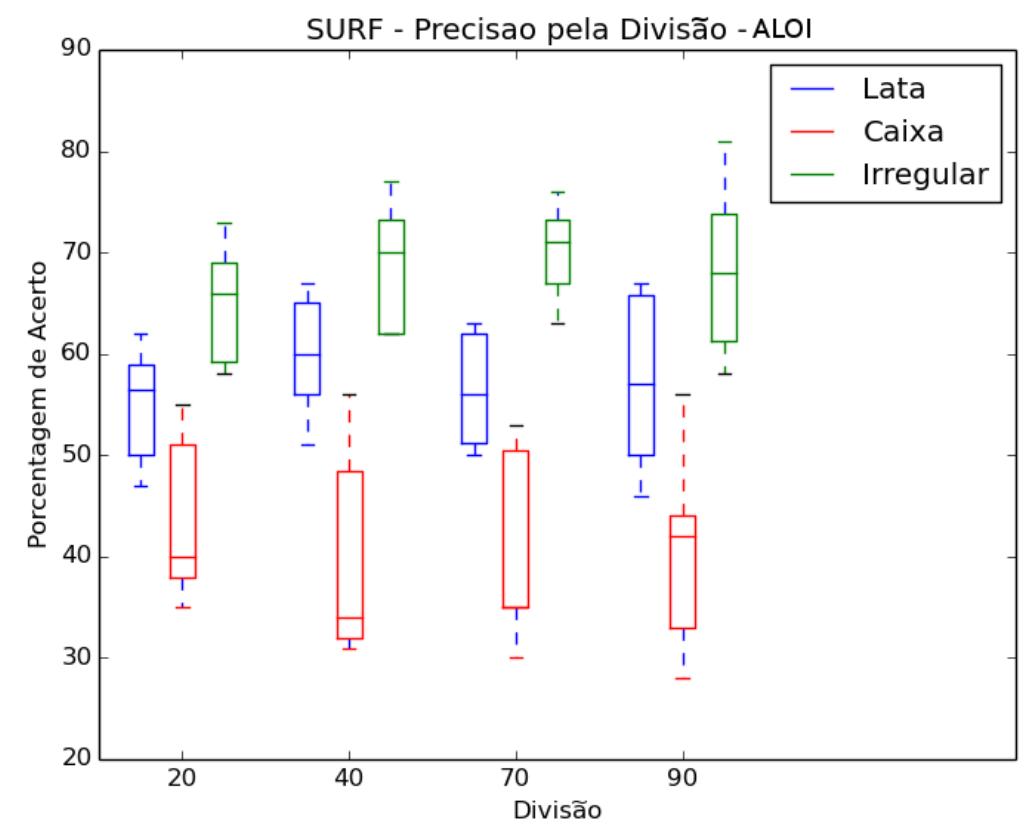

Fonte: Autor.

Com o gráfico da Figura 35 é notável que, para que a técnica SURF obtenha um bom resultado, levando em consideração o menor valor do intervalo. Para cada objeto teve um valor para alcançar bons resultados, para o objeto Irregular ter melhores resultados é indicado que 
tenha pelo menos $30 \%$ dos dados para Treino, conforme pode se visto no valor de divisão 70 onde o intervalo se manteve menor e atingiu 70\% de precisão. Já para o objeto Lata o melhor seria com $60 \%$ de dados para Treino, conforme pode ser visto na divisão por 40 .

\subsubsection{Desempenho com Alteração de Luminosidade}

Foram executados 10 testes com base sem a unificação dos vetores tanto de Teste como de Treino. Quantidade de imagens por classe de objeto para Teste foi de 120. Coletados os resultados de desempenho das matrizes de confusão geradas, obteve a média em porcentagem de acerto na Figura 36. Para o objeto Lata obteve média de $37.7 \%$ de acerto, para o objeto Caixa teve média de $34.2 \%$ e para o Irregular média de $30.1 \%$.

Figura 36 - Gráfico das médias das precisões geradas com a variação de luminosidade para cada classe - SURF ALOI.

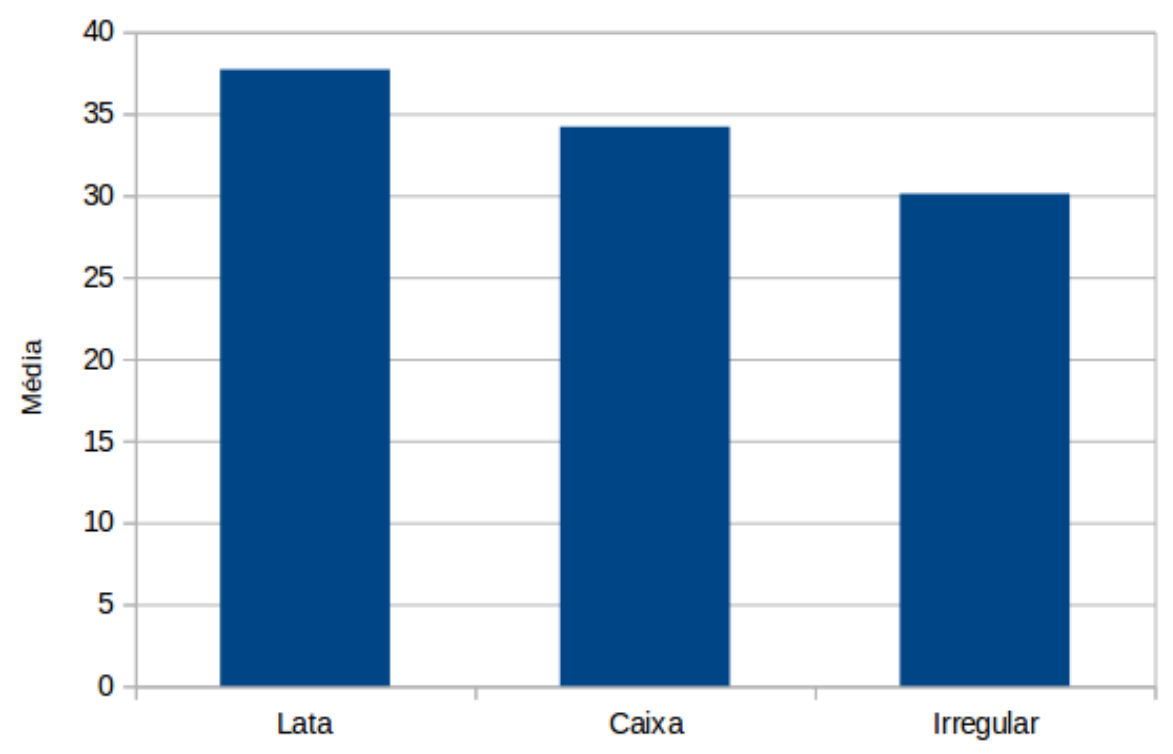

Fonte: Autor.

Com os valores de média, foi possível calcular o Desvio Padrão da amostra para cada objeto. Sendo para a Caixa o valor de desvio padrão de 24.03, a Lata de 5.03 e o Irregular de 11.96. Gerando assim, um comparativo no gráfico da Figura 37a.

Utilizando como base os valores de Desvio Padrão divido pela raiz quadrada da média de precisão obtida, foi possível encontrar o Erro Padrão gerado pela média dos dados. Sendo para a Lata 3,91, para Caixa 0,86 e para o Irregular 2,18, conforme pode ser visto o comparativo no gráfico da Figura $37 \mathrm{~b}$. 
Figura 37 - Gráfico do desvio padrão e erro padrão - SURF ALOI.

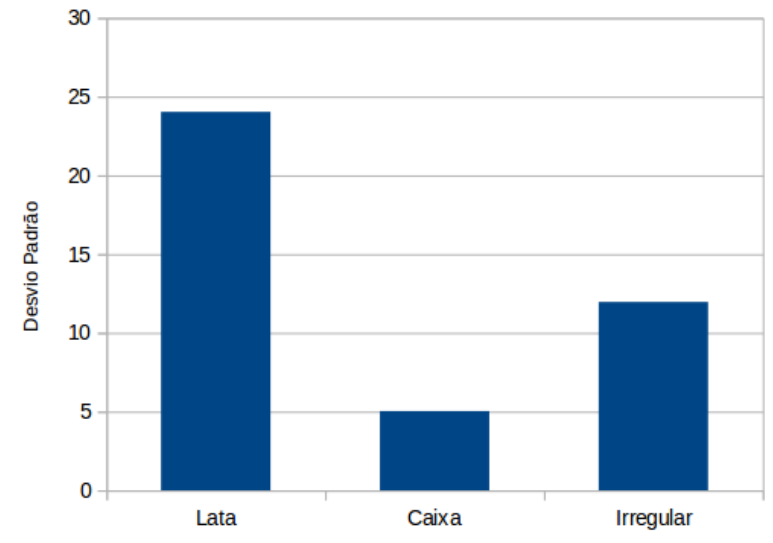

(a) Desvio padrão

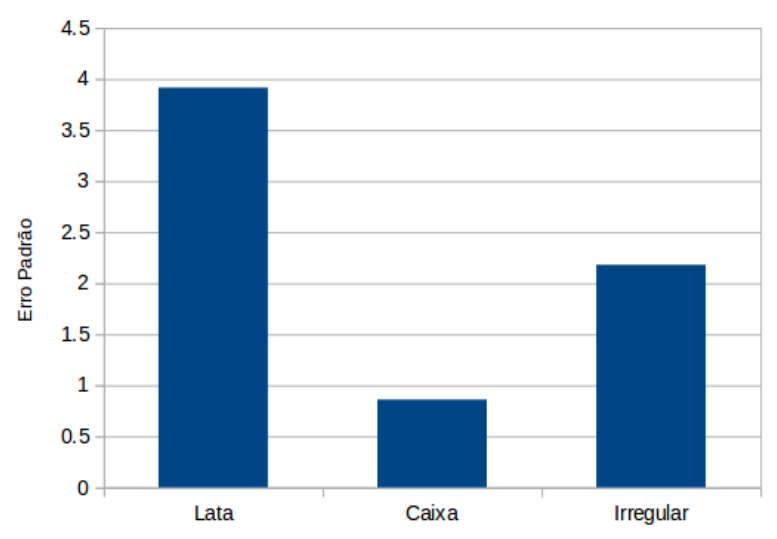

(b) Erro Padrão

Fonte: Autor

\subsubsection{Experimento - ORB}

Os parâmetros utilizados inicialmente para extração dos pontos característicos foram os mesmos padrões impostos na biblioteca OpenCV, sendo os mesmos utilizados pelos criadores da técnica.

Com a busca por grade aplicado aos vetores de características, foi notado que o kernel da SVM que melhor separou foi o Linear, junto com o valor de gamma igual a 0,0001 e o parâmetro de Custo em 1000.

\subsubsection{Desempenho Pela Divisão}

A Figura 38 mostra todos os valores que foram coletados das precisões em cada estágio de separação dos dados de entrada, mostrando onde foram os máximos e mínimos encontrados e, no quadrante central, está no intervalo de $25 \%$ à $75 \%$ de todos os valores encontrados. Em todos constam um traço indicando onde está a mediana desses dados. As cruzes são outliers, valores de precisão da matriz de confusão que não fazem parte da maior parte dos valores que foram encontrados nos demais testes.

Com o gráfico da Figura 38 é notável que, para que a técnica ORB obtenha um bom resultado, levando em consideração o menor valor do intervalo, para cada objeto teve um valor diferente. Para o objeto Irregular ter melhores resultados é bom que tenha pelo menos $30 \%$ dos dados para Treino, conforme pode se visto no valor de divisão 70 onde o intervalo se manteve menor e atingiu mais que $70 \%$ de precisão. Já para o objeto Caixa obteve resultados muito próximos, mas assumindo que o intervalo tem que ser menor, o que obteve melhor resultado foi o valor de divisão 70. O caso da Lata não obtiveram resultados expressivos mas mostra que quanto mais imagens para treino melhores serão os resultados. 
Figura 38 - Gráfico dos valores da precisão pela divisão dos dados em porcentagem de teste ORB ALOI.

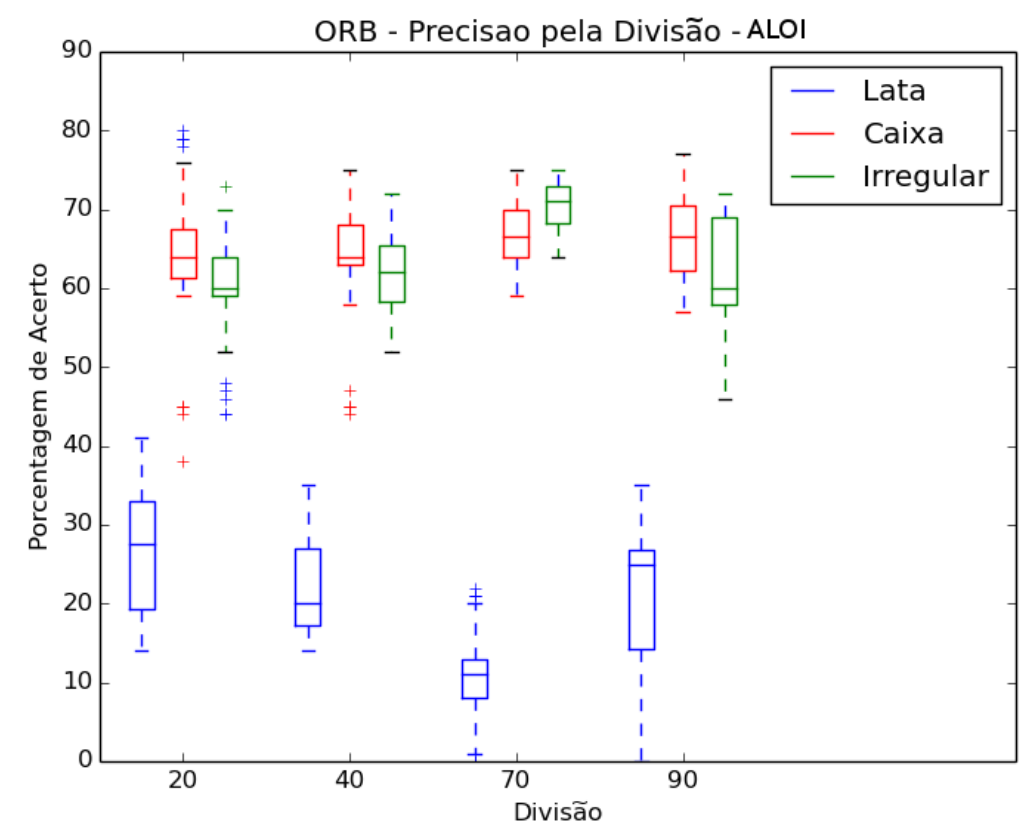

Fonte: Autor.

A técnica apresentou bastantes outliers mostrando que a técnica ORB apresenta instabilidade nos resultados.

\subsubsection{Desempenho com Alteração de Luminosidade}

Foram executados 10 testes com base sem a unificação dos vetores tanto de Teste como de Treino. Quantidade de imagens por classe de objeto para Teste foi de 120. Coletados os resultados de desempenho das matrizes de confusão geradas, obteve a média em porcentagem de acerto na Figura 39. Para o objeto Lata obteve média de 32,2\% de acerto, para o objeto Caixa teve média de $11,5 \%$ e para o Irregular média de $20,1 \%$.

Com os valores de média, foi possível calcular o desvio padrão da amostra para cada objeto. Sendo para a Caixa valor de desvio padrão de 24,03, a Lata de 5,03 e o Irregular de 11,96. Gerando assim, um comparativo no gráfico da Figura 40a.

Utilizando como base os valores de Desvio Padrão divido pela raiz quadrada da média de todos os níveis de divisão, é possível encontrar o Erro Padrão gerado pela média dos dados. Sendo para a Lata 2,14, para Caixa 4,05 e para o Irregular 1,99, conforme pode ser visto o comparativo no gráfico da Figura 40b. 
Figura 39 - Gráfico das médias das precisões geradas com a variação de luminosidade para cada classe - ORB ALOI.

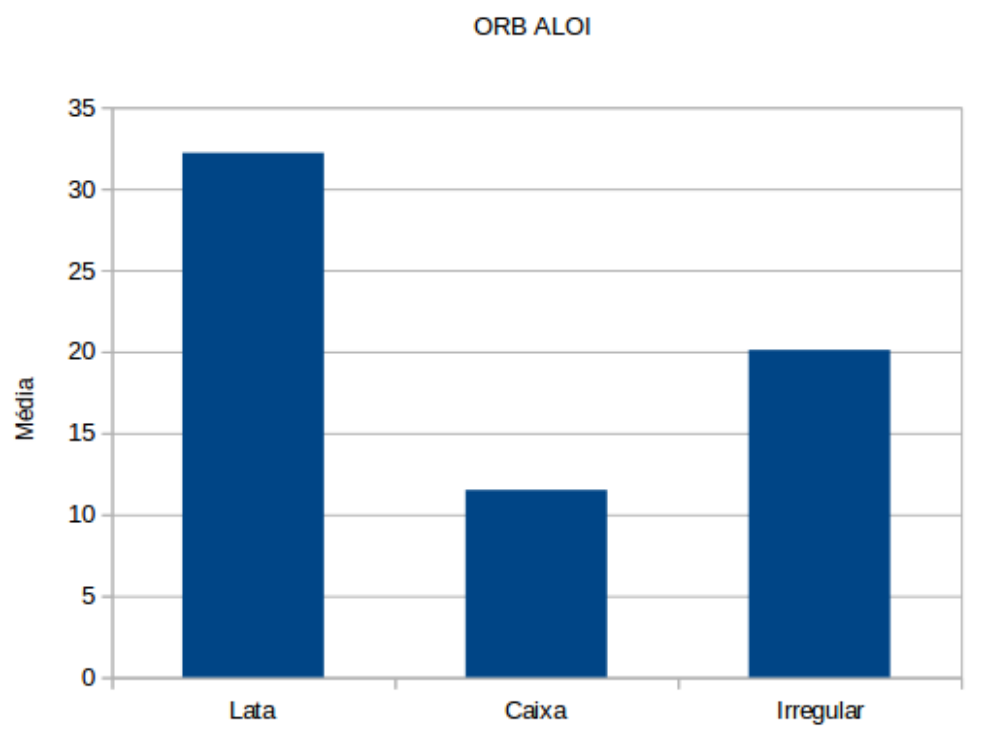

Fonte: Autor.

Figura 40 - Gráfico do desvio padrão e erro padrão - ORB ALOI.

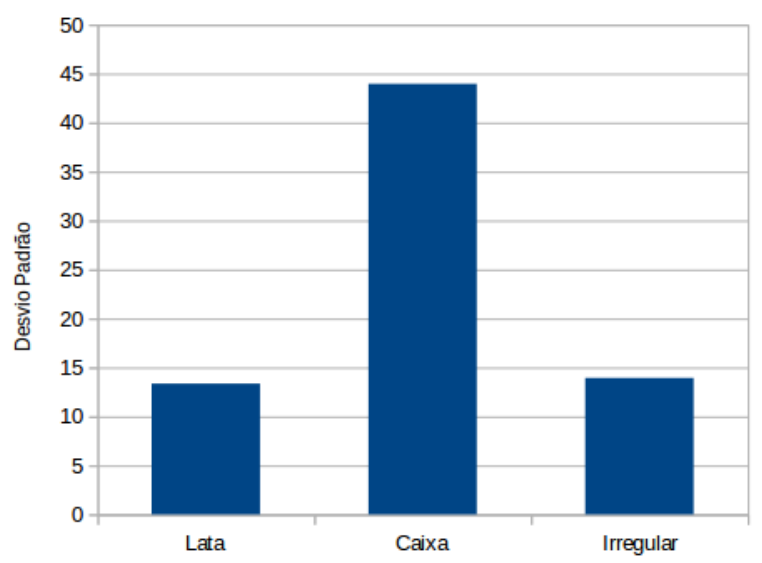

(a) Desvio padrão

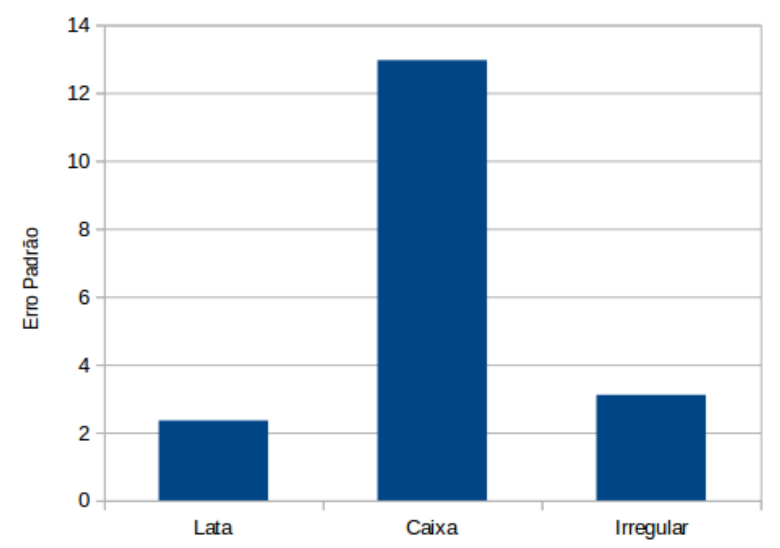

(b) Erro Padrão

Fonte: Autor.

\subsection{DISCUSSÃO - COMPARANDO OS RESULTADOS COM A BASE ALOI}

Comparando os resultados encontrados das três técnicas para rotular qual técnica foi melhor com cada tipo de objeto para executar os testes com a base de imagens do laboratório. Foram gerados três gráficos para facilitar a comparação dos resultados obtidos entre todas as técnicas (Figura 41 e Figura 42). Na Figura 41 mostra para cada técnica qual foi a média de todas as precisões com os testes com variação de luminosidade. Os outros dois gráficos 
são os cálculos derivados das precisões, na Figura 42a tem-se os dados de cada desvio padrão encontrado e na Figura 42 b os valores dos erros padrões.

Figura 41 - Gráfico de média das técnicas - ALOI.

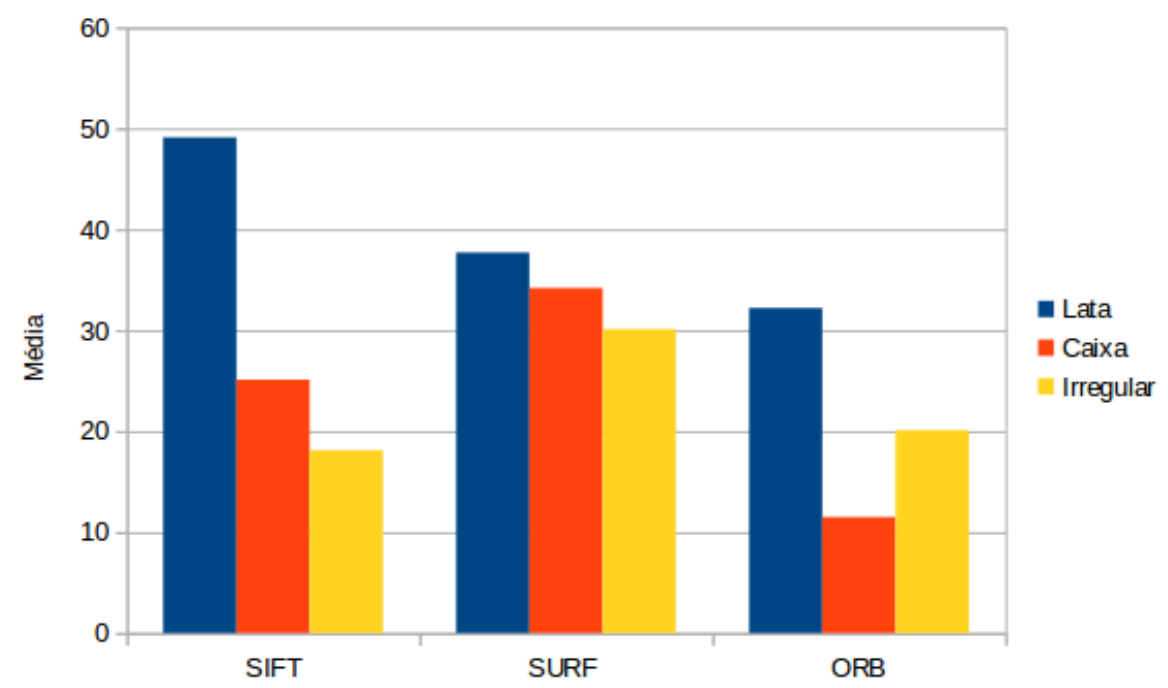

Fonte: Autor.

Figura 42 - Gráfico de desvio padrão e erro padrão das técnicas - ALOI.

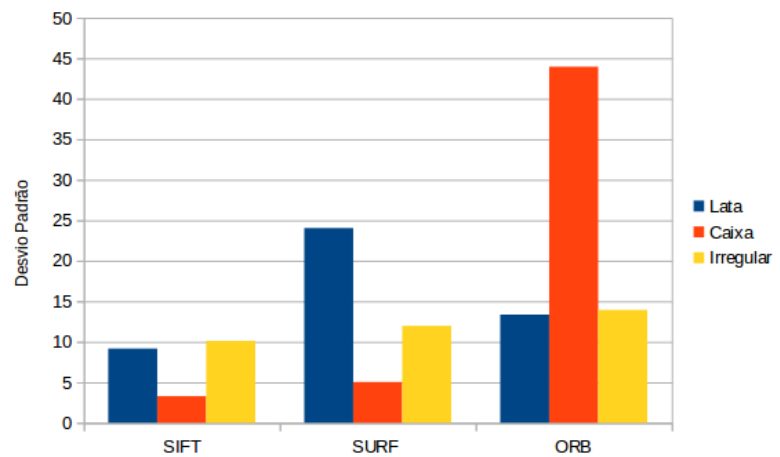

(a) Desvio Padrão

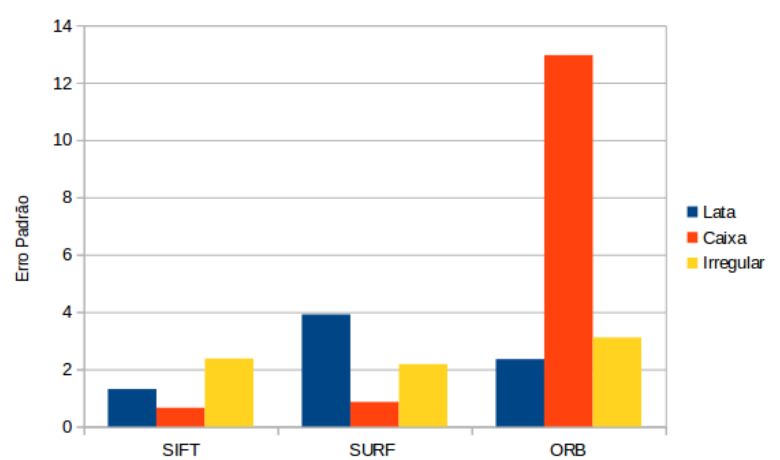

(b) Erro Padrão

Fonte: Autor.

Como o critério para escolha de qual técnica foi melhor com cada tipo de objeto era se tiver maior média, menor desvio padrão e menor erro padrão, as técnicas foram rotuladas como:

a) Para o objeto Caixa, o que teve melhor média foi o SURF, o desvio padrão e o erro padrão foi maior que o do SIFT, porém, a diferença de um resultado para o outro foi muito pequena. Portanto, o SURF foi o que teve melhor desempenho com o objeto Caixa;

b) Para o objeto Lata, o SIFT teve melhor média, e menores valores de desvio padrão e erro padrão. Portanto, foi rotulada a técnica como melhor para o objeto Lata;

c) E por último, o objeto Irregular, a técnica SURF teve melhor média, menores valores de Desvio Padrão e Erro Padrão, sendo escolhido como melhor para o objeto irregular. 
Portanto SIFT será brevemente rotulado como bom em objetos Retangulares, o SURF brevemente rotulado com os objetos do tipo Cilíndricos e Irregulares.

Para o próximo teste, como o HAAR e o HOG já não estão dentro do escopo por não terem requisitos mínimos para serem testados no cenário deste trabalho, as três técnicas serão testadas também com as imagens do laboratório, como podemos ver a seguir.

\subsection{EXPERIMENTO 2 - LABORATÓRIO}

No segundo experimento foram testadas as três técnicas com os objetos que existem no laboratório. Há uma prateleira similar a utilizada na competição (Figura 43). Conforme a regra da RoboCup (BEEK et al., 2017) o robô estará parado a uma distância de 1,5 metros da prateleira e terá de identificar os objetos. Portanto, a câmera foi posta na mesma distância.

Figura 43 - Prateleira do laboratório com os objetos dispostos.

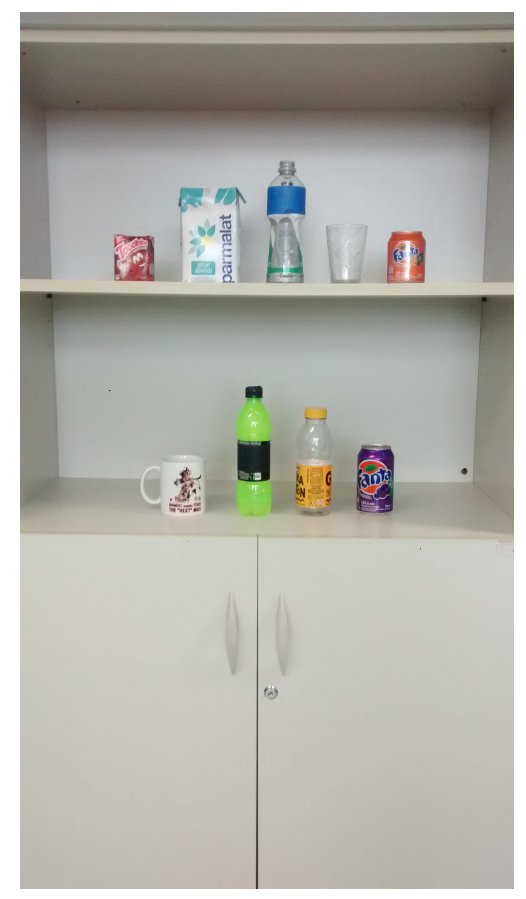

Fonte: Autor.

Antes de executar o experimento foi feita a base de imagens de $360^{\circ}$ do objetos, sendo retiradas dos três tipos de objetos. As imagens foram feitas fora da prateleira em cima de uma mesa giratória vazia e com luminosidade de duas luzes convencionais dicróicas de teto, como pode ser visto o cenário de criação da base na Figura 44. A câmera estava a 72 centímetros de distância do centro do objeto, a 70 centímetros do chão e a mesa estava a uma altura de 50 centímetros do chão. Os objetos foram rotacionados sem alterar sua distância da câmera com uma quantidade suficiente de imagens que completem $360^{\circ}$ do objeto, totalizando 16 imagens, de resolução 1920x1080 pixels, cada uma com diferença de 22,5 graus de angulação, rotacionando o objeto no eixo $y$. 
Figura 44 - Cenário para extração das imagens para formação da base de imagens do laboratório.

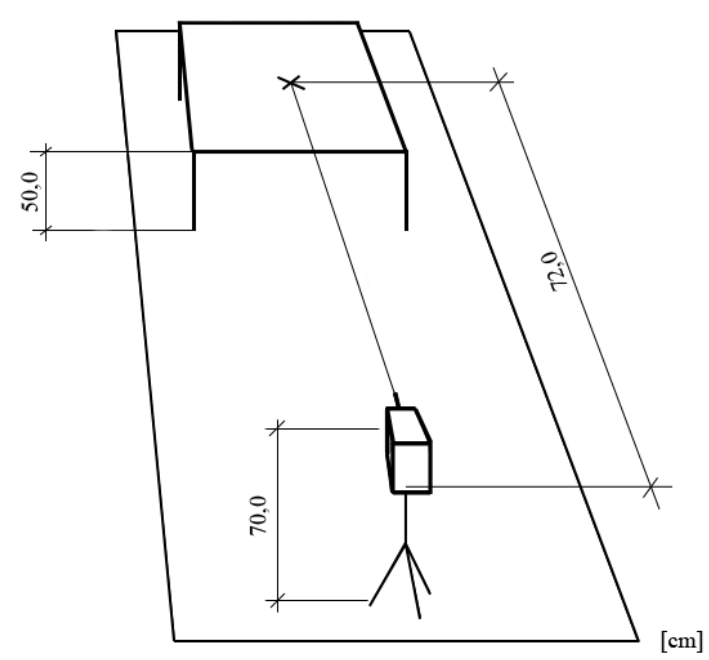

Fonte: Autor.

Gerou-se a base em $360^{\circ}$ com luminosidade estático e com os objetos que podem ser vistos na Figura 45. O primeiro é o objeto cilíndrico (Figura 45 a); o segundo o retangular (Figura 45 b); e, por último, o objeto irregular (Figura 45 c). Todas as imagens estavam em preto e branco, de apenas um canal.

Figura 45 - Imagem dos objetos da base de dados do lab.

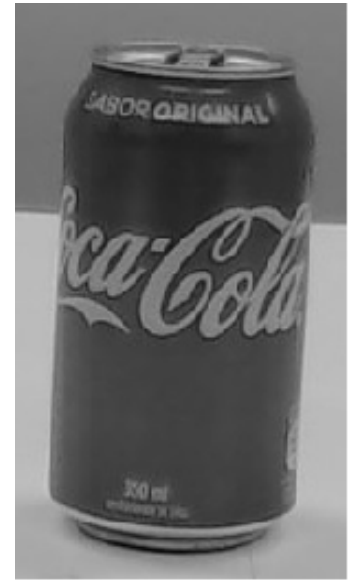

(a)

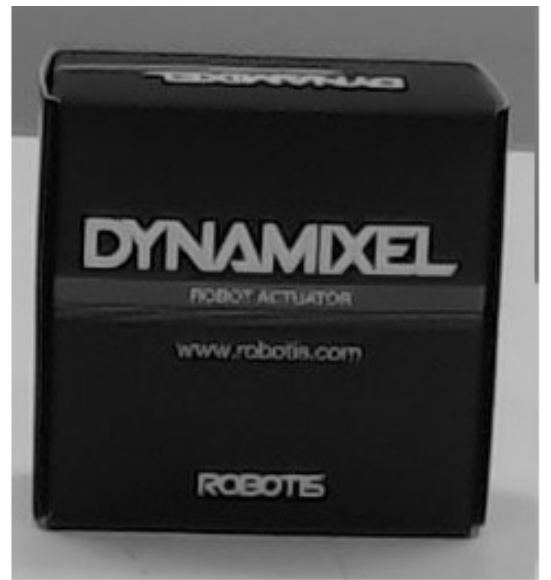

(b)

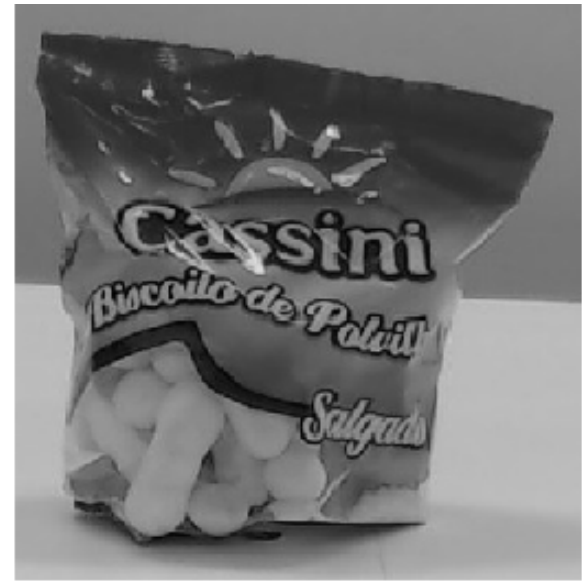

(c)

Fonte: Autor.

Para formar a base de imagens com variações, foram extraídas 13 imagens de cada objeto a uma distância de $1,5 \mathrm{~m}$ da prateleira (Figura 43), o objeto estava a $15 \mathrm{~cm}$ de distância da beira da superfície e, em algumas das imagens, tiveram alteração da luminosidade sendo retiradas imagens do objeto no canto ao fundo da prateleira, que contia a sombra que a luz do teto incidia na lateral da prateleira. Para que o efeito de sombra ocorresse, foram utilizadas 
as luzes dicróicas duplas do teto acesas (a disposições dos itens citados pode ser observada na Figura 46). A câmera estava a uma altura de 150 centímetros do chão, com distância da prateleira de 150 centímetros, a posição do objeto estava na altura de 121,5 centímetros do chão e 15 centímetros da borda da prateleira, quando estava na sombra estava há uma distância de 45,4 centímetros da borda. A iluminação estava a uma distância da prateleira de 139 centímetros e a 250 centímetros de altura.

Figura 46 - Cenário para extração das imagens do ambiente.

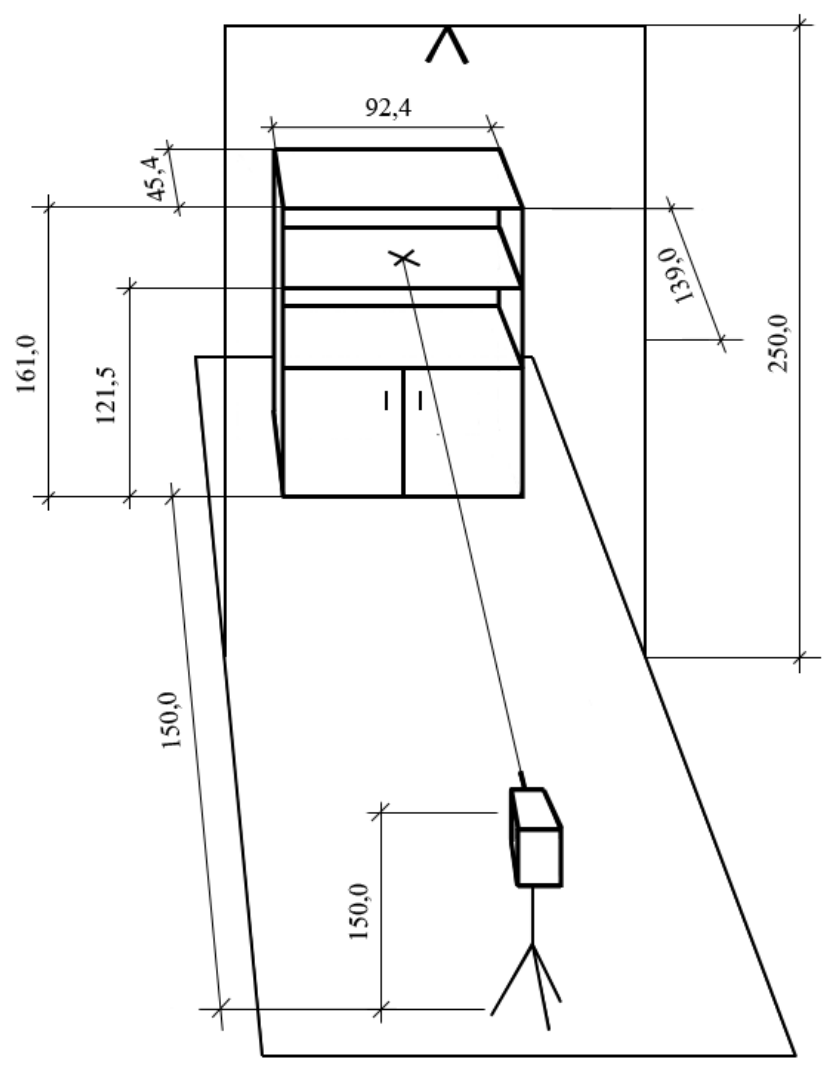

$[\mathrm{cm}]$

Fonte: Autor.

Esse cenário posto, gerou as imagens do objeto caixa (Figura 47), do objeto lata (Figura 48) e do objeto irregular (Figura 49). As figuras (a) estavam sem variação de luminosidade somente a luz contida no ambiente por duas lâmpadas dicróicas no teto e nas figuras (b) foram utilizadas com a sombra que a luz do teto e a lateral da prateleira, provocavam no objeto, imitando uma possível oclusão da luz incidente no objeto em residências ou durante a competição.

Com as bases criadas para treino e teste do classificador, foram executadas as técnicas de extração de características e, um vetor de treino com imagens $360^{\circ}$ e outro para testes com imagens com variação de luminosidade, inseridos na SVM para que execute a separação correta e a geração das matrizes de confusão para cada técnica. 
Figura 47 - Imagem do objeto caixa extraída do laboratório.
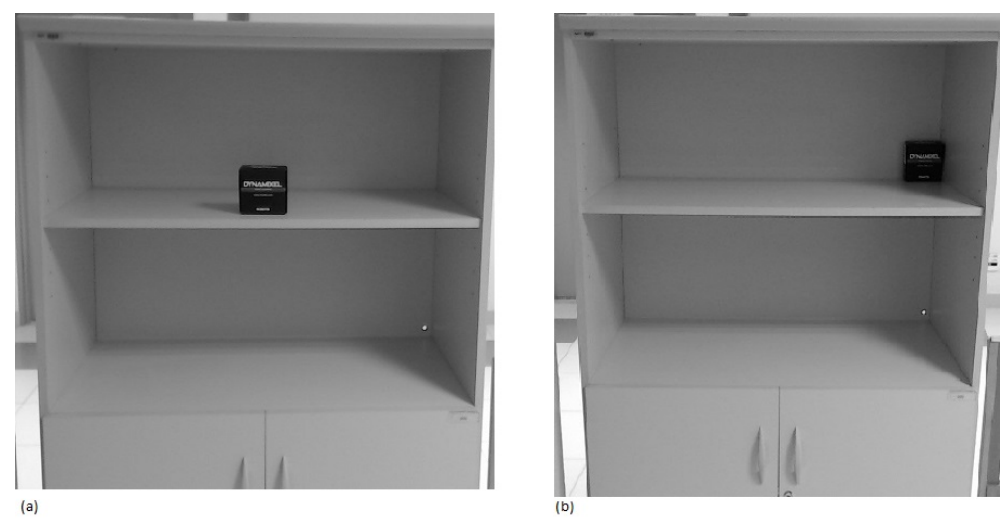

Fonte: Autor.

Figura 48 - Imagem do objeto lata extraída do laboratório.
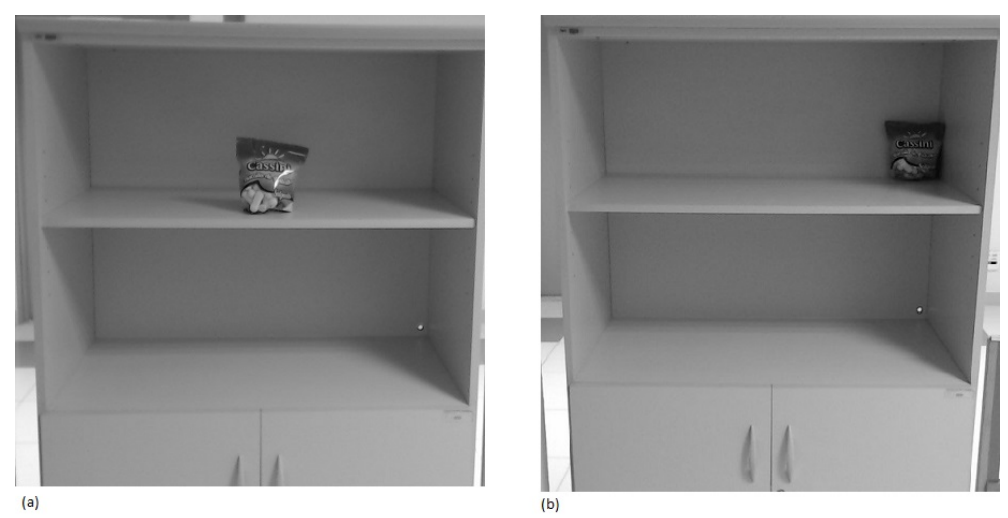

Fonte: Autor.

Figura 49 - Imagem do objeto irregular extraídas do laboratório.
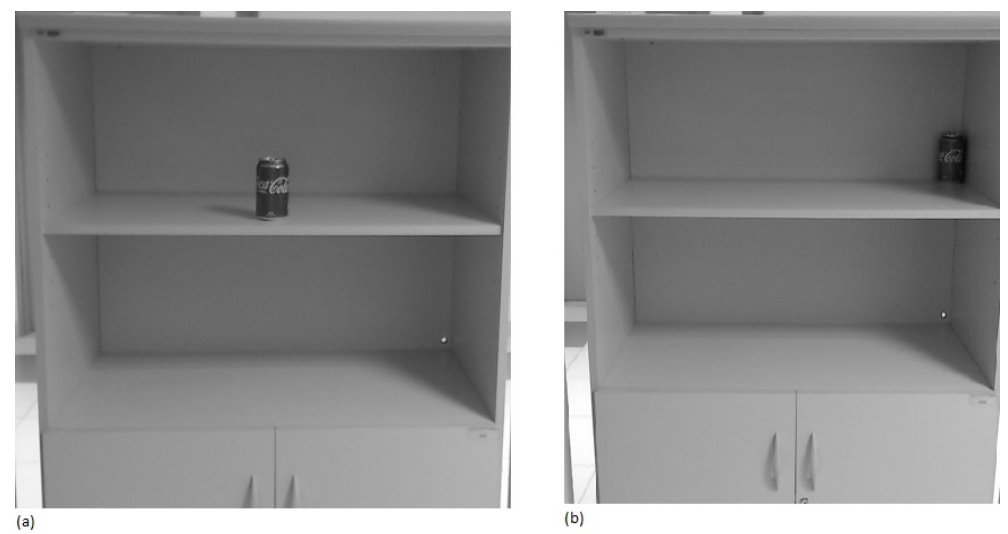

Fonte: Autor.

As métricas foram executadas da mesma forma que no experimento com variação de luminosidade da ALOI, onde o as imagens não foram unidas. Foram utilizados para treino as 
imagens de $360^{\circ}$ do objeto e as imagens tiradas do cenário com a prateleira foi utilizado para teste. A seguir são apresentados os resultados obtidos nos experimentos com as três técnicas

\subsubsection{Experimento - SIFT}

Com a busca por grade, foi notado que o kernel da SVM que melhor separou os dados de entrada foi o RBF, junto com o valor de gamma igual a 0,001 e o parâmetro de Custo em 1000.

\subsubsection{Desempenho com Alteração de Luminosidade}

Foram executados 10 testes com base sem a unificação dos vetores tanto de teste como de treino. Quantidade de imagens por classe de objeto para teste foram de 13. Coletados os resultados de desempenho das matrizes de confusão geradas, obteve a média em porcentagem de acerto na Figura 50. Para o objeto Lata obteve média de 52,8\% de acerto, para o objeto Caixa teve média de 5,3\% e para o Irregular média de 71,5\%.

Figura 50 - Gráfico das médias das precisões geradas com a variação de luminosidade para cada classe - SIFT lab.

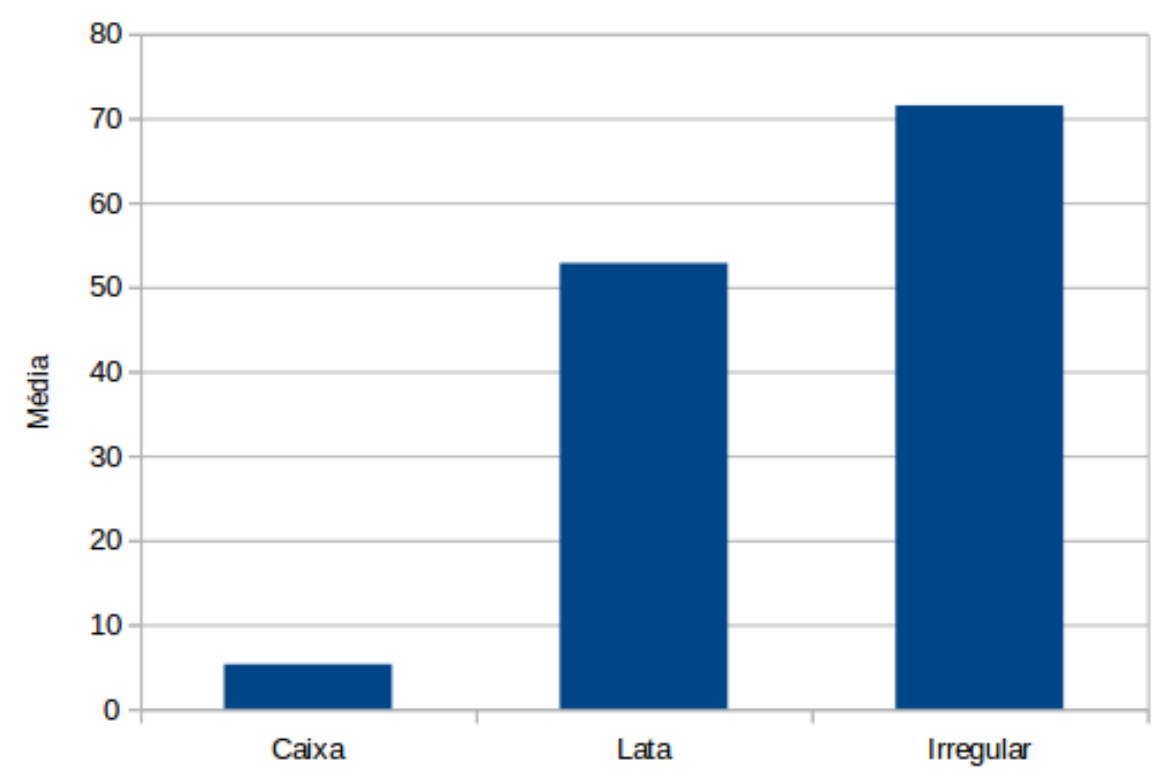

Fonte: Autor.

Com os valores de média, foi possível calcular o desvio padrão da amostra para cada objeto. Sendo para a Caixa valor de Desvio Padrão de 7,13, a Lata de 16,13 e o Irregular de 37,03. Gerando assim, um comparativo no gráfico da Figura 51a.

Utilizando como base os valores de Desvio Padrão divido pela raiz quadrada da média de precisão obtida, foi possível encontrar o Erro Padrão gerado pela média dos dados. Sendo 
Figura 51 - Gráfico do desvio padrão e erro padrão - SIFT lab.

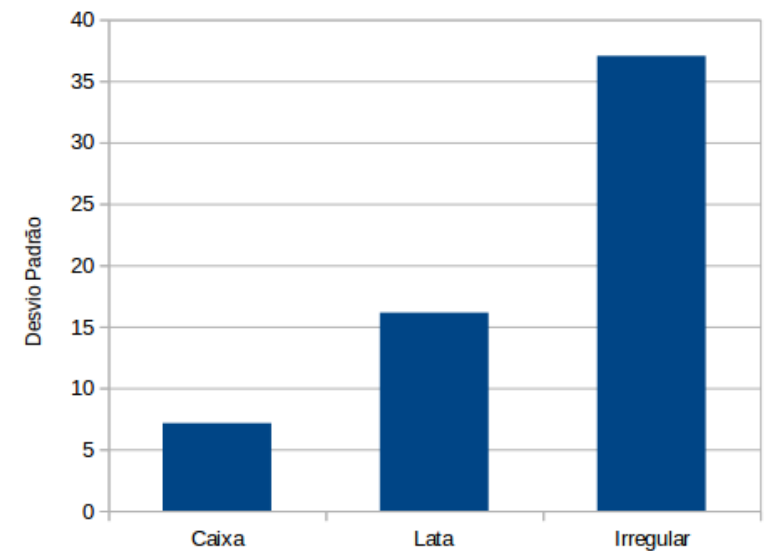

(a) Desvio padrão

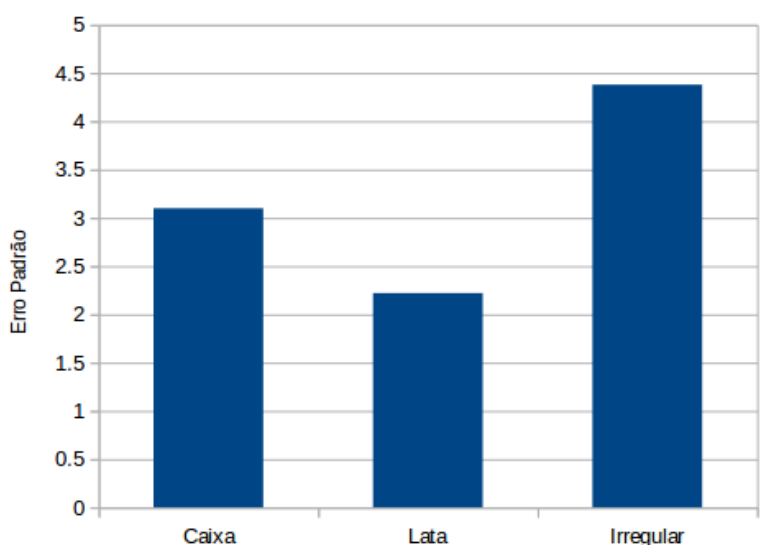

(b) Erro Padrão

Fonte: Autor.

para a Lata 2,22, para Caixa 3,10 e para o Irregular 4,38, conforme pode ser visto o comparativo no gráfico da Figura 51 b

\subsubsection{Experimento - SURF}

Com a busca por grade, foi notado que o kernel da SVM que melhor separou foi o RBF, junto com o valor de gamma igual a 0,1 e o parâmetro de Custo em 1000.

\subsubsection{Desempenho com Alteração de Luminosidade}

Foram executados 10 testes com base sem a unificação dos vetores tanto de teste como de treino. Quantidade de imagens por classe de objeto para teste foi de 13. Coletados os resultados de desempenho das matrizes de confusão geradas, obteve a média em porcentagem de acerto na Figura 52. Para o objeto Lata obteve média de $67 \%$ de acerto, para o objeto Caixa teve média de $16,2 \%$ e para o Irregular média de $40,7 \%$.

Com os valores de média, foi possível calcular o Desvio Padrão da amostra para cada objeto. Sendo para a Caixa valor de desvio padrão de 23,62, a Lata de 16,49 e o Irregular de 33,40. Gerando assim, um comparativo no gráfico da Figura 53a.

Utilizando como base os valores de Desvio Padrão divido pela raiz quadrada da média de precisão obtida, foi possível encontrar o Erro Padrão gerado pela média dos dados. Sendo para a Lata 2,01, para Caixa 5,87 e para o Irregular 5,24, conforme pode ser visto o comparativo no gráfico da Figura 53b. 
Figura 52 - Gráfico das médias das precisões geradas com a variação de luminosidade para cada classe - SURF lab.

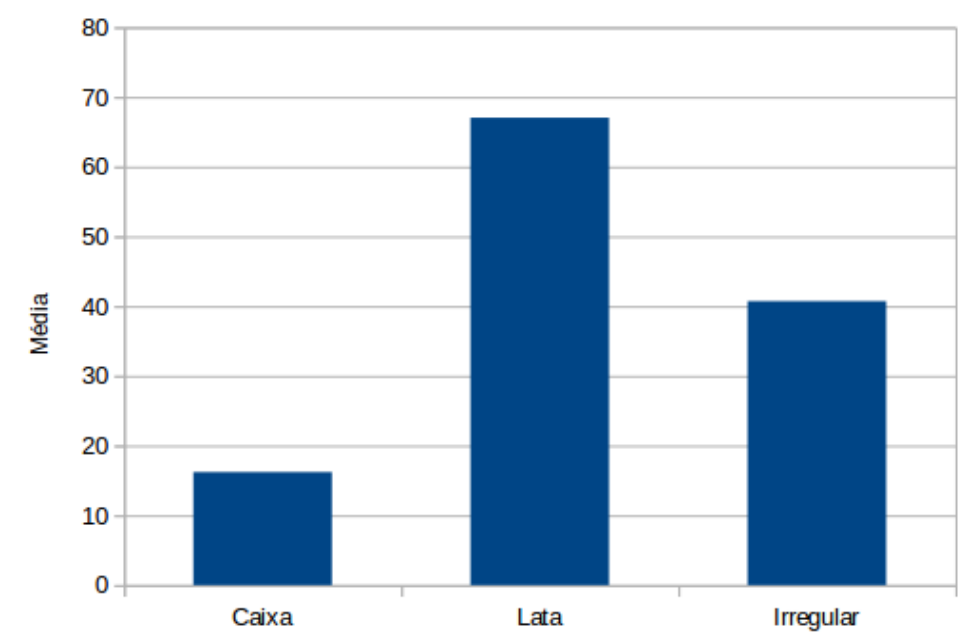

Fonte: Autor

Figura 53 - Gráfico do desvio padrão e erro padrão - SURF lab.
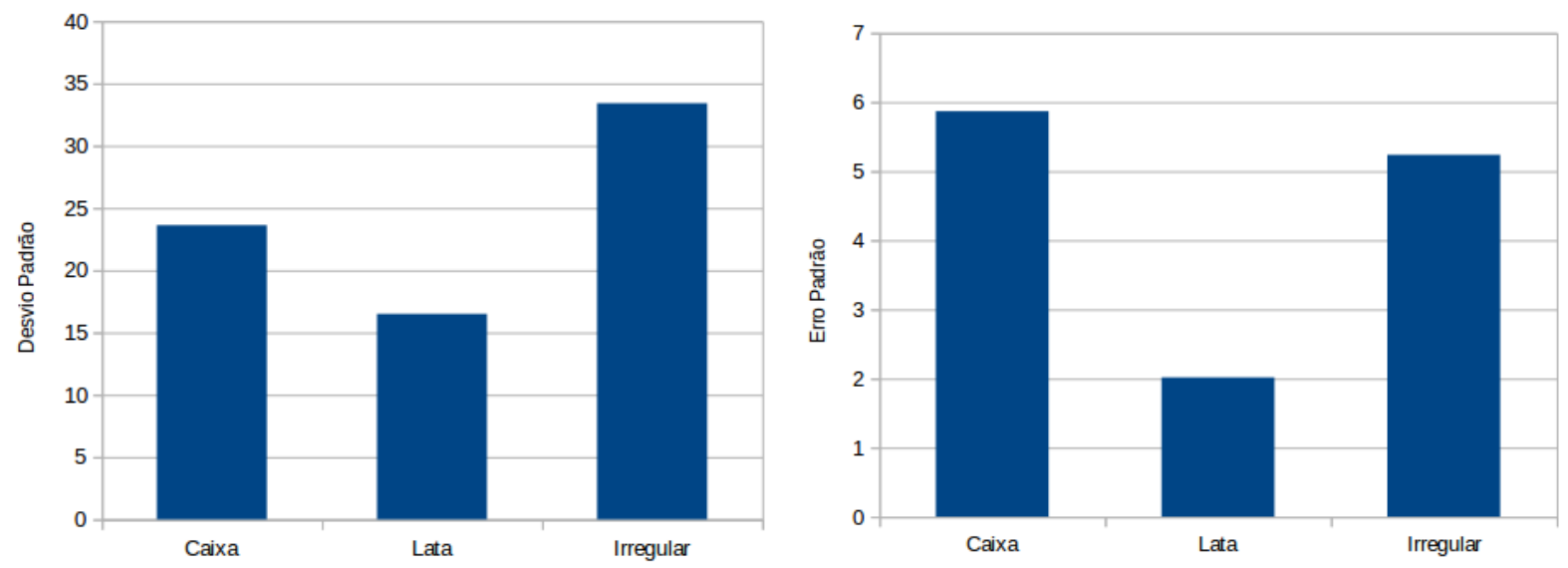

(a) Desvio padrão

(b) Erro Padrão

Fonte: Autor.

\subsubsection{Experimento - ORB}

Com a busca por grade, foi notado que o kernel da SVM que melhor separou foi o Linear, junto com o valor de gamma igual a 0,0001 e o parâmetro de Custo em 1000.

\subsubsection{Desempenho com Alteração de Luminosidade}

Foram executados 10 testes com base sem a unificação dos vetores tanto de teste como de treino. Quantidade de imagens por classe de objeto para teste foi de 13. Coletados os resultados de desempenho das matrizes de confusão geradas, obteve a média em porcentagem 
de acerto na Figura 54. Para o objeto Lata obteve média de 62,5\% de acerto, para o objeto Caixa teve média de $0 \%$ e para o Irregular média de $81,4 \%$.

Figura 54 - Gráfico das médias das precisões geradas com a variação de luminosidade para cada classe - ORB lab.

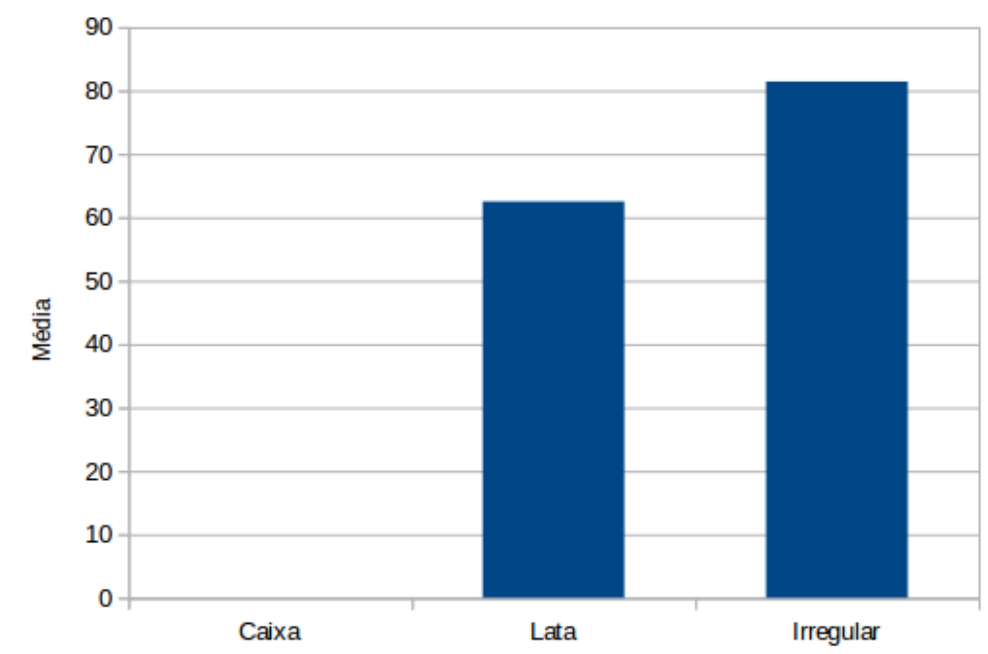

Fonte: Autor.

Com os valores de média, foi possível calcular o Desvio Padrão da amostra para cada objeto. Sendo para a Caixa valor de Desvio Padrão de 0, a Lata de 8,44 e o Irregular de 10,34. Gerando assim, um comparativo no gráfico da Figura 55a.

Figura 55 - Gráfico do desvio padrão e erro padrão - ORB lab.

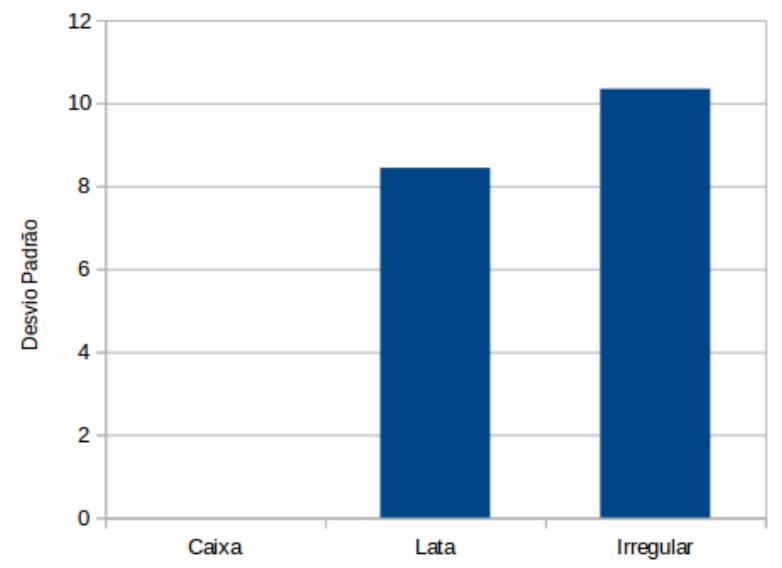

(a) Desvio padrão

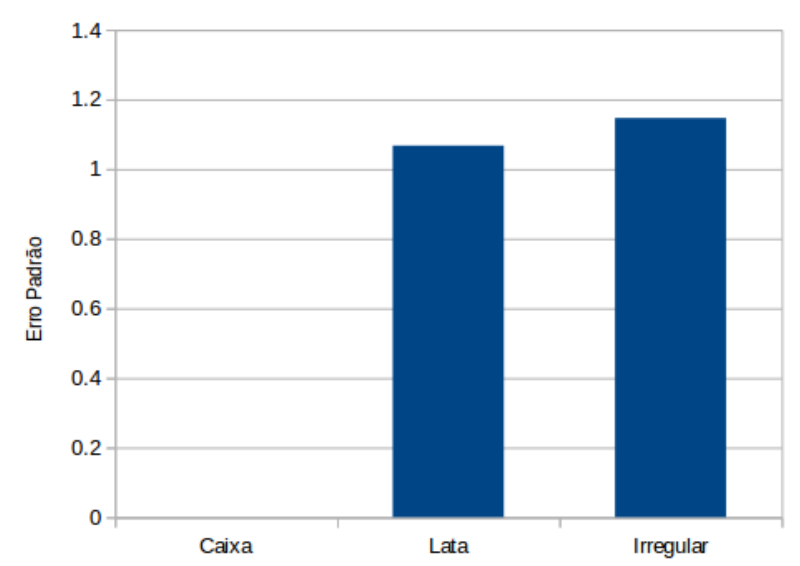

(b) Erro Padrão

Fonte: Autor.

Utilizando como base os valores de Desvio Padrão divido pela raiz quadrada da média de todos os níveis de divisão, é possível encontrar o Erro Padrão gerado pela média dos dados. Sendo para a Lata 1,07, para Caixa 0 e para o Irregular 1,15, conforme pode ser visto o comparativo no gráfico da Figura 55b. 


\subsection{DISCUSSÃO - COMPARANDO OS RESULTADOS DO LABORATÓRIO}

Comparando os resultados encontrados das três técnicas para rotular qual técnica foi melhor com cada tipo de objeto do laboratório. Foram gerados três gráficos para facilitar a comparação dos resultados obtidos entre todas as técnicas (Figura 56 e Figura 57). Na Figura 56 mostra para cada técnica qual foi a média de todas as precisões com os testes no ambiente do laboratório. Os outros dois gráficos são os cálculos derivados das precisões, na Figura 57a tem-se os dados de cada desvio padrão encontrado e na Figura 57b os valores dos erros padrões.

Figura 56 - Gráfico de média das técnicas - lab.

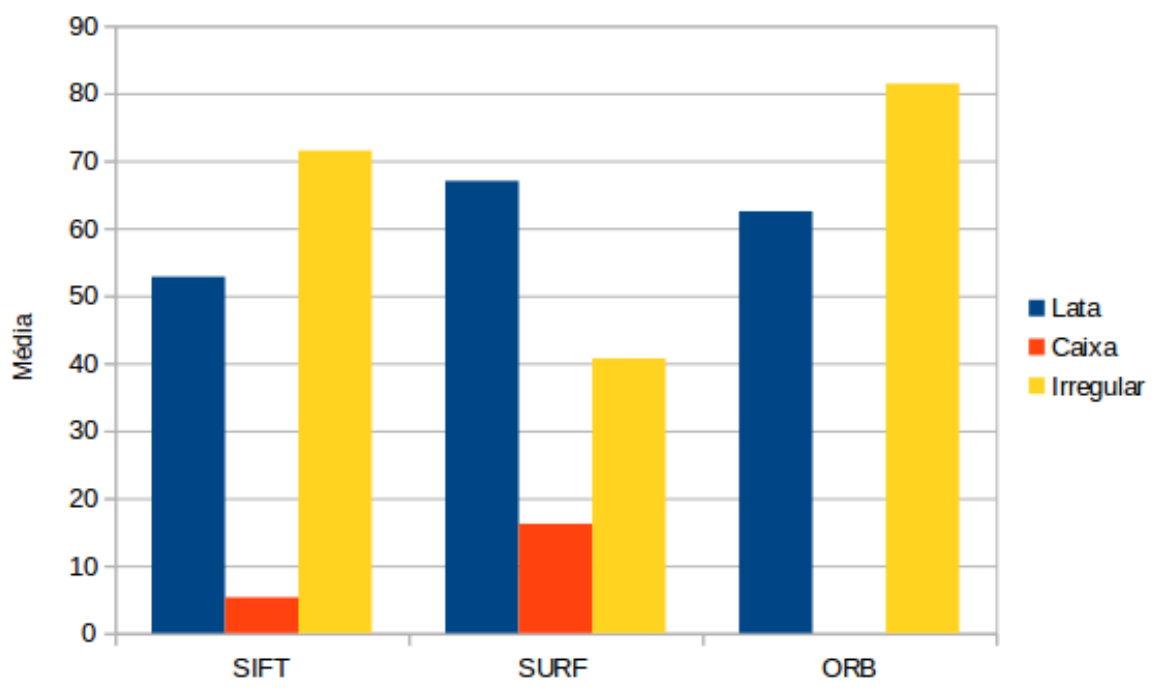

Fonte: Autor.

Figura 57 - Gráfico de desvio padrão e erro padrão das técnicas - lab.

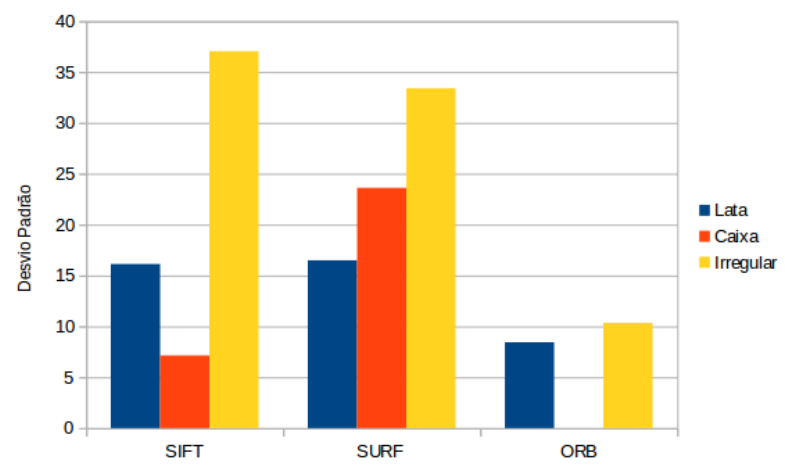

(a) Desvio Padrão

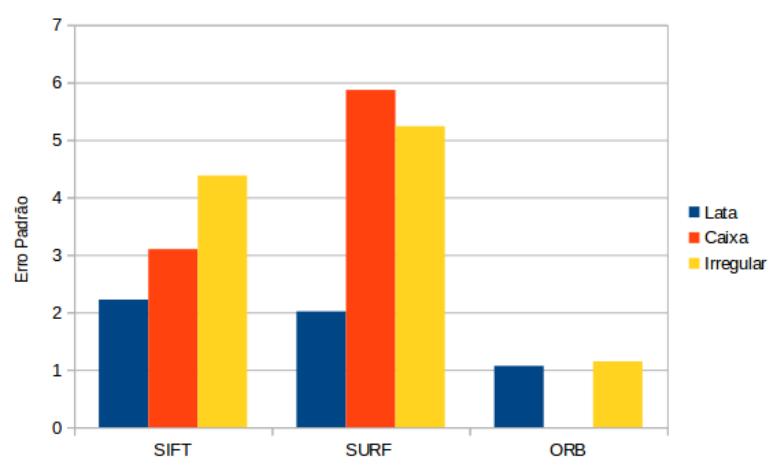

(b) Erro Padrão

Fonte: Autor

Como o critério para escolha de qual técnica foi melhor com cada tipo de objeto era se tiver maior média, menor desvio padrão e menor erro padrão, as técnicas foram rotuladas como: 
a) Para o objeto Lata, a técnica que teve melhor média foi o SURF, porém, não teve menor valor de desvio padrão e erro padrão. O segundo melhor foi a técnica ORB que teve baixos valores de desvio padrão e erro padrão. Portanto, a técnica ORB demonstrou ser estável durante o experimento tornando assim, melhor para utilização, obtendo melhor desempenho no reconhecimento dos objetos do tipo Lata.

b) Para o objeto Caixa o que obteve melhor resultado de média de precisão foi o SURF, mas teve o maior erro padrão de todas as técnicas. Como a técnica SIFT teve valor de média abaixo de $10 \%$ a técnica que melhor teve resultado foi a SURF. Portanto sendo o SURF o melhor neste teste para o objeto Caixa.

c) E por fim, para o objeto Irregular a técnica que teve melhores resultados nos três quesitos, chegando a $80 \%$ de acerto foi a ORB. Portanto sendo a melhor técnica para o objeto Irregular. 


\section{CONCLUSÃO}

Esse trabalho apresentou estudo sobre visão computacional, onde o principal objetivo era solucionar o problema do pouco conhecimento que se tem sobre qual técnica de extração de características de imagem era necessário para encontrar três tipos de objetos, cilíndricos, retangulares e irregulares. Fato ocorrido para ser utilizado na competição de robótica RoboCup na categoria @ Home, que simula ambientes e tarefas cotidianas de lares e residências. Onde os três tipos de objetos, estudados neste trabalho, encontram-se na competição para reconhecimento.

Para a realização do primeiro experimento foi utilizada a base de imagem da ALOI, ambiente controlado, onde contém diversas imagens de objetos que podem ser encontrados no cotidiano com diversas variações de luminosidade. Para o experimento Desempenho pela Divisão, foi verificado em qual porcentagem de imagem de treino é necessário para que a técnica tenha bons resultados, resultando em que todas elas dependem de no mínimo 30\% de imagens, se o total de imagens eram 360 para cada tipo de objeto, portanto, para cada um seria necessário em média 108 imagens para que tenham sucesso na execução de reconhecimento. Portanto, com pouca imagem para treino tem-se resultados variáveis e baixo. Quando for aumentando a quantidade de imagens para treino as técnicas tenderam a melhores e mais estáveis resultados.

Na etapa seguinte as técnicas foram utilizadas de forma diferente, simulando a situação que a competição exige. Extração de imagens de $360^{\circ}$ do objeto e imagens retiradas do ambiente. A utilização separada das imagens trouxe resultados expressivos sobre a aleatoriedade que cada técnica tem em encontrar pontos chaves na imagem e robustez em reconhecer objetos com variação de luminosidade. Resultando nas técnicas que tiveram melhor desempenho, sendo para Lata o SIFT, para a Caixa e o Irregular o SURF, conforme pode ser visto a na Tabela 3 na linha da ALOI.

Tabela 3 - Resultados finais

\begin{tabular}{l|l|l|l}
\hline & Lata & Caixa & Irregular \\
\hline ALOI & SIFT & SURF & SURF \\
\hline Lab & ORB & SURF & ORB \\
\hline
\end{tabular}

Fonte: Autor.

Com a realização do segundo experimento com a base criada do laboratório, a dificuldade de um ambiente real para a extração e classificação dos dados foi discrepante comparados aos resultados obtidos com a base da ALOI. Os resultados apresentaram porcentagens diferenciadas e, no caso do ORB com o objeto caixa, o não reconhecimento foi exemplificado. Entretanto, obtiveram resultados satisfatórios que demonstraram quais técnicas foram melhores com quais objetos. A técnica que alcançou melhor resultado para Lata foi o ORB, fazendo assim, resultado diferente do primeiro experimento, sendo plausível a utilização das duas técnicas para reconhecer objetos do tipo Cilíndrico, o mesmo ocorreu para os objetos do tipo Irregular 
que teve o ORB como melhor no reconhecimento. E por fim, para o objeto do tipo Caixa SURF manteve estabilidade nos dois experimentos.

Portanto, para reconhecer a gama de objetos testados neste trabalho, é necessária a implementação das três técnicas, para que possam juntas reconhecer e alcançar pontuações boas na competição e, no caso de residências, os robôs serem robustos no reconhecimento destes três tipos de objetos.

A partir deste trabalho, foram encontradas diversas dificuldades e sugestões que poderão servir como trabalhos futuros:

a) aplicação de novas técnicas à mesma metodologia apresentada, para que sejam estipulados novos resultados para comparação com este trabalho. Um fato necessário para comprovação dos rótulos atribuídos ou alteração do rótulo para uma técnica com melhor desempenho;

b) a técnica HOG utiliza imagens redimensionadas para o formato de uma pedestre que está em vias públicas. Sua metodologia, na teoria, é deveras interessante para utilização no reconhecimento de formas de objetos, porém, é necessário estudos para utilização de imagens com definição maior do que a criada, sendo em Full $H D$ de 1920x 1080 pixels;

c) aumentar a gama de tipos objetos utilizados neste trabalho para rotular mais objetos com técnicas, sendo possível a utilização de qual técnica for melhor para cada problema encontrado em ambientes que os robôs autônomos estiverem;

d) aplicar a conclusão que este trabalho alcançou em robôs autônomos residencias, coletando informações de desempenho do reconhecimento de objetos em diversos cômodos da residência. 


\section{REFERÊNCIAS}

AGRAWAL, Motilal; KONOLIGE, Kurt; BLAS, Morten Rufus. Censure: Center surround extremas for realtime feature detection and matching. In: SPRINGER. EUROPEAN Conference on Computer Vision. [S.1.: s.n.], 2008. p. 102-115.

ANDREW, Alex M. An Introduction to Support Vector Machines and Other Kernel-Based Learning Methods by Nello Christianini and John Shawe-Taylor. Cambridge: Univ Press, 2000.

BAY, Herbert et al. Speeded-up robust features (SURF). Computer Vision and Image Understanding, Elsevier, v. 110, n. 3, p. 346-359, 2008.

BEEK, Loy van et al. RoboCup@Home 2017: Rules and Regulations. [S.1.: s.n.], 2017. http://www.robocupathome.org/rules/2017_rulebook.pdf.

BRADSKI, Gary; KAEHLER, Adrian. Learning OpenCV: Computer vision with the OpenCV library. [S.1.]: "O’Reilly Media, Inc.", 2008.

BYEONG-HO, KANG. A Review on Image and Video processing. International Journal of Multimedia and Ubiquitous Engineering, v. 2, n. 2, p. 49-64, 2007.

CALONDER, Michael et al. Brief: Binary robust independent elementary features. In: SPRINGER. EUROPEAN Conference on Computer Vision. [S.1.: s.n.], 2010. p. 778-792.

CORTES, Corinna; VAPNIK, Vladimir. Support-vector networks. Machine learning, Springer, v. 20, n. 3, p. 273-297, 1995.

DALAL, Navneet; TRIGGS, Bill. Histograms of oriented gradients for human detection. In: IEEE. COMPUTER Vision and Pattern Recognition. [S.1.: s.n.], 2005. v. 1, p. 886-893.

FISCHLER, Martin A; BOLLES, Robert C. Random sample consensus: a paradigm for model fitting with applications to image analysis and automated cartography. Communications of the ACM, ACM, v. 24, n. 6, p. 381-395, 1981.

FLITTON, Gregory T; BRECKON, Toby P; BOUALLAGU, Najla Megherbi. Object recognition using $3 \mathrm{~d}$ sift in complex ct volumes. In: BMVC. [S.1.: s.n.], 2010. p. 1-12.

FREUND, Yoav; SCHAPIRE, Robert E. A desicion-theoretic generalization of on-line learning and an application to boosting. In: SPRINGER. EUROPEAN Conference on Computational Learning Theory. [S.1.: s.n.], 1995. p. 23-37. 
GEUSEBROEK et al. The Amsterdam library of object images. International Journal of Computer Vision, Springer, v. 61, n. 1, p. 103-112, 2005.

GONZALEZ, Rafael C; WOODS, Richard E. Processamento de imagens digitais. [S.1.]: Edgard Blucher, 2000.

HAAR, Alfred. Zur theorie der orthogonalen funktionensysteme. Mathematische Annalen, Springer, v. 69, n. 3, p. 331-371, 1910.

HARRIS, Chris; STEPHENS, Mike. A combined corner and edge detector. In: CITESEER, 50. ALVEY vision conference. [S.1.: s.n.], 1988. v. 15, p. 10-5244.

KOHAVI, Ron et al. A study of cross-validation and bootstrap for accuracy estimation and model selection. In: INTERNATIONAL JOINT CONFERENCE ON ARTIFICIAL INTELLIGENCE, 2. IJCAI. [S.1.: s.n.], 1995. v. 14, p. 1137-1145.

LIANG, Yixiong et al. Multi-task GLOH feature selection for human age estimation. In: IEEE. IMAGE Processing (ICIP), 2011 18th IEEE International Conference on. [S.l.: s.n.], 2011. p. 565-568.

LIENHART, Rainer; MAYDT, Jochen. An extended set of haar-like features for rapid object detection. In: IEEE. IMAGE Processing. 2002. Proceedings. 2002 International Conference on. [S.1.: s.n.], 2002. v. 1, p. i-i.

LORENA, Ana Carolina; CARVALHO, André CPLF de. Introduçao aos Classificadores de Margens Largas. Sao Carlos-SP, 2003.

LOWE, David G. Distinctive image features from scale-invariant keypoints. International Journal of Computer Vision, Springer, v. 60, n. 2, p. 91-110, 2004.

. Object recognition from local scale-invariant features. In: IEEE. COMPUTER vision, 1999. The proceedings of the seventh IEEE international conference on. [S.l.: s.n.], 1999. v. 2, p. 1150-1157.

LUNENBURG, JJM et al. Tech United Eindhoven@ Home 2016 Team Description Paper. Joao Pessoa, Brazil, 2016.

MACEDO, Cristiano et al. Uma abordagem otimizada para reconhecimento de logomarcas de veículos usando SURF. Universidade Federal de São Carlos, 2015.

MACEDO, Cristiano; FERNANDES, Marcio Merino. Recognition of Vehicle Logos using SURF. Proceedings of XI Workshop de Visão Computacional, 2015. 
MATAS, Jiri et al. Robust wide-baseline stereo from maximally stable extremal regions.

Image and vision computing, Elsevier, v. 22, n. 10, p. 761-767, 2004.

MEYER ZU BORGSEN, Sebastian; KORTHALS, Timo; WACHSMUTH, Sven. ToBI-Team of Bielefeld The Human-Robot Interaction System for RoboCup@Home, 2016.

MUJA, Marius; LOWE, David G. Fast approximate nearest neighbors with automatic algorithm configuration. VISAPP (1), v. 2, n. 331-340, p. 2, 2009.

OLIVA, Aude; TORRALBA, Antonio. Modeling the shape of the scene: A holistic representation of the spatial envelope. International Journal of Computer Vision, Springer, v. 42, n. 3, p. 145-175, 2001.

RODRIGUES, Leonardo Almeida et al. DETECÇÃO E RECONHECIMENTO DE OBJETOS EM IMAGENS UTILIZANDO ALGORITMOS DE EXTRAÇÃO DE PONTOS CHAVE. In: 2. COLLOQUIUM Exactarum. [S.1.: s.n.], 2014. v. 6.

RODRIGUES, Paulo Sérgio; ALBUQUERQUE ARAÚJO, Arnaldo de. Um algoritmo para reconhecimento de objetos baseado em regioes. In: ANAIS do III Workshop em Tratamento de Imagens-UFMG. [S.1.: s.n.], 2002. v. 1, p. 72-80.

ROSIN, Paul L. Measuring corner properties. Computer Vision and Image Understanding, Elsevier, v. 73, n. 2, p. 291-307, 1999.

RUBLEE, Ethan et al. ORB: An efficient alternative to SIFT or SURF. In: IEEE. COMPUTER Vision (ICCV), 2011 IEEE International Conference on. [S.1.: s.n.], 2011. p. 2564-2571.

RUSSELL, Stuart; NORVIG, Peter. A modern approach. Artificial Intelligence. Prentice-Hall, Egnlewood Cliffs, Citeseer, v. 25, p. 27, 1995.

RUSU, Radu Bogdan; BLODOW, Nico; BEETZ, Michael. Fast point feature histograms (FPFH) for 3D registration. In: IEEE. ROBOTICS and Automation, 2009. ICRA'09. IEEE International Conference on. [S.1.: s.n.], 2009. p. 3212-3217.

RUSU, Radu Bogdan; COUSINS, Steve. 3d is here: Point cloud library (pcl). In: IEEE. ROBOTICS and Automation (ICRA), 2011 IEEE International Conference on. [S.l.: s.n.], 2011. p. $1-4$.

SCIKIT-LEARN. [S.1.: s.n.], 2017. http://scikit-learn.org/stable/index.html. Accessed: 2017-08-16. 
SHI, Jianbo et al. Good features to track. In: IEEE. COMPUTER Vision and Pattern Recognition, 1994. Proceedings CVPR'94., 1994 IEEE Computer Society Conference on. [S.1.: s.n.], 1994. p. 593-600.

SHUAI, Wei et al. WrightEagle@ Home 2016 Team Description Paper, 2016.

SILVA BARROS, Ricardo da et al. IDENTIFICAÇÃO DE OBJETOS DO FUTEBOL DE ROBÔS UTILIZANDO ALGORITMO DE DESCRIÇÃO DE PONTOS CHAVE. In: 2. COLLOQUIUM Exactarum. [S.1.: s.n.], 2016. v. 7, p. 102-118.

SILVA, Francisco Assis da et al. Evaluation of Keypoint Detectors and Descriptors. Local: Rio de Janeiro: UFF, 2013.

TUYTELAARS et al. Local invariant feature detectors: a survey. Foundations and trends $\mathbb{R}$ in computer graphics and vision., Local: Now Publishers, In: v. 3, n. 3, p. 177-280, 2008.

VILÃO JR, Claudio O et al. Evaluating the Performance of Two Computer Vision Techniques for a Mobile Humanoid Agent Acting at RoboCup KidSized Soccer League. In: SPRINGER. LATIN American Robotics Symposium. [S.1.: s.n.], 2016. p. 1-19.

VILÃO, Claudio O; BIANCHI, Reinaldo AC. Um sistema de visão computacional monocular para um robô móvel humanoide. In: DISSERTAÇÃO - Centro Universitário da FEI. [S.l.: s.n.], 2016.

VILÃO, Claudio O et al. A single camera vision system for a humanoid robot. In: IEEE. ROBOTICS: SBR-LARS Robotics Symposium and Robocontrol (SBR LARS Robocontrol), 2014 Joint Conference on. [S.1.: s.n.], 2014. p. 181-186.

VIOLA, Paul; JONES, Michael. Rapid object detection using a boosted cascade of simple features. In: IEEE. COMPUTER Vision and Pattern Recognition, 2001. CVPR 2001. Proceedings of the 2001 IEEE Computer Society Conference on. [S.1.: s.n.], 2001. v. 1, p. i-i. WISSPEINTNER, Thomas et al. RoboCup@ Home: Scientific competition and benchmarking for domestic service robots. In: Interaction Studies, Local: John Benjamins Publishing, v. 10, n. 3, p. 392-426, 2009.

ZHANG, Zhengyou. Microsoft kinect sensor and its effect. IEEE multimedia, IEEE, v. 19, n. 2, p. 4-10, 2012. 
APÊNDICE A - DADOS COLETADOS DOS EXPERIMENTOS - PRECISÃO PELA DIVISÃO 
Resultados Retirados das Matrizes de Confusão - Precisão Pela Divisão - SIFT

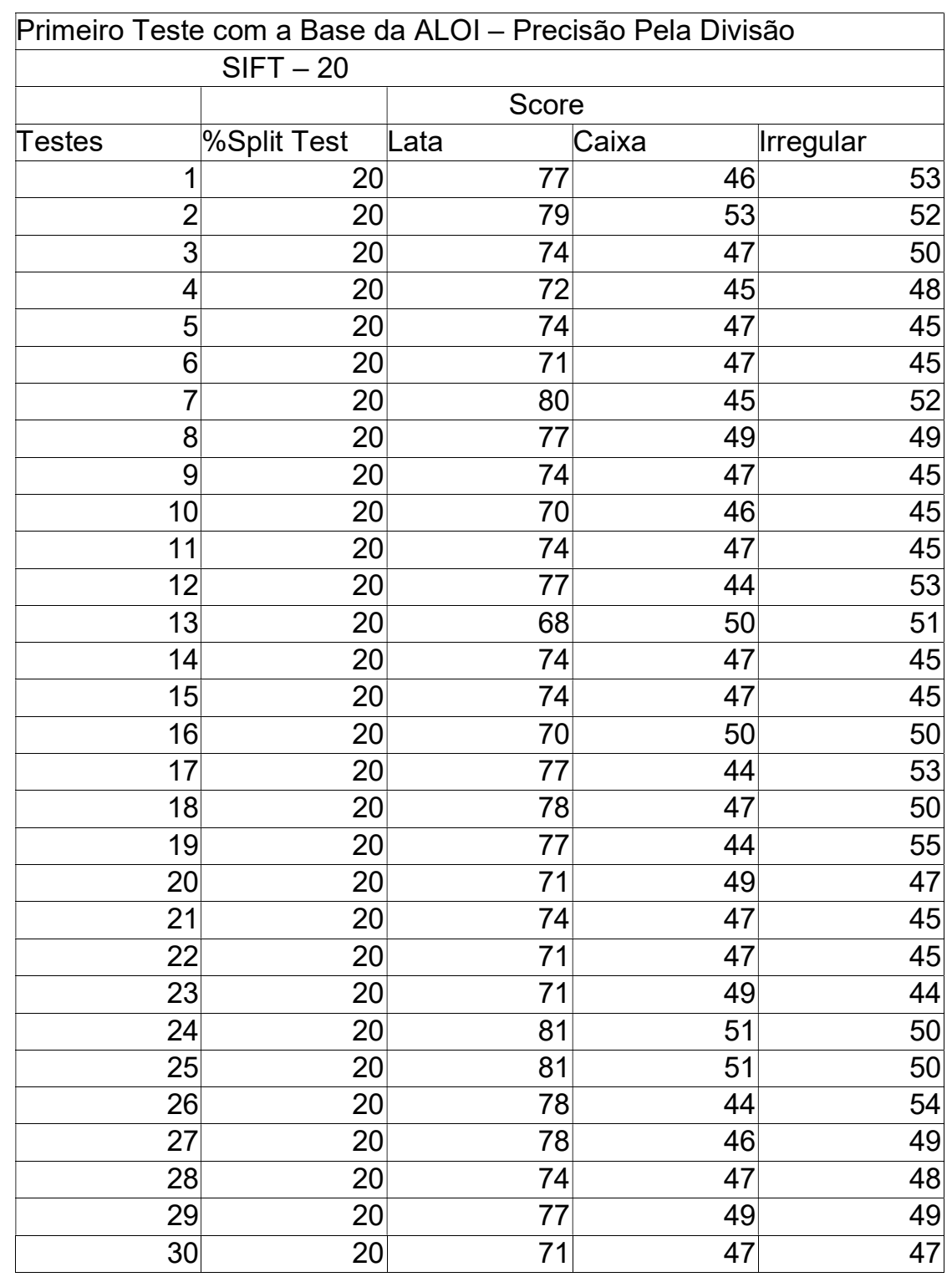


Resultados Retirados das Matrizes de Confusão - Precisão Pela Divisão - SIFT

\begin{tabular}{|r|r|r|r|r|r|r|}
\hline \multicolumn{7}{|c|}{ Primeiro Teste com a Base da ALOI - Precisão Pela Divisão } \\
\hline \multicolumn{7}{|c|}{ SIFT - 20 } \\
\hline
\end{tabular}


Resultados Retirados das Matrizes de Confusão - Precisão Pela Divisão - SIFT

\begin{tabular}{|c|c|c|c|}
\hline \multicolumn{4}{|c|}{ Primeiro Teste com a Base da ALOI - PrecisãodPela } \\
\hline \multicolumn{4}{|c|}{ SIFT -20} \\
\hline \multicolumn{4}{|c|}{ F1 Score } \\
\hline Testes & Lata & Caixa & Irregular \\
\hline 1 & 72 & 47 & 56 \\
\hline 2 & 71 & 54 & 56 \\
\hline 3 & 66 & 49 & 57 \\
\hline 4 & 63 & 48 & 54 \\
\hline 5 & 66 & 47 & 53 \\
\hline 6 & 63 & 49 & 51 \\
\hline 7 & 72 & 48 & 56 \\
\hline 8 & 72 & 48 & 54 \\
\hline 9 & 66 & 47 & 53 \\
\hline 10 & 63 & 47 & 51 \\
\hline 11 & 66 & 47 & 53 \\
\hline 12 & 70 & 46 & 57 \\
\hline 13 & 65 & 47 & 57 \\
\hline 14 & 66 & 47 & 53 \\
\hline 15 & 66 & 47 & 53 \\
\hline 16 & 66 & 47 & 57 \\
\hline 17 & 70 & 46 & 57 \\
\hline 18 & 72 & 48 & 55 \\
\hline 19 & 71 & 46 & 58 \\
\hline 20 & 63 & 50 & 53 \\
\hline 21 & 66 & 47 & 53 \\
\hline 22 & 63 & 49 & 51 \\
\hline 23 & 63 & 49 & 50 \\
\hline 24 & 73 & 52 & 56 \\
\hline 25 & 73 & 52 & 56 \\
\hline 26 & 71 & 46 & 57 \\
\hline 27 & 72 & 47 & 53 \\
\hline 28 & 66 & 48 & 55 \\
\hline 29 & 72 & 48 & 54 \\
\hline 30 & 63 & 50 & 53 \\
\hline
\end{tabular}


Resultados Retirados das Matrizes de Confusão - Precisão Pela Divisão - SIFT

\begin{tabular}{|c|c|c|c|c|c|}
\hline \multicolumn{6}{|c|}{ Primeiro Teste com a Base da ALOI - Precisão Pela Divisão } \\
\hline \multicolumn{6}{|c|}{\begin{tabular}{|c|} 
SIFT -40 \\
\end{tabular}} \\
\hline \multirow[b]{2}{*}{ Testes } & \multirow[b]{2}{*}{$\%$ Split Test } & \multicolumn{3}{|c|}{ Score } & \\
\hline & & Lata & & & \\
\hline 1 & 40 & & 75 & 42 & 55 \\
\hline 2 & 40 & & 78 & 43 & 56 \\
\hline 3 & 40 & & 69 & 48 & 47 \\
\hline 4 & 40 & & 69 & 53 & 47 \\
\hline 5 & 40 & & 69 & 50 & 46 \\
\hline 6 & 40 & & 67 & 54 & 48 \\
\hline 7 & 40 & & 78 & 43 & 56 \\
\hline 8 & 40 & & 75 & 44 & 53 \\
\hline 9 & 40 & & 69 & 51 & 46 \\
\hline 10 & 40 & & 67 & 54 & 48 \\
\hline 11 & 40 & & 69 & 51 & 46 \\
\hline 12 & 40 & & 71 & 51 & 54 \\
\hline 13 & 40 & & 70 & 50 & 53 \\
\hline 14 & 40 & & 69 & 51 & 46 \\
\hline 15 & 40 & & 69 & 51 & 46 \\
\hline 16 & 40 & & 69 & 50 & 53 \\
\hline 17 & 40 & & 71 & 51 & 53 \\
\hline 18 & 40 & & 75 & 45 & 53 \\
\hline 19 & 40 & & 71 & 50 & 54 \\
\hline 20 & 40 & & 68 & 54 & 47 \\
\hline 21 & 40 & & 69 & 51 & 46 \\
\hline 22 & 40 & & 67 & 54 & 48 \\
\hline 23 & 40 & & 67 & 54 & 48 \\
\hline 24 & 40 & & 78 & 42 & 55 \\
\hline 25 & 40 & & 78 & 42 & 55 \\
\hline 26 & 40 & & 71 & 50 & 54 \\
\hline 27 & 40 & & 75 & 44 & 54 \\
\hline 28 & 40 & & 69 & 51 & 47 \\
\hline 29 & 40 & & 75 & 45 & 54 \\
\hline 30 & 40 & & 69 & 53 & 48 \\
\hline
\end{tabular}


Resultados Retirados das Matrizes de Confusão - Precisão Pela Divisão - SIFT

\begin{tabular}{|c|c|c|c|c|c|c|}
\hline \multicolumn{7}{|c|}{ Primeiro Teste com a Base da ALOI - Precisão Pela Divisão } \\
\hline \multicolumn{7}{|c|}{ SIFT -40} \\
\hline \multirow[b]{2}{*}{ Testes } & \multicolumn{2}{|c|}{ Lata } & \multicolumn{2}{|l|}{ Caixa } & \multicolumn{2}{|l|}{ Irregular } \\
\hline & Precisão & Revocação & Precisão & & Precisão & Revocação \\
\hline 1 & 72 & 45 & 54 & 69 & 75 & $\begin{array}{ll}5 & 49\end{array}$ \\
\hline 2 & 72 & 48 & 56 & 66 & 78 & 55 \\
\hline 3 & 64 & 49 & 51 & 59 & 69 & 50 \\
\hline 4 & 64 & 54 & 51 & 60 & 69 & 56 \\
\hline 5 & 64 & 50 & 51 & 59 & 69 & 50 \\
\hline 6 & 63 & 55 & 51 & 60 & 67 & 55 \\
\hline 7 & 72 & 48 & 56 & 66 & 78 & 53 \\
\hline 8 & 72 & 46 & 53 & 69 & 75 & 48 \\
\hline 9 & 64 & 51 & 51 & 60 & 69 & 50 \\
\hline 10 & 63 & 54 & 51 & 59 & 67 & 55 \\
\hline 11 & 64 & 51 & 51 & 60 & 69 & 51 \\
\hline 12 & 68 & 52 & 56 & 65 & 71 & 52 \\
\hline 13 & 65 & 50 & 58 & 60 & 70 & 50 \\
\hline 14 & 64 & 51 & 51 & 60 & 69 & 51 \\
\hline 15 & 64 & 51 & 51 & 59 & 69 & 51 \\
\hline 16 & 64 & 50 & 58 & 60 & 69 & 50 \\
\hline 17 & 68 & 52 & 56 & 65 & 71 & 52 \\
\hline 18 & 72 & 47 & 53 & 69 & 75 & 49 \\
\hline 19 & 68 & 52 & 56 & 65 & 71 & 53 \\
\hline 20 & 64 & 54 & 51 & 60 & 68 & 55 \\
\hline 21 & 64 & 51 & 51 & 60 & 69 & 51 \\
\hline 22 & 63 & 55 & 51 & 60 & 67 & 55 \\
\hline 23 & 63 & 54 & 51 & 60 & 67 & 55 \\
\hline 24 & 71 & 46 & 56 & 66 & 78 & 51 \\
\hline 25 & 71 & 46 & 56 & 66 & 78 & 51 \\
\hline 26 & 78 & 51 & 55 & 65 & 71 & 53 \\
\hline 27 & 71 & 47 & 54 & 68 & 75 & 50 \\
\hline 28 & 64 & 51 & 52 & 59 & 69 & 51 \\
\hline 29 & 71 & 47 & 54 & 68 & 75 & 50 \\
\hline 30 & 64 & 54 & 51 & 60 & 69 & 55 \\
\hline
\end{tabular}


Resultados Retirados das Matrizes de Confusão - Precisão Pela Divisão - SIFT

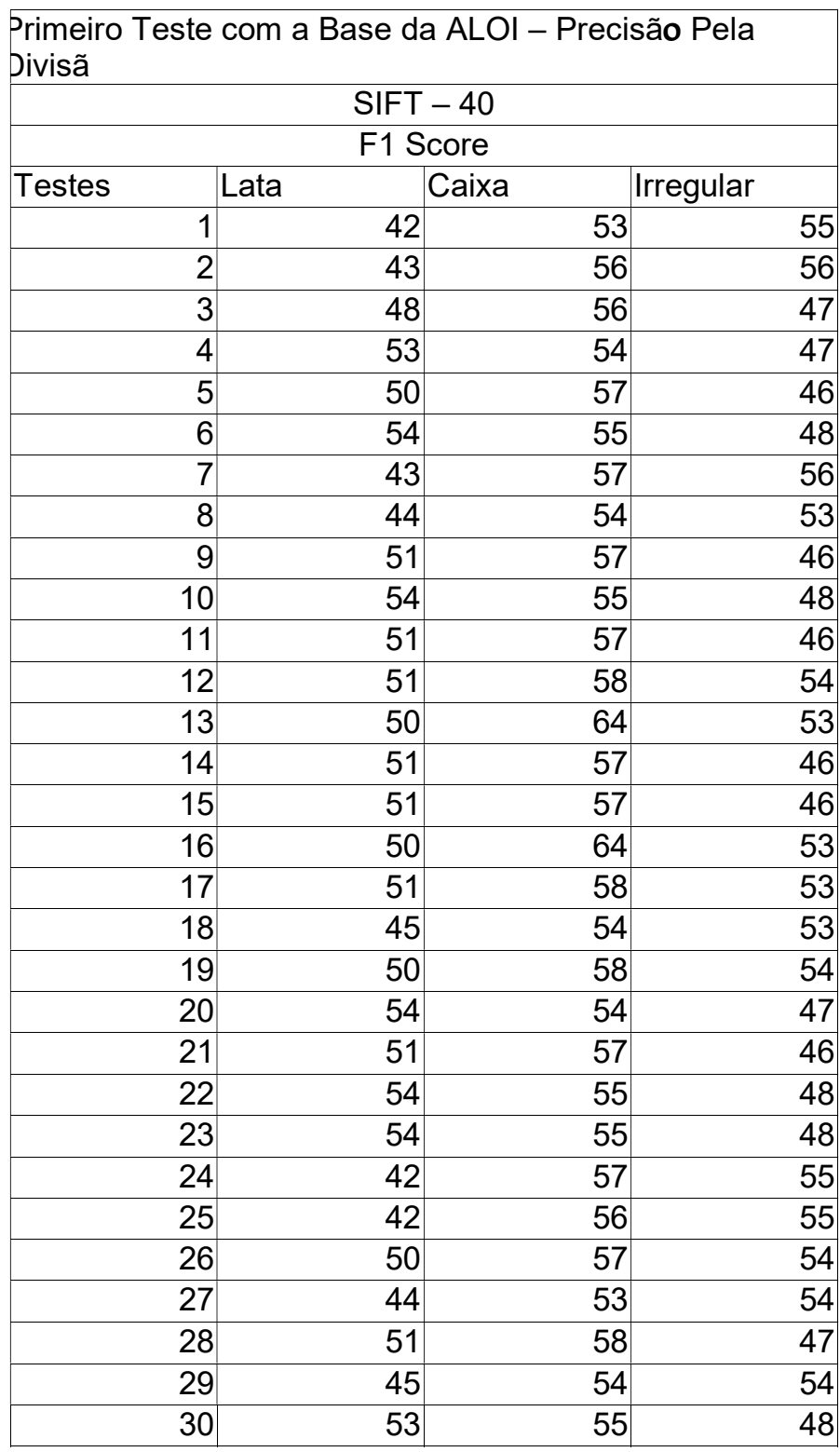


Resultados Retirados das Matrizes de Confusão - Precisão Pela Divisão - SIFT

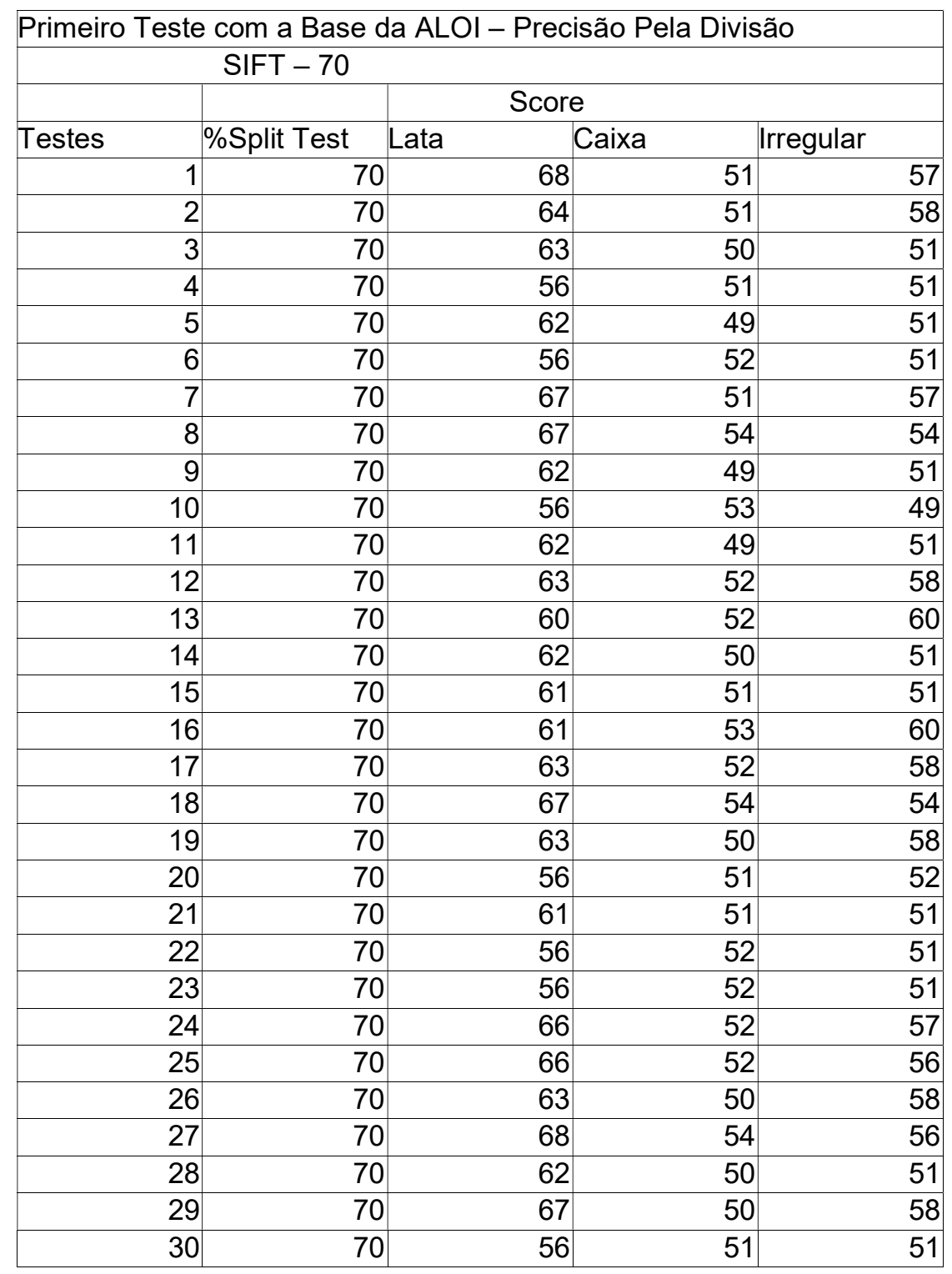


Resultados Retirados das Matrizes de Confusão - Precisão Pela Divisão - SIFT

\begin{tabular}{|r|r|r|r|r|r|r|}
\hline \multicolumn{7}{|c|}{ Primeiro Teste com a Base da ALOI - Precisão Pela Divisão } \\
\hline \multicolumn{7}{|c|}{ SIFT - 70} \\
\hline
\end{tabular}


Resultados Retirados das Matrizes de Confusão - Precisão Pela Divisão - SIFT

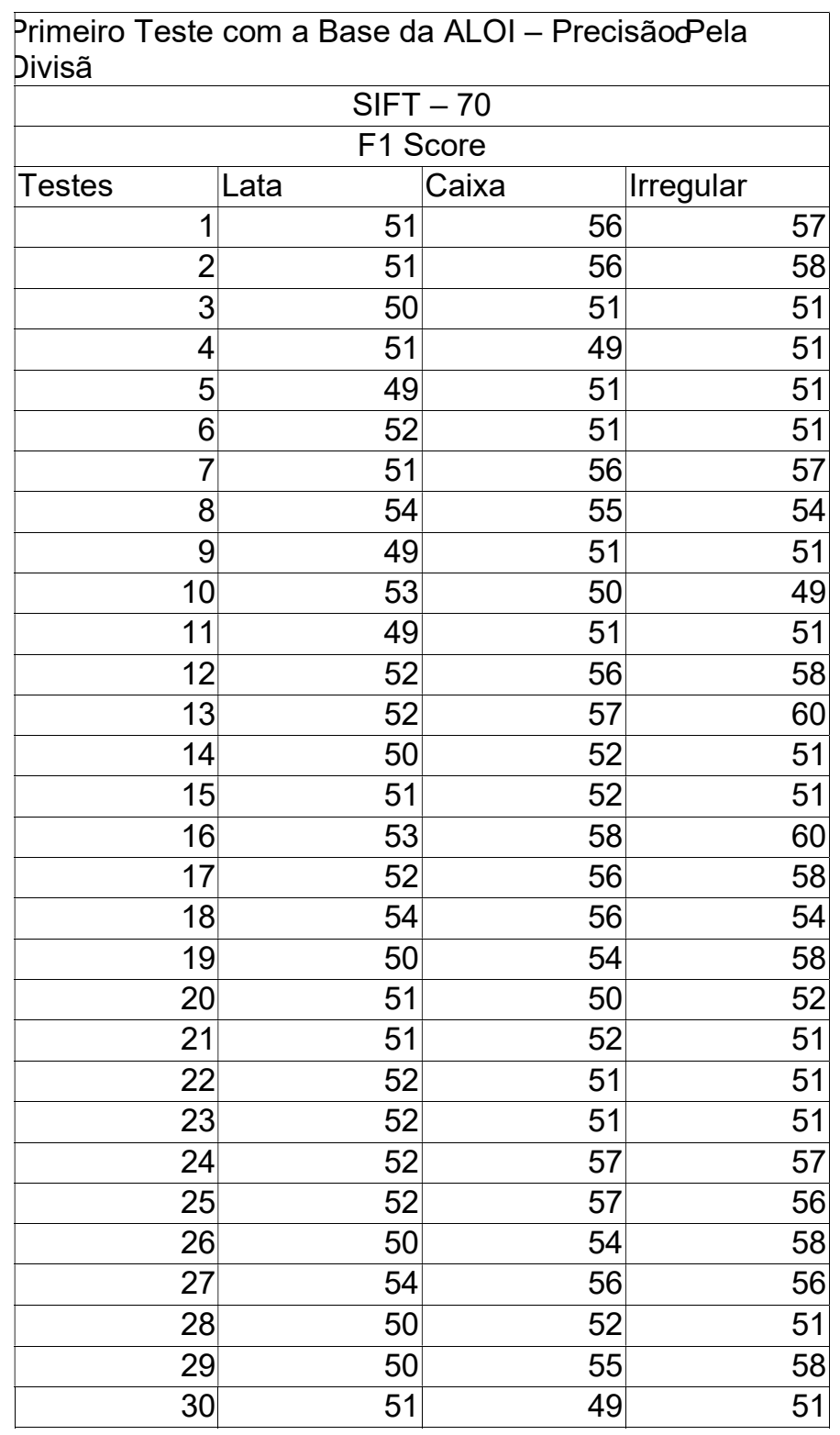


Resultados Retirados das Matrizes de Confusão - Precisão Pela Divisão - SIFT

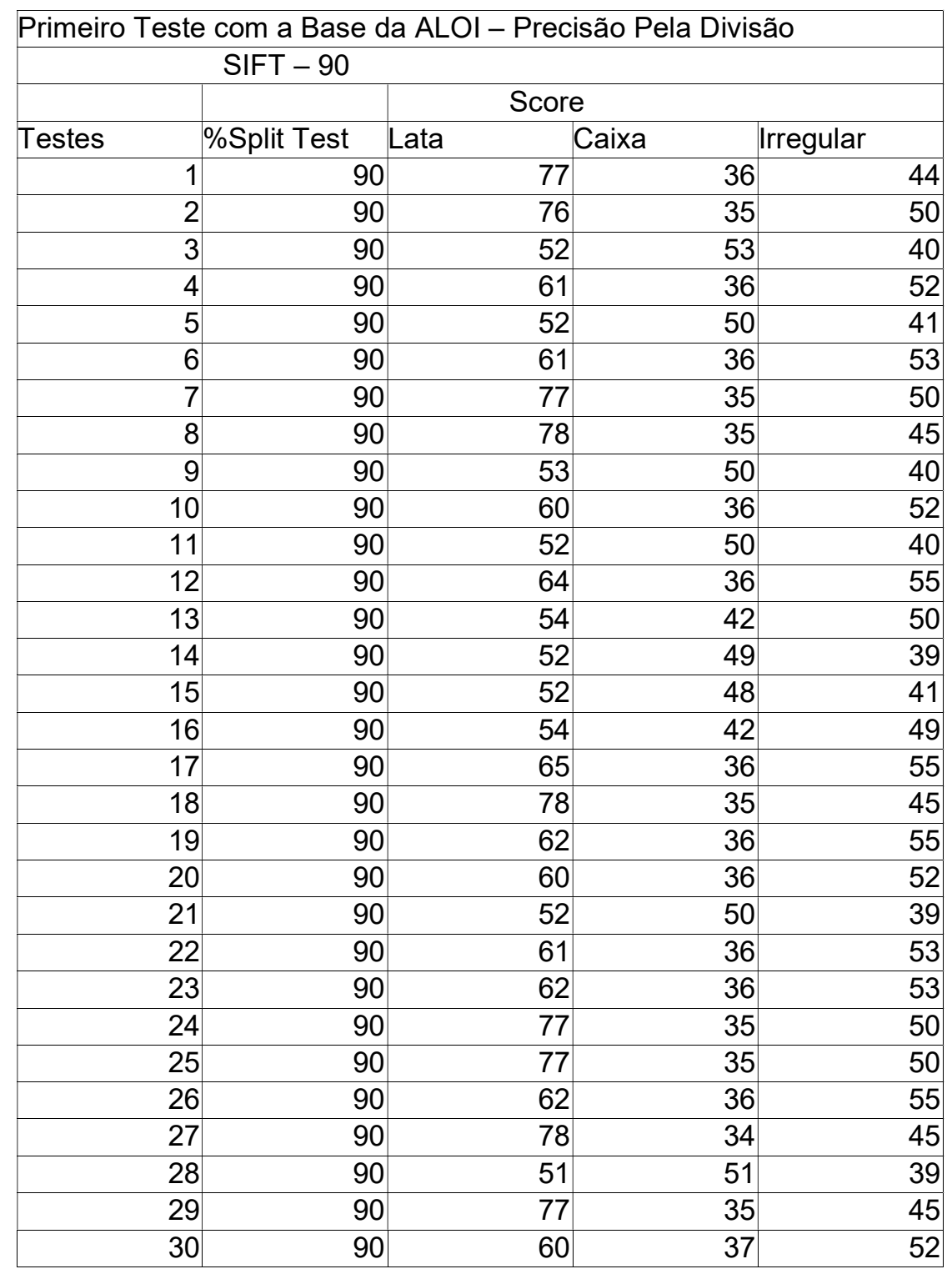


Resultados Retirados das Matrizes de Confusão - Precisão Pela Divisão - SIFT

\begin{tabular}{|r|r|r|r|r|r|r|}
\hline \multicolumn{7}{|c|}{ Primeiro Teste com a Base da ALOI - Precisão Pela Divisão } \\
\hline \multicolumn{2}{|c|}{ SIFT - 90} \\
\hline
\end{tabular}


Resultados Retirados das Matrizes de Confusão - Precisão Pela Divisão - SIFT

\begin{tabular}{|c|c|c|c|}
\hline \multicolumn{4}{|c|}{$\begin{array}{l}\text { Primeiro Teste com a Base da ALOI - PrecisãodPela } \\
\text { Divisã }\end{array}$} \\
\hline \multicolumn{4}{|c|}{ SIFT -90} \\
\hline \multicolumn{4}{|c|}{ F1 Score } \\
\hline Testes & & Caixa & Irregular \\
\hline 1 & 36 & 53 & 44 \\
\hline 2 & 35 & 54 & 50 \\
\hline 3 & 53 & 58 & 40 \\
\hline 4 & 36 & 46 & 52 \\
\hline 5 & 50 & 56 & 41 \\
\hline 6 & 36 & 47 & 53 \\
\hline 7 & 35 & 54 & 50 \\
\hline 8 & 35 & 55 & 45 \\
\hline 9 & 50 & 57 & 40 \\
\hline 10 & 36 & 46 & 52 \\
\hline 11 & 50 & 57 & 40 \\
\hline 12 & 36 & 49 & 55 \\
\hline 13 & 42 & 54 & 50 \\
\hline 14 & 49 & 57 & 39 \\
\hline 15 & 48 & 56 & 41 \\
\hline 16 & 42 & 54 & 49 \\
\hline 17 & 36 & 49 & 55 \\
\hline 18 & 35 & 54 & 45 \\
\hline 19 & 36 & 49 & 55 \\
\hline 20 & 36 & 46 & 52 \\
\hline 21 & 50 & 56 & 39 \\
\hline 22 & 36 & 47 & 53 \\
\hline 23 & 36 & 47 & 53 \\
\hline 24 & 35 & 55 & 50 \\
\hline 25 & 35 & 55 & 50 \\
\hline 26 & 36 & 49 & 55 \\
\hline 27 & 34 & 54 & 45 \\
\hline 28 & 51 & 56 & 39 \\
\hline 29 & 35 & 52 & 45 \\
\hline 30 & 37 & 47 & 52 \\
\hline
\end{tabular}


Resultados Retirados das Matrizes de Confusão - Precisão Pela Divisão - SURF

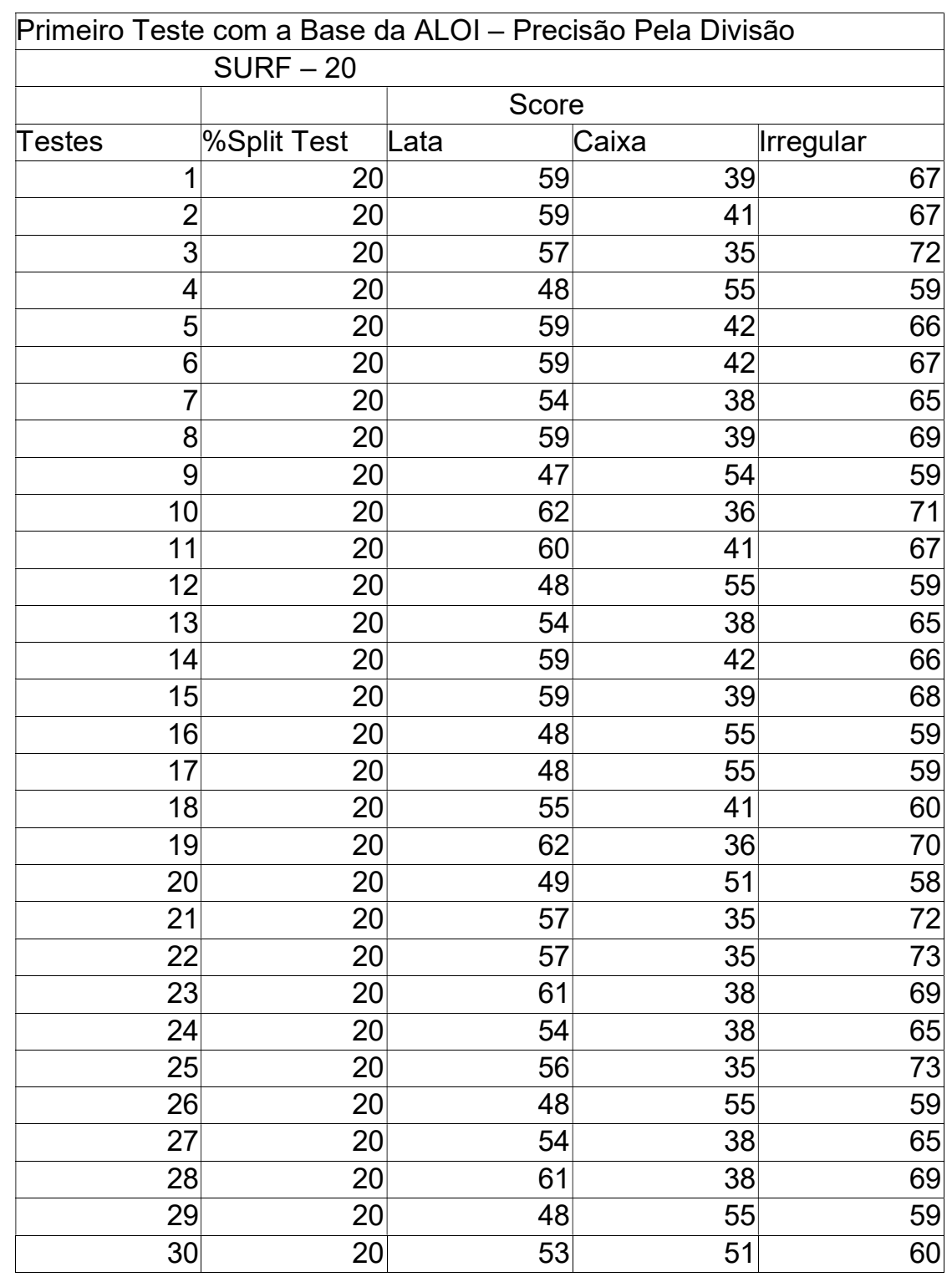


Resultados Retirados das Matrizes de Confusão - Precisão Pela Divisão - SURF

\begin{tabular}{|c|c|c|c|c|c|c|}
\hline \multicolumn{7}{|c|}{ Primeiro Teste com a Base da ALOI - Precisão Pela Divisão } \\
\hline \multicolumn{7}{|c|}{ SURF -20} \\
\hline \multirow[b]{2}{*}{ Testes } & \multicolumn{2}{|c|}{ Lata } & \multicolumn{2}{|l|}{ Caixa } & \multicolumn{2}{|l|}{ Irregular } \\
\hline & Precisão & Revocação & Precisão & Revocação & Precisão & Revocação \\
\hline 1 & 62 & 44 & 58 & 65 & 59 & 52 \\
\hline 2 & 63 & 46 & 59 & 67 & 59 & 52 \\
\hline 3 & 61 & 40 & 62 & 65 & 57 & 46 \\
\hline 4 & 55 & 49 & 57 & 64 & 48 & 44 \\
\hline 5 & 63 & 47 & 58 & 67 & 59 & 52 \\
\hline 6 & 63 & 47 & 59 & 67 & 59 & 53 \\
\hline 7 & 57 & 41 & 58 & 62 & 54 & 44 \\
\hline 8 & 63 & 44 & 59 & 68 & 59 & 51 \\
\hline 9 & 54 & 48 & 57 & 63 & 47 & 43 \\
\hline 10 & 67 & 42 & 60 & 72 & 62 & 50 \\
\hline 11 & 63 & 46 & 59 & 67 & 60 & 52 \\
\hline 12 & 55 & 49 & 57 & 64 & 48 & 44 \\
\hline 13 & 57 & 41 & 58 & 62 & 54 & 44 \\
\hline 14 & 63 & 47 & 58 & 67 & 59 & 52 \\
\hline 15 & 63 & 44 & 59 & 67 & 59 & 51 \\
\hline 16 & 55 & 49 & 57 & 64 & 48 & 44 \\
\hline 17 & 55 & 49 & 57 & 64 & 48 & 44 \\
\hline 18 & 56 & 47 & 59 & 62 & 51 & 43 \\
\hline 19 & 67 & 42 & 59 & 72 & 62 & 49 \\
\hline 20 & 55 & 46 & 57 & 62 & 49 & 41 \\
\hline 21 & 61 & 40 & 62 & 65 & 57 & 47 \\
\hline 22 & 61 & 40 & 62 & 66 & 57 & 47 \\
\hline 23 & 66 & 43 & 59 & 72 & 61 & 49 \\
\hline 24 & 57 & 41 & 58 & 62 & 54 & 44 \\
\hline 25 & 61 & 40 & 62 & 66 & 56 & 46 \\
\hline 26 & 55 & 49 & 57 & 64 & 48 & 44 \\
\hline 27 & 57 & 41 & 58 & 62 & 54 & 44 \\
\hline 28 & 66 & 43 & 59 & 71 & 61 & 49 \\
\hline 29 & 55 & 49 & 57 & 64 & 48 & 44 \\
\hline 30 & 58 & 47 & 59 & 63 & 53 & 43 \\
\hline
\end{tabular}


Resultados Retirados das Matrizes de Confusão - Precisão Pela Divisão - SURF

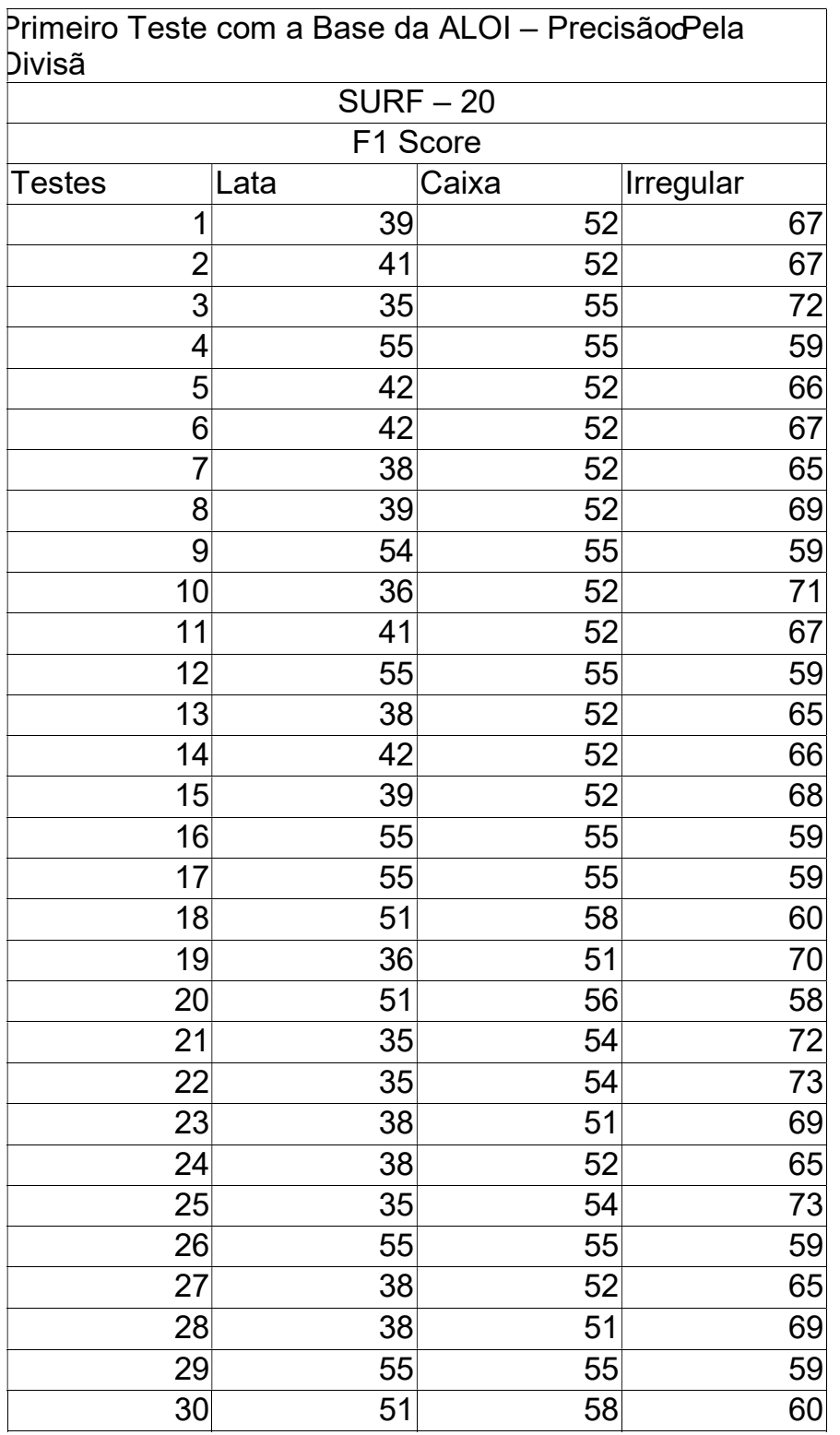


Resultados Retirados das Matrizes de Confusão - Precisão Pela Divisão - SURF

\begin{tabular}{|c|c|c|c|c|c|}
\hline \multicolumn{6}{|c|}{ Primeiro Teste com a Base da ALOI - Precisão Pela Divisão } \\
\hline \multicolumn{6}{|c|}{ SURF -40} \\
\hline \multirow[b]{2}{*}{ Testes } & \multirow[b]{2}{*}{$\%$ Split Test } & \multicolumn{3}{|c|}{ Score } & \\
\hline & & Lata & & & \\
\hline 1 & 40 & & 65 & 32 & 71 \\
\hline 2 & 40 & & 65 & 34 & 70 \\
\hline 3 & 40 & & 60 & 31 & 74 \\
\hline 4 & 40 & & 52 & 56 & 63 \\
\hline 5 & 40 & & 64 & 34 & 70 \\
\hline 6 & 40 & & 66 & 33 & 70 \\
\hline 7 & 40 & & 56 & 35 & 65 \\
\hline 8 & 40 & & 66 & 32 & 70 \\
\hline 9 & 40 & & 51 & 55 & 62 \\
\hline 10 & 40 & & 66 & 32 & 76 \\
\hline 11 & 40 & & 65 & 33 & 70 \\
\hline 12 & 40 & & 52 & 55 & 62 \\
\hline 13 & 40 & & 56 & 35 & 65 \\
\hline 14 & 40 & & 66 & 34 & 70 \\
\hline 15 & 40 & & 66 & 33 & 70 \\
\hline 16 & 40 & & 52 & 54 & 62 \\
\hline 17 & 40 & & 53 & 55 & 62 \\
\hline 18 & 40 & & 56 & 47 & 62 \\
\hline 19 & 40 & & 65 & 32 & 76 \\
\hline 20 & 40 & & 57 & 47 & 62 \\
\hline 21 & 40 & & 60 & 31 & 74 \\
\hline 22 & 40 & & 60 & 31 & 74 \\
\hline 23 & 40 & & 67 & 32 & 77 \\
\hline 24 & 40 & & 56 & 36 & 65 \\
\hline 25 & 40 & & 60 & 31 & 74 \\
\hline 26 & 40 & & 53 & 55 & 62 \\
\hline 27 & 40 & & 56 & 35 & 65 \\
\hline 28 & 40 & & 66 & 31 & 77 \\
\hline 29 & 40 & & 53 & 55 & 62 \\
\hline 30 & 40 & & 58 & 49 & 62 \\
\hline
\end{tabular}


Resultados Retirados das Matrizes de Confusão - Precisão Pela Divisão - SURF

\begin{tabular}{|r|r|r|r|r|r|r|}
\hline \multicolumn{7}{|c|}{ Primeiro Teste com a Base da ALOI - Precisão Pela Divisão } \\
\hline \multicolumn{7}{|c|}{ SURF - 40 } \\
\hline
\end{tabular}


Resultados Retirados das Matrizes de Confusão - Precisão Pela Divisão - SURF

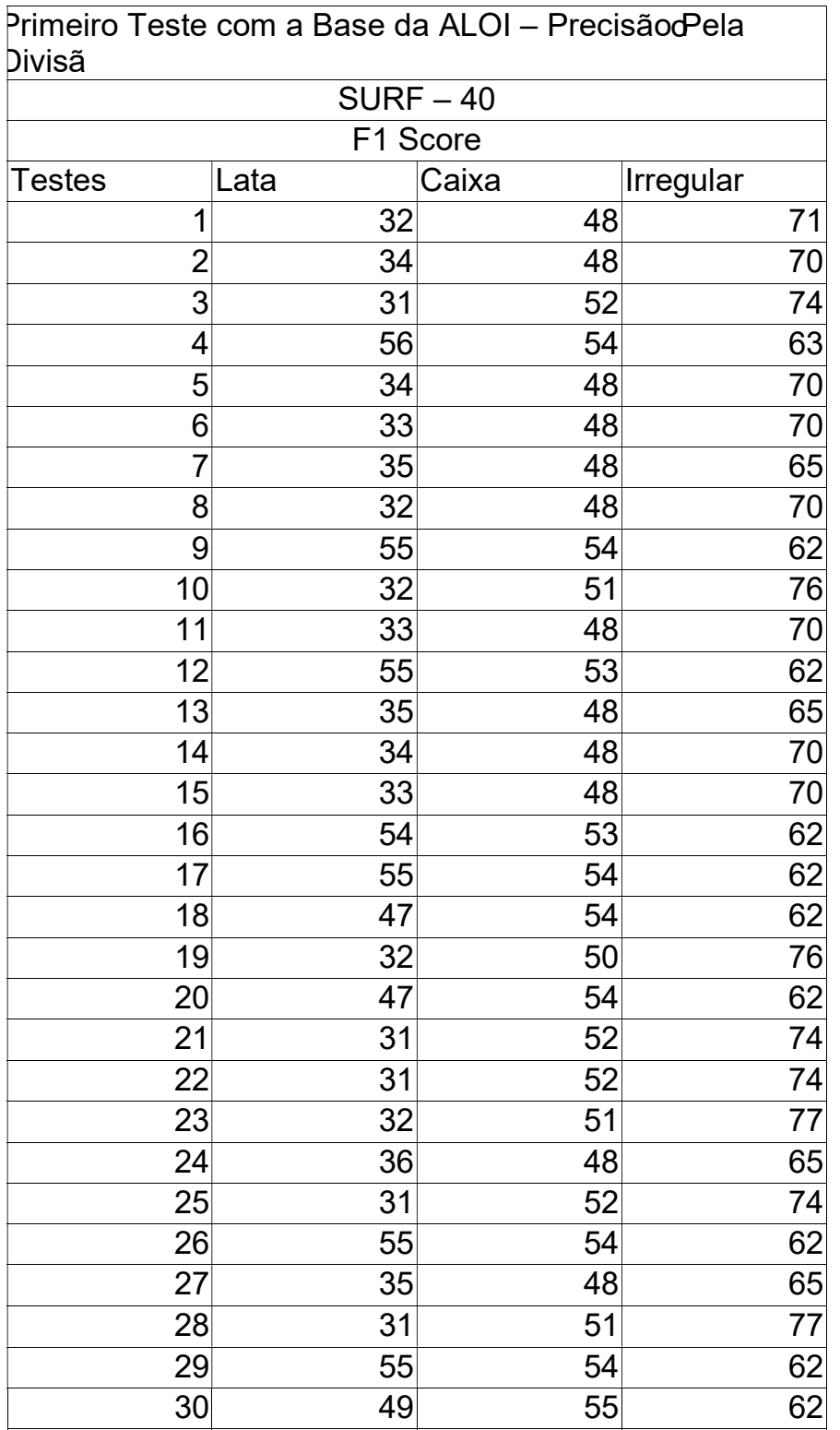


Resultados Retirados das Matrizes de Confusão - Precisão Pela Divisão - SURF

\begin{tabular}{|c|c|c|c|c|c|}
\hline \multicolumn{6}{|c|}{ Primeiro Teste com a Base da ALOI - Precisão Pela Divisão } \\
\hline \multicolumn{6}{|c|}{ SURF -70} \\
\hline \multirow[b]{2}{*}{ Testes } & \multirow[b]{2}{*}{$\%$ Split Test } & \multicolumn{3}{|c|}{ Score } & \\
\hline & & $\mathrm{La}$ & & \multicolumn{2}{|c|}{ Irregular } \\
\hline 1 & & 70 & 63 & 35 & 71 \\
\hline 2 & & 70 & 62 & 35 & 71 \\
\hline 3 & & 70 & 56 & 31 & 76 \\
\hline 4 & & 70 & 51 & 53 & 64 \\
\hline 5 & & 70 & 62 & 35 & 71 \\
\hline 6 & & 70 & 63 & 35 & 71 \\
\hline 7 & & 70 & 56 & 34 & 67 \\
\hline 8 & & 70 & 62 & 35 & 71 \\
\hline 9 & & 70 & 51 & 53 & 63 \\
\hline 10 & & 70 & 60 & 38 & 75 \\
\hline 11 & & 70 & 63 & 35 & 71 \\
\hline 12 & & 70 & 51 & 53 & 64 \\
\hline 13 & & 70 & 56 & 35 & 67 \\
\hline 14 & & 70 & 62 & 35 & 71 \\
\hline 15 & & 70 & 63 & 35 & 71 \\
\hline 16 & & 70 & 52 & 53 & 63 \\
\hline 17 & & 70 & 63 & 35 & 71 \\
\hline 18 & & 70 & 50 & 49 & 69 \\
\hline 19 & & 70 & 61 & 38 & 75 \\
\hline 20 & & 70 & 50 & 52 & 67 \\
\hline 21 & & 70 & 56 & 30 & 76 \\
\hline 22 & & 70 & 56 & 31 & 76 \\
\hline 23 & & 70 & 60 & 37 & 74 \\
\hline 24 & & 70 & 56 & 34 & 67 \\
\hline 25 & & 70 & 56 & 31 & 76 \\
\hline 26 & & 70 & 51 & 52 & 64 \\
\hline 27 & & 70 & 56 & 34 & 67 \\
\hline 28 & & 70 & 59 & 38 & 75 \\
\hline 29 & & 70 & 51 & 52 & 64 \\
\hline 30 & & 70 & 51 & 51 & 67 \\
\hline
\end{tabular}


Resultados Retirados das Matrizes de Confusão - Precisão Pela Divisão - SURF

\begin{tabular}{|r|r|r|r|r|r|r|}
\hline \multicolumn{7}{|c|}{ Primeiro Teste com a Base da ALOI - Precisão Pela Divisão } \\
\hline \multicolumn{2}{|c|}{ SURF -70} \\
\hline
\end{tabular}


Resultados Retirados das Matrizes de Confusão - Precisão Pela Divisão - SURF

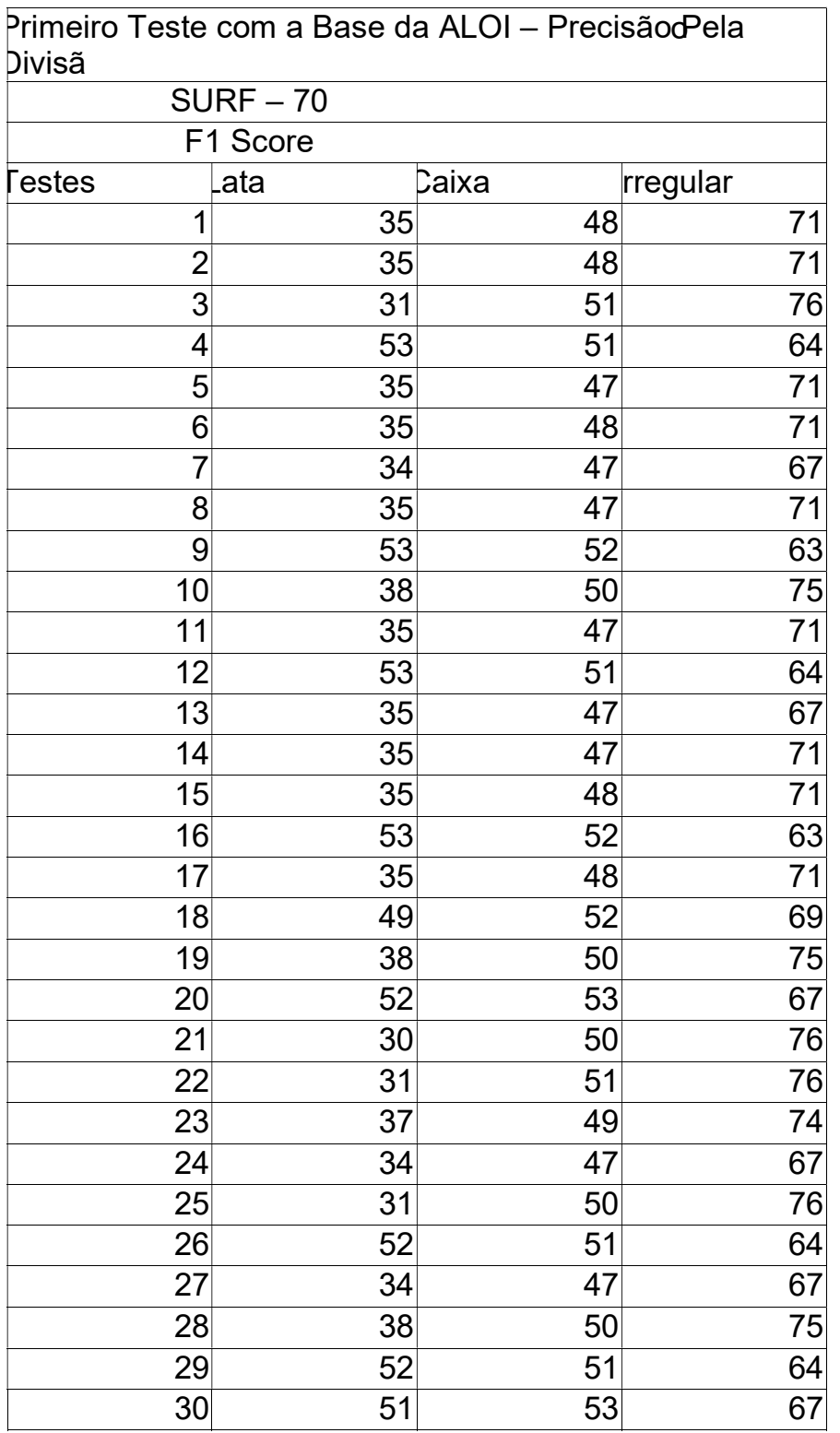


Resultados Retirados das Matrizes de Confusão - Precisão Pela Divisão - SURF

\begin{tabular}{|c|c|c|c|c|c|}
\hline Primeiro Teste & com a Base & e da ALC & Preci & ivis & \\
\hline & SURF - 90 & & & & \\
\hline & & & Score & & \\
\hline Testes & \%Split Test & Lata & & & \\
\hline 1 & & 90 & 66 & 43 & 62 \\
\hline 2 & & 90 & 67 & 42 & 60 \\
\hline 3 & & 90 & 52 & 31 & 81 \\
\hline 4 & & 90 & 50 & 55 & 67 \\
\hline 5 & & 90 & 65 & 43 & 60 \\
\hline 6 & & 90 & 67 & 43 & 59 \\
\hline 7 & & 90 & 61 & 28 & 29 \\
\hline 8 & & 90 & 67 & 44 & 61 \\
\hline 9 & & 90 & 50 & 56 & 66 \\
\hline 10 & & 90 & 57 & 39 & 74 \\
\hline 11 & & 90 & 67 & 42 & 60 \\
\hline 12 & & 90 & 49 & 55 & 67 \\
\hline 13 & & 90 & 60 & 28 & 69 \\
\hline 14 & & 90 & 67 & 42 & 58 \\
\hline 15 & & 90 & 66 & 44 & 61 \\
\hline 16 & & 90 & 50 & 55 & 67 \\
\hline 17 & & 90 & 67 & 42 & 60 \\
\hline 18 & & 90 & 47 & 43 & 72 \\
\hline 19 & & 90 & 57 & 39 & 75 \\
\hline 20 & & 90 & 48 & 45 & 72 \\
\hline 21 & & 90 & 52 & 31 & 81 \\
\hline 22 & & 90 & 53 & 31 & 80 \\
\hline 23 & & 90 & 56 & 42 & 74 \\
\hline 24 & & 90 & 61 & 28 & 69 \\
\hline 25 & & 90 & 53 & 31 & 79 \\
\hline 26 & & 90 & 49 & 54 & 67 \\
\hline 27 & & 90 & 61 & 28 & 69 \\
\hline 28 & & 90 & 57 & 39 & 76 \\
\hline 29 & & 90 & 49 & 54 & 67 \\
\hline 30 & & 90 & 46 & 43 & 73 \\
\hline
\end{tabular}


Resultados Retirados das Matrizes de Confusão - Precisão Pela Divisão - SURF

\begin{tabular}{|r|r|r|r|r|r|r|}
\hline \multicolumn{7}{|c|}{ Primeiro Teste com a Base da ALOI - Precisão Pela Divisão } \\
\hline \multicolumn{7}{|c|}{ SURF - 90} \\
\hline
\end{tabular}


Resultados Retirados das Matrizes de Confusão - Precisão Pela Divisão - SURF

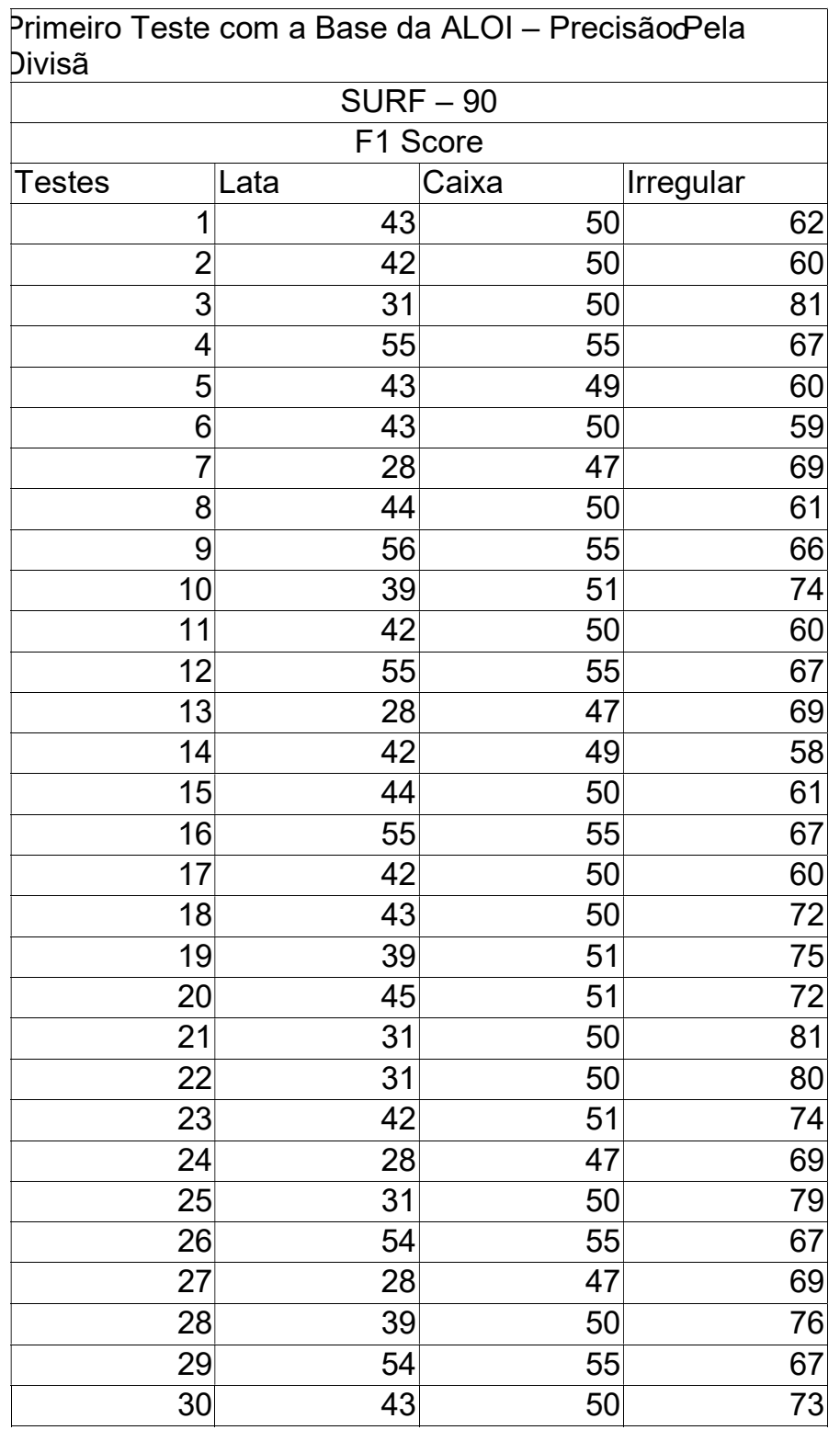


Resultados Retirados das Matrizes de Confusão - Precisão Pela Divisão - ORB

\begin{tabular}{|c|c|c|c|c|c|}
\hline Primeiro Teste & com a Base & da ALC & Preci & Divis & \\
\hline & ORB - 20 & & & & \\
\hline & & & Score & & \\
\hline Testes & \%Split Test & Lata & & & \\
\hline 1 & 2 & & 26 & 61 & 64 \\
\hline 2 & 2 & & 38 & 45 & 70 \\
\hline 3 & 2 & & 15 & 62 & 59 \\
\hline 4 & 2 & & 23 & 65 & 68 \\
\hline 5 & 2 & & 20 & 66 & 59 \\
\hline 6 & 2 & & 41 & 38 & 73 \\
\hline 7 & 2 & & 30 & 62 & 62 \\
\hline 8 & 2 & & 40 & 45 & 65 \\
\hline 9 & 2 & & 41 & 44 & 69 \\
\hline 10 & 2 & & 33 & 76 & 48 \\
\hline 11 & 2 & & 29 & 59 & 63 \\
\hline 12 & 2 & & 27 & 79 & 52 \\
\hline 13 & 2 & & 23 & 64 & 59 \\
\hline 14 & 2 & & 28 & 61 & 65 \\
\hline 15 & 2 & & 19 & 65 & 60 \\
\hline 16 & 2 & & 33 & 79 & 47 \\
\hline 17 & 2 & & 32 & 79 & 44 \\
\hline 18 & 2 & & 17 & 64 & 62 \\
\hline 19 & 2 & & 21 & 65 & 60 \\
\hline 20 & 2 & & 15 & 62 & 59 \\
\hline 21 & 2 & & 14 & 65 & 61 \\
\hline 22 & 2 & & 20 & 68 & 59 \\
\hline 23 & 2 & & 14 & 62 & 60 \\
\hline 24 & 2 & & 34 & 78 & 44 \\
\hline 25 & 2 & & 15 & 64 & 59 \\
\hline 26 & 2 & & 17 & 64 & 60 \\
\hline 27 & 2 & & 33 & 76 & 46 \\
\hline 28 & 2 & & 30 & 64 & 64 \\
\hline 29 & 2 & & 41 & 45 & 67 \\
\hline 30 & 2 & & 28 & 80 & 52 \\
\hline
\end{tabular}


Resultados Retirados das Matrizes de Confusão - Precisão Pela Divisão - ORB

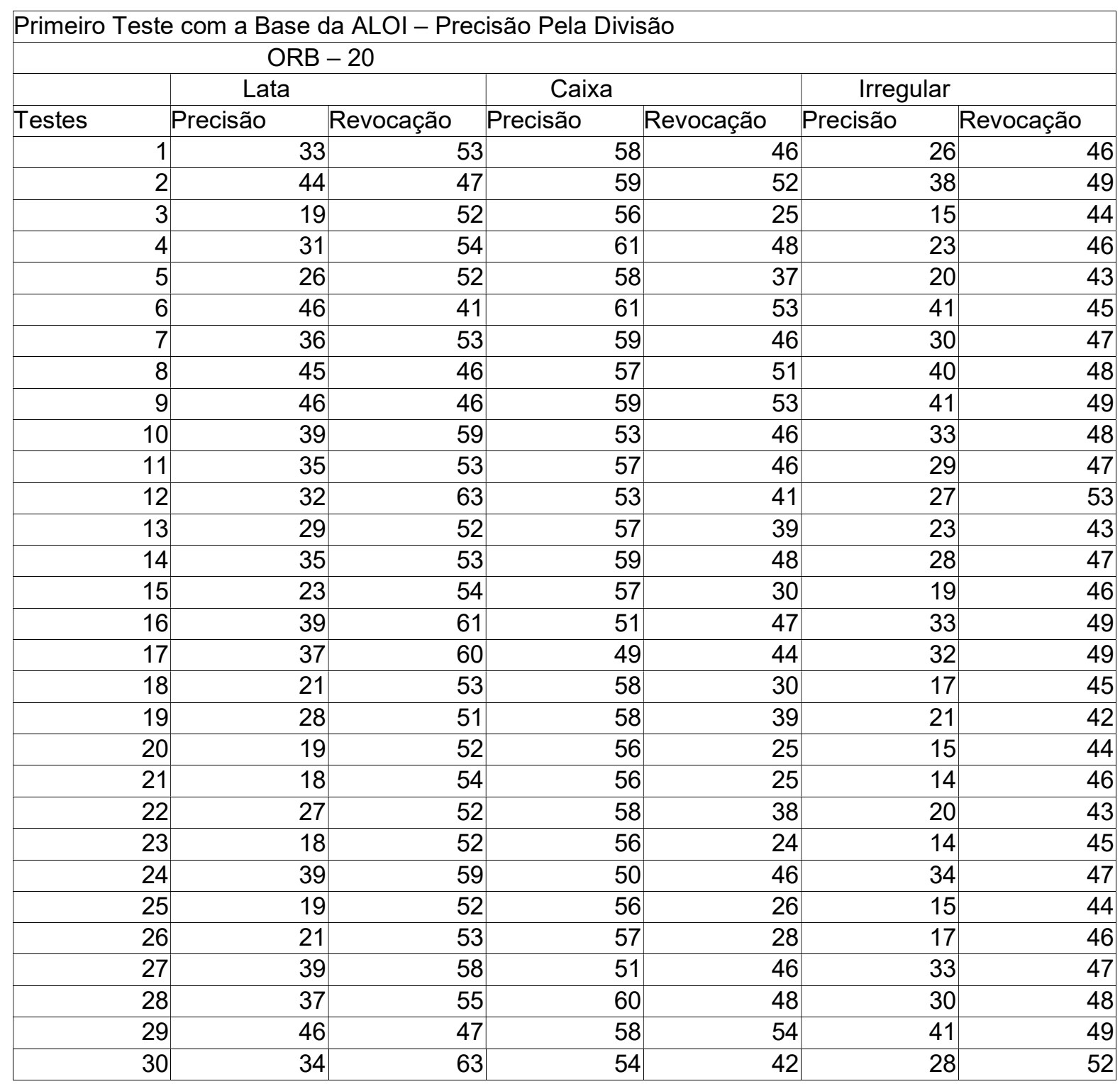


Resultados Retirados das Matrizes de Confusão - Precisão Pela Divisão - ORB

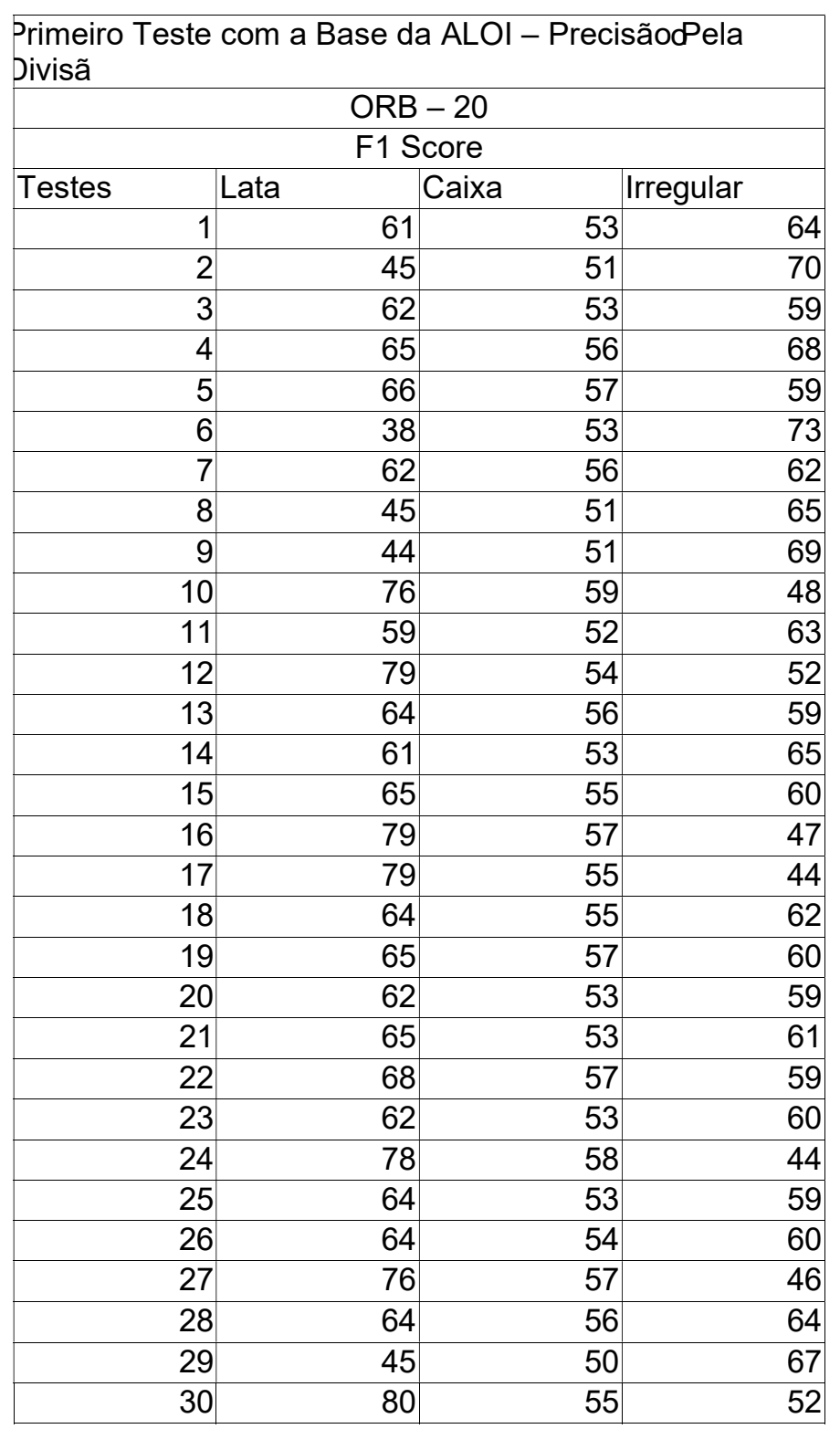


Resultados Retirados das Matrizes de Confusão - Precisão Pela Divisão - ORB

\begin{tabular}{|c|c|c|c|c|c|}
\hline Primeiro Teste & com a Base & e da Al & rec & ivis & \\
\hline & ORB - 40 & & & & \\
\hline & & & core & & \\
\hline Testes & \%Split Test & Lata & & & \\
\hline 1 & & 40 & 18 & 64 & 66 \\
\hline 2 & & 40 & 31 & 45 & 72 \\
\hline 3 & & 40 & 16 & 63 & 59 \\
\hline 4 & & 40 & 21 & 58 & 64 \\
\hline 5 & & 40 & 18 & 68 & 64 \\
\hline 6 & & 40 & 35 & 44 & 72 \\
\hline 7 & & 40 & 27 & 66 & 63 \\
\hline 8 & & 40 & 33 & 45 & 70 \\
\hline 9 & & 40 & 32 & 47 & 71 \\
\hline 10 & & 40 & 27 & 74 & 52 \\
\hline 11 & & 40 & 21 & 64 & 66 \\
\hline 12 & & 40 & 18 & 73 & 57 \\
\hline 13 & & 40 & 19 & 66 & 60 \\
\hline 14 & & 40 & 18 & 63 & 67 \\
\hline 15 & & 40 & 15 & 65 & 62 \\
\hline 16 & & 40 & 26 & 75 & 54 \\
\hline 17 & & 40 & 26 & 75 & 55 \\
\hline 18 & & 40 & 14 & 66 & 63 \\
\hline 19 & & 40 & 19 & 65 & 61 \\
\hline 20 & & 40 & 17 & 63 & 59 \\
\hline 21 & & 40 & 15 & 64 & 62 \\
\hline 22 & & 40 & 18 & 68 & 64 \\
\hline 23 & & 40 & 16 & 64 & 62 \\
\hline 24 & & 40 & 27 & 75 & 52 \\
\hline 25 & & 40 & 16 & 63 & 58 \\
\hline 26 & & 40 & 16 & 63 & 62 \\
\hline 27 & & 40 & 27 & 74 & 53 \\
\hline 28 & & 40 & 24 & 64 & 63 \\
\hline 29 & & 40 & 34 & 45 & 70 \\
\hline 30 & & 40 & 22 & 73 & 56 \\
\hline
\end{tabular}


Resultados Retirados das Matrizes de Confusão - Precisão Pela Divisão - ORB

\begin{tabular}{|r|r|r|r|r|r|r|}
\hline \multicolumn{7}{|c|}{ Primeiro Teste com a Base da ALOI - Precisão Pela Divisão } \\
\hline \multicolumn{2}{|c|}{ ORB -40} \\
\hline
\end{tabular}


Resultados Retirados das Matrizes de Confusão - Precisão Pela Divisão - ORB

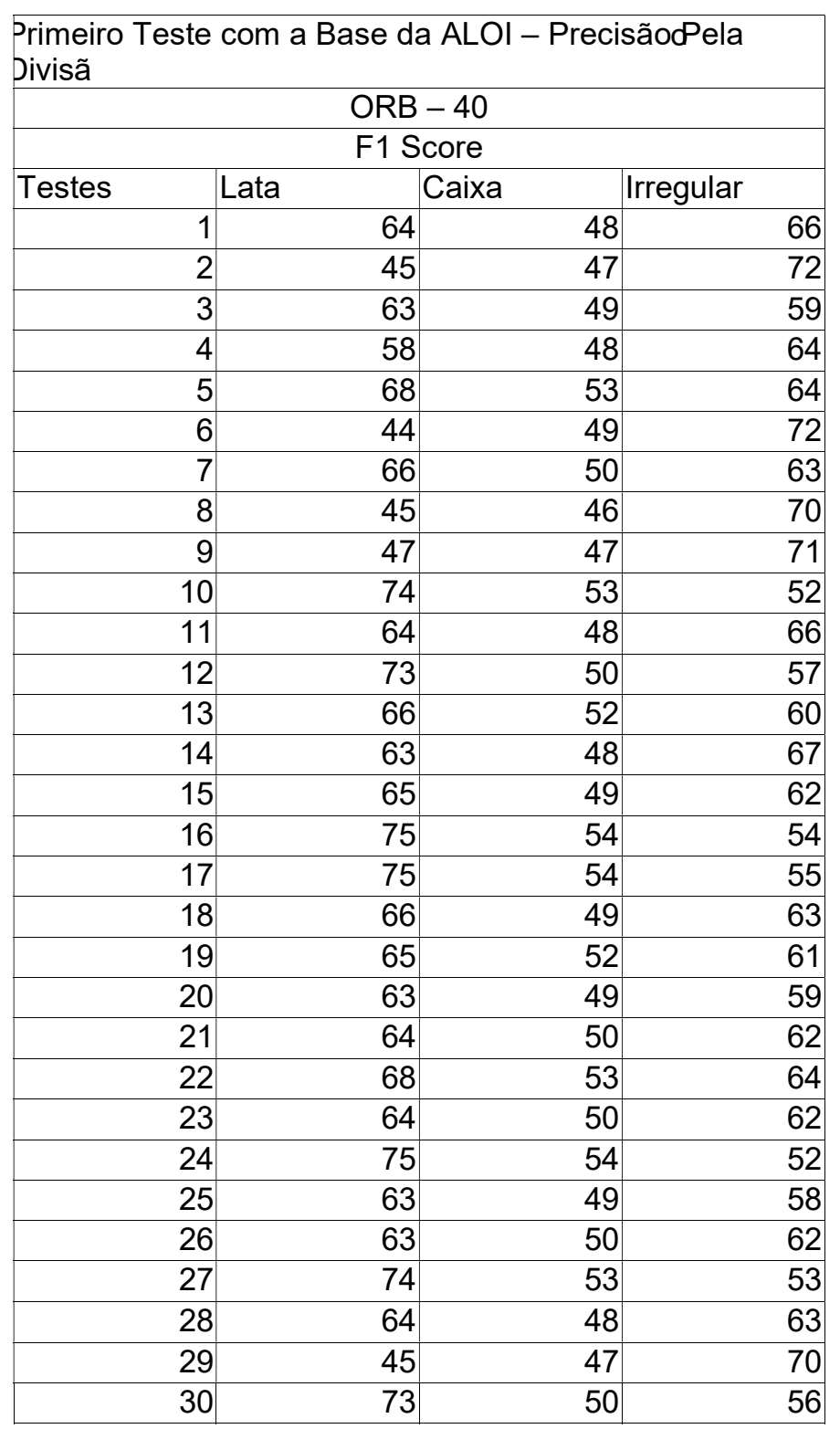


Resultados Retirados das Matrizes de Confusão - Precisão Pela Divisão - ORB

\begin{tabular}{|c|c|c|c|c|c|}
\hline Primeiro Teste & com a Base & e da $A L$ & rec & ivis & \\
\hline & ORB - 70 & & & & \\
\hline & & & core & & \\
\hline Testes & \%Split Test & Lata & & & \\
\hline 1 & 7 & 70 & 8 & 70 & 68 \\
\hline 2 & & 70 & 0 & 60 & 75 \\
\hline 3 & & 70 & 11 & 64 & 71 \\
\hline 4 & & 70 & 20 & 59 & 71 \\
\hline 5 & & 70 & 10 & 67 & 73 \\
\hline 6 & & 70 & 0 & 64 & 73 \\
\hline 7 & & 70 & 14 & 69 & 64 \\
\hline 8 & & 70 & 1 & 60 & 74 \\
\hline 9 & & 70 & 0 & 59 & 75 \\
\hline 10 & & 70 & 21 & 74 & 64 \\
\hline 11 & & 70 & 3 & 68 & 69 \\
\hline 12 & & 70 & 11 & 73 & 69 \\
\hline 13 & & 70 & 11 & 66 & 71 \\
\hline 14 & & 70 & 4 & 69 & 69 \\
\hline 15 & & 70 & 11 & 66 & 73 \\
\hline 16 & & 70 & 22 & 75 & 65 \\
\hline 17 & & 70 & 20 & 75 & 64 \\
\hline 18 & & 70 & 11 & 66 & 74 \\
\hline 19 & & 70 & 12 & 67 & 71 \\
\hline 20 & & 70 & 13 & 63 & 71 \\
\hline 21 & & 70 & 12 & 65 & 69 \\
\hline 22 & & 70 & 8 & 69 & 73 \\
\hline 23 & & 70 & 12 & 65 & 71 \\
\hline 24 & & 70 & 21 & 75 & 64 \\
\hline 25 & & 70 & 12 & 63 & 71 \\
\hline 26 & & 70 & 12 & 65 & 71 \\
\hline 27 & & 70 & 21 & 74 & 65 \\
\hline 28 & & 70 & 13 & 70 & 64 \\
\hline 29 & & 70 & 0 & 60 & 75 \\
\hline 30 & & 70 & 11 & 71 & 72 \\
\hline
\end{tabular}


Resultados Retirados das Matrizes de Confusão - Precisão Pela Divisão - ORB

\begin{tabular}{|c|c|c|c|c|c|c|}
\hline \multicolumn{7}{|c|}{ Primeiro Teste com a Base da ALOI - Precisão Pela Divisão } \\
\hline \multicolumn{7}{|c|}{ ORB -70} \\
\hline \multirow[b]{2}{*}{ Testes } & \multicolumn{2}{|c|}{ Lata } & \multicolumn{2}{|l|}{ Caixa } & \multicolumn{2}{|l|}{ Irregular } \\
\hline & Precisão & Revocação & Precisão & & Precisão $\quad \mathrm{F}$ & Revocação \\
\hline 1 & 14 & 54 & 57 & 52 & 8 & 44 \\
\hline 2 & 0 & 48 & 58 & 0 & 0 & 40 \\
\hline 3 & 17 & 56 & 58 & 30 & 11 & 51 \\
\hline 4 & 30 & 52 & 58 & 60 & 20 & 46 \\
\hline 5 & 16 & 58 & 59 & 38 & 10 & 50 \\
\hline 6 & 1 & 50 & 58 & 33 & 0 & 40 \\
\hline 7 & 22 & 54 & 56 & 50 & 14 & 45 \\
\hline 8 & 2 & 48 & 57 & 67 & 1 & 40 \\
\hline 9 & 0 & 48 & 57 & 0 & 0 & 40 \\
\hline 10 & 30 & 60 & 58 & 52 & 21 & 51 \\
\hline 11 & 5 & 52 & 57 & 31 & 3 & 43 \\
\hline 12 & 18 & 61 & 58 & 39 & 11 & 52 \\
\hline 13 & 18 & 56 & 58 & 39 & 11 & 50 \\
\hline 14 & 7 & 53 & 58 & 39 & 4 & 42 \\
\hline 15 & 16 & 58 & 60 & 32 & 11 & 52 \\
\hline 16 & 31 & 61 & 59 & 55 & 22 & 51 \\
\hline 17 & 29 & 61 & 58 & 53 & 20 & 51 \\
\hline 18 & 16 & 58 & 60 & 34 & 11 & 51 \\
\hline 19 & 18 & 57 & 58 & 38 & 12 & 50 \\
\hline 20 & 18 & 57 & 58 & 31 & 13 & 51 \\
\hline 21 & 17 & 57 & 58 & 31 & 12 & 51 \\
\hline 22 & 13 & 58 & 59 & 36 & 8 & 50 \\
\hline 23 & 17 & 57 & 59 & 30 & 12 & 51 \\
\hline 24 & 30 & 61 & 58 & 53 & 21 & 51 \\
\hline 25 & 18 & 56 & 58 & 31 & 12 & 51 \\
\hline 26 & 17 & 57 & 60 & 31 & 12 & 51 \\
\hline 27 & 30 & 60 & 59 & 53 & 21 & 51 \\
\hline 28 & 21 & 54 & 57 & 54 & 13 & 44 \\
\hline 29 & 0 & 48 & 57 & 0 & 0 & 40 \\
\hline 30 & 17 & 59 & 59 & 43 & 11 & 51 \\
\hline
\end{tabular}


Resultados Retirados das Matrizes de Confusão - Precisão Pela Divisão - ORB

\begin{tabular}{|c|c|c|c|}
\hline \multicolumn{4}{|c|}{ Primeiro Teste com a Base da ALOI - PrecisãodPela } \\
\hline \multicolumn{4}{|c|}{ ORB -70} \\
\hline \multicolumn{4}{|c|}{ F1 Score } \\
\hline Testes & Lata & Caixa & Irregular \\
\hline 1 & 70 & 50 & 68 \\
\hline 2 & 60 & 47 & 75 \\
\hline 3 & 64 & 50 & 71 \\
\hline 4 & 59 & 49 & 71 \\
\hline 5 & 67 & 50 & 73 \\
\hline 6 & 64 & 48 & 73 \\
\hline 7 & 69 & 51 & 64 \\
\hline 8 & 60 & 47 & 74 \\
\hline 9 & 59 & 46 & 75 \\
\hline 10 & 74 & 54 & 64 \\
\hline 11 & 68 & 49 & 69 \\
\hline 12 & 73 & 50 & 69 \\
\hline 13 & 66 & 49 & 71 \\
\hline 14 & 69 & 51 & 69 \\
\hline 15 & 66 & 50 & 73 \\
\hline 16 & 75 & 54 & 65 \\
\hline 17 & 75 & 53 & 64 \\
\hline 18 & 66 & 51 & 74 \\
\hline 19 & 67 & 49 & 71 \\
\hline 20 & 63 & 50 & 71 \\
\hline 21 & 65 & 50 & 69 \\
\hline 22 & 69 & 50 & 73 \\
\hline 23 & 65 & 51 & 71 \\
\hline 24 & 75 & 53 & 64 \\
\hline 25 & 63 & 50 & 71 \\
\hline 26 & 65 & 51 & 71 \\
\hline 27 & 74 & 54 & 65 \\
\hline 28 & 70 & 51 & 64 \\
\hline 29 & 60 & 46 & 75 \\
\hline 30 & 71 & 50 & 72 \\
\hline
\end{tabular}


Resultados Retirados das Matrizes de Confusão - Precisão Pela Divisão - ORB

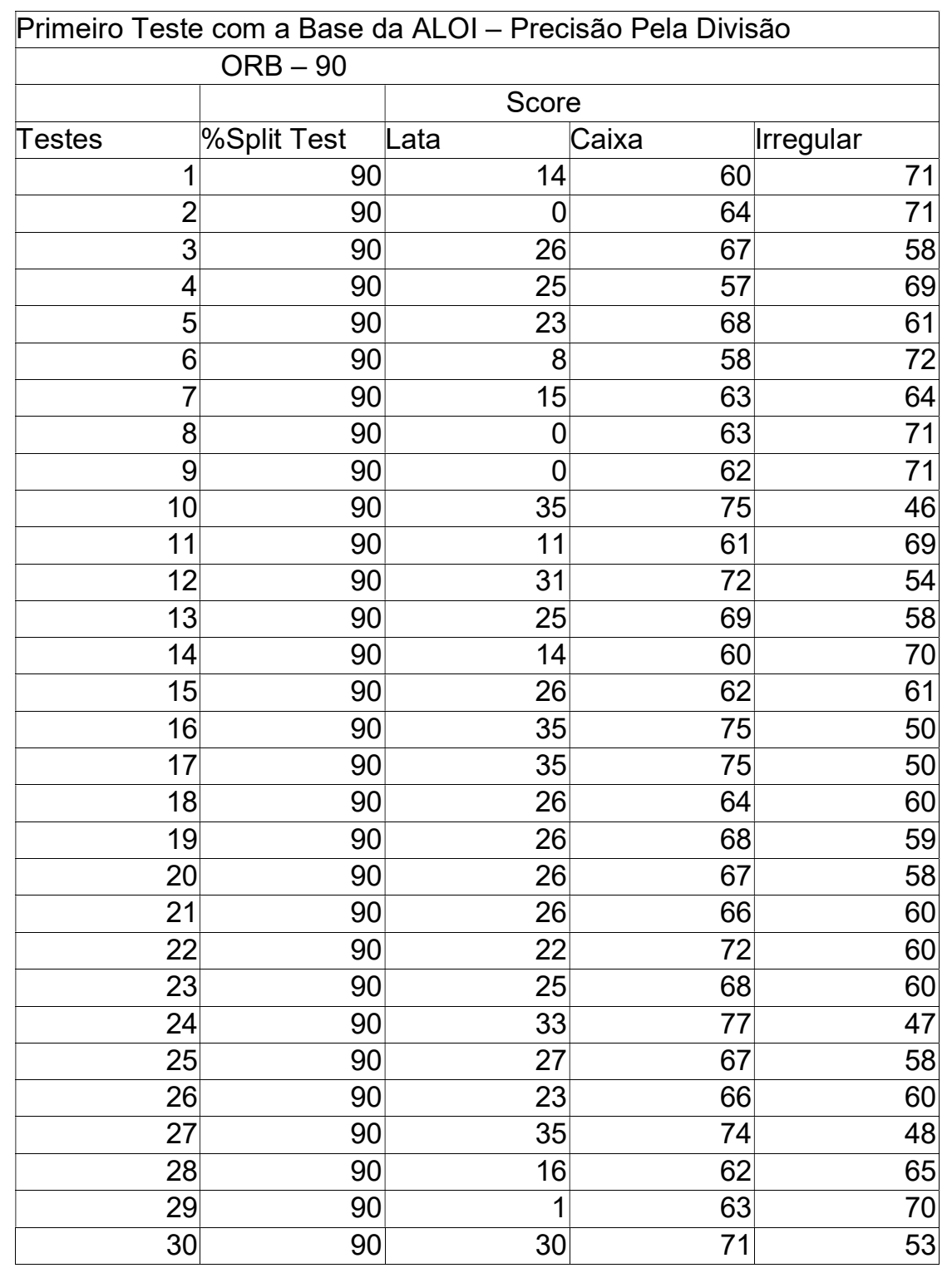


Resultados Retirados das Matrizes de Confusão - Precisão Pela Divisão - ORB

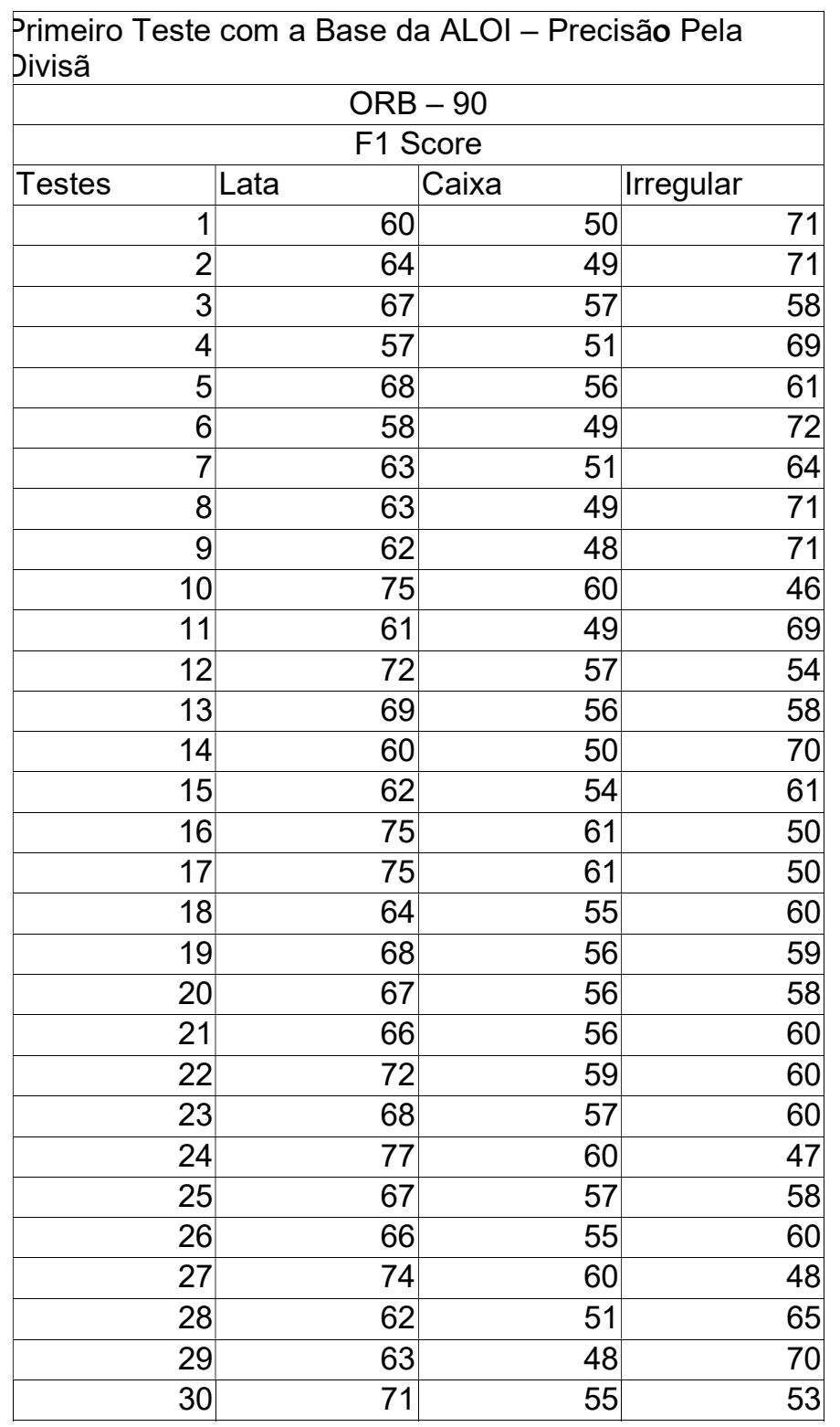



APÊNDICE B - DADOS COLETADOS DOS EXPERIMENTOS - DESEMPENHO COM ALTERAÇÃO DE LUMINOSIDADE 
Desempenho com Alteração de Luminosidade

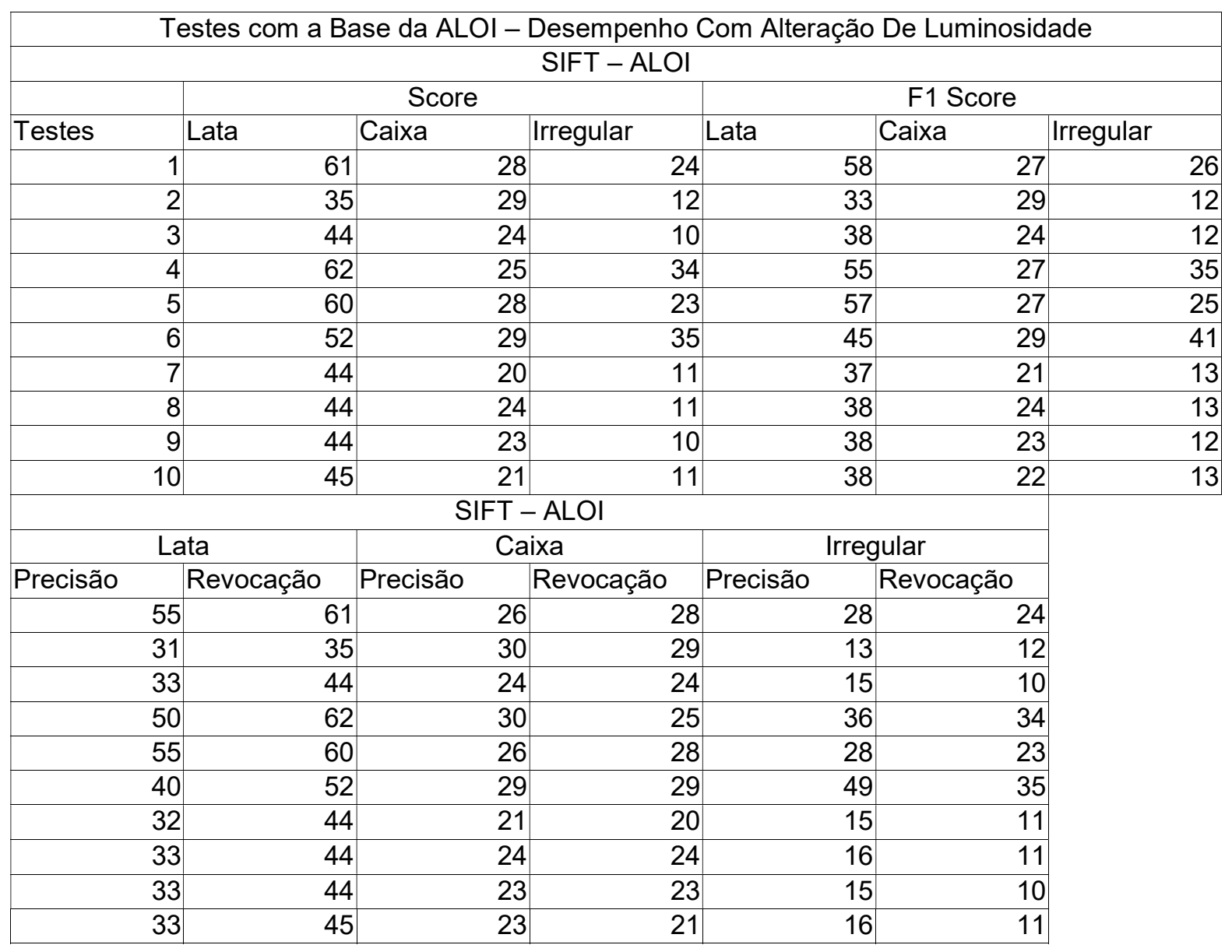


Desempenho com Alteração de Luminosidade

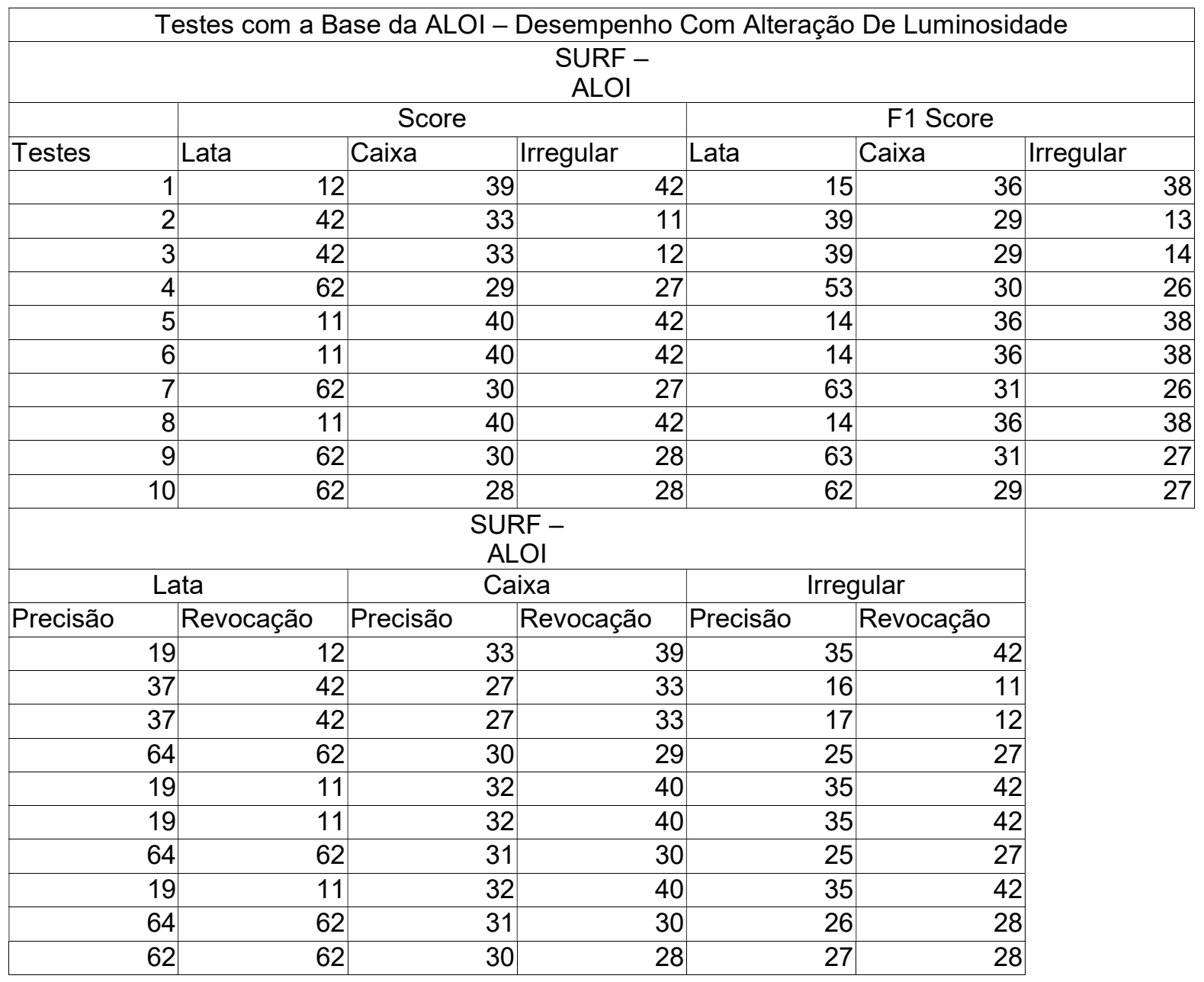


Desempenho com Alteração de Luminosidade

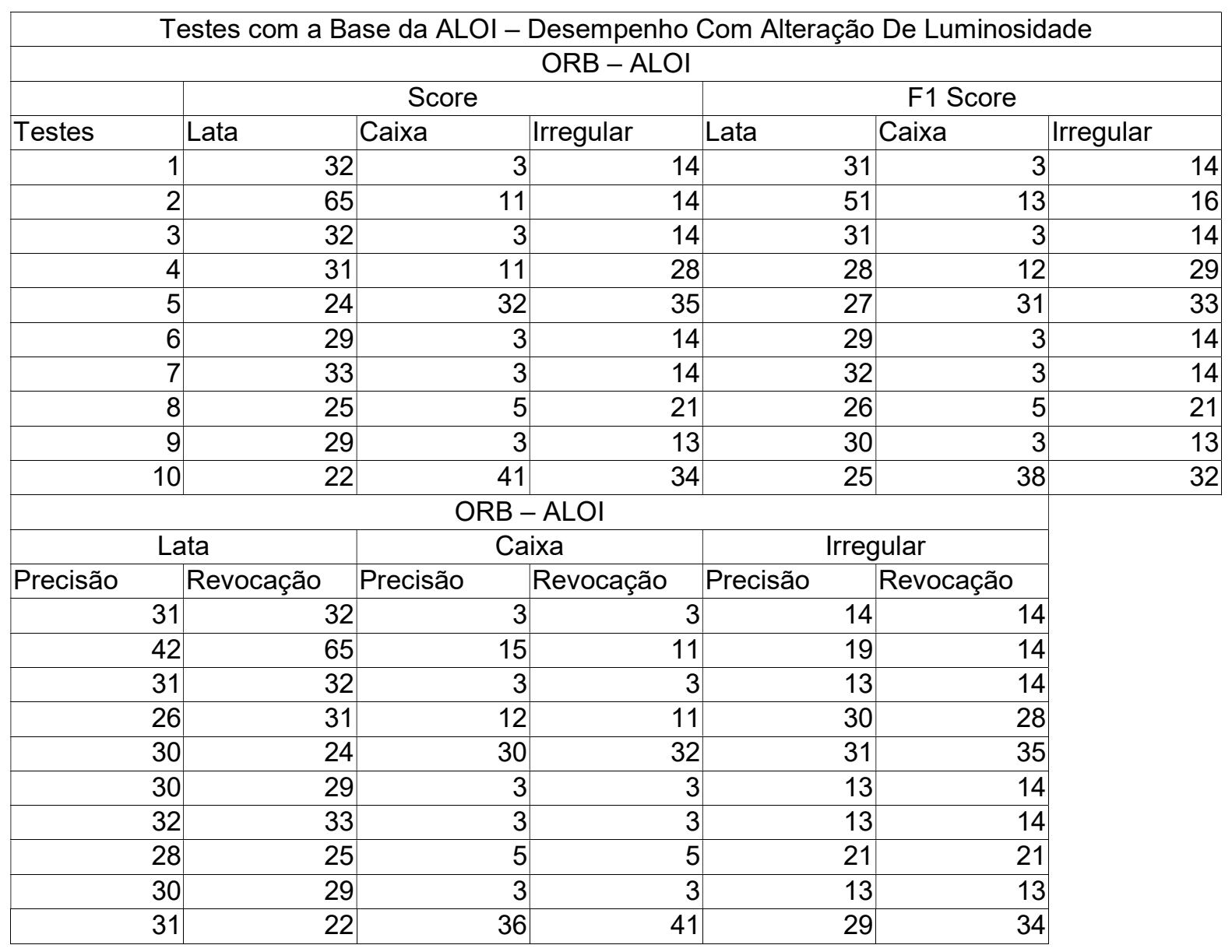


Desempenho com Alteração de Luminosidade

\begin{tabular}{|c|c|c|c|c|c|c|}
\hline \multicolumn{7}{|c|}{ Testes com a Base do Laboratório - Desempenho Com Alteração De Luminosidade } \\
\hline \multicolumn{7}{|c|}{ SIFT - Lab } \\
\hline \multirow[b]{2}{*}{ Testes } & \multicolumn{3}{|c|}{ Score } & \multicolumn{3}{|c|}{ F1 Score } \\
\hline & Lata & Caixa & Irregular & Lata & Caixa & Irregular \\
\hline 1 & 0 & 46 & 100 & 0 & 39 & 96 \\
\hline 2 & 8 & 38 & 31 & 10 & 34 & 29 \\
\hline 3 & 0 & 38 & 38 & 0 & 37 & 31 \\
\hline 4 & 0 & 46 & 100 & 0 & 39 & 96 \\
\hline 5 & 0 & 77 & 100 & 0 & 57 & 96 \\
\hline 6 & 15 & 38 & 23 & 18 & 33 & 23 \\
\hline 7 & 15 & 69 & 100 & 21 & 58 & 93 \\
\hline 8 & 0 & 69 & 100 & 0 & 53 & 96 \\
\hline 9 & 15 & 69 & 100 & 21 & 58 & 93 \\
\hline 10 & 0 & 38 & 23 & 0 & 31 & 23 \\
\hline \multicolumn{6}{|c|}{ SIFT - Lab } & \\
\hline \multicolumn{2}{|c|}{ Lata } & \multicolumn{2}{|c|}{ Caixa } & \multicolumn{2}{|c|}{ Irregular } & \\
\hline Precisão & Revocação & Precisão & Revocação & Precisão & & \\
\hline 0 & 0 & 33 & 46 & 93 & 100 & \\
\hline 12 & 8 & 31 & 38 & 27 & 31 & \\
\hline 0 & 0 & 36 & 38 & 26 & 38 & \\
\hline 0 & 0 & 33 & 46 & 93 & 100 & \\
\hline 0 & 0 & 45 & 77 & 93 & 100 & \\
\hline 22 & 15 & 29 & 38 & 23 & 23 & \\
\hline 33 & 15 & 50 & 69 & 87 & 100 & \\
\hline 0 & 0 & 43 & 69 & 93 & 100 & \\
\hline 33 & 15 & 50 & 69 & 87 & 100 & \\
\hline 0 & 0 & 26 & 38 & 23 & 23 & \\
\hline
\end{tabular}


Desempenho com Alteração de Luminosidade

\begin{tabular}{|c|c|c|c|c|c|c|}
\hline \multicolumn{7}{|c|}{ Testes com a Base do Laboratório - Desempenho Com Alteração De Luminosidade } \\
\hline \multicolumn{7}{|c|}{ SURF - Lab } \\
\hline \multirow[b]{2}{*}{ Testes } & \multicolumn{3}{|c|}{ Score } & \multicolumn{3}{|c|}{ F1 Score } \\
\hline & Lata & Caixa & Irregular & Lata & Caixa & Irregular \\
\hline 1 & 23 & 54 & 38 & 22 & 61 & 36 \\
\hline 2 & 8 & 62 & 31 & 7 & 70 & 29 \\
\hline 3 & 0 & 46 & 100 & 0 & 40 & 93 \\
\hline 4 & 0 & 77 & 8 & 0 & 80 & 8 \\
\hline 5 & 0 & 92 & 15 & 0 & 71 & 21 \\
\hline 6 & 23 & 54 & 38 & 22 & 61 & 36 \\
\hline 7 & 23 & 54 & 38 & 22 & 61 & 36 \\
\hline 8 & 77 & 92 & 100 & 83 & 86 & 100 \\
\hline 9 & 8 & 62 & 31 & 7 & 70 & 29 \\
\hline 10 & 0 & 77 & 8 & 0 & 80 & 8 \\
\hline \multicolumn{6}{|c|}{ SURF - Lab } & \\
\hline \multicolumn{2}{|c|}{ Lata } & \multicolumn{2}{|c|}{ Caixa } & \multicolumn{2}{|c|}{ Irregular } & \\
\hline Precisão & Revocação & Precisão & Revocação & Precisão & & \\
\hline 21 & 23 & 70 & 54 & 33 & 38 & \\
\hline 7 & 8 & 80 & 27 & 31 & 31 & \\
\hline 0 & 0 & 35 & 46 & 87 & 100 & \\
\hline 0 & 0 & 83 & 77 & 8 & 8 & \\
\hline 0 & 0 & 57 & 92 & 33 & 15 & \\
\hline 21 & 23 & 70 & 54 & 33 & 38 & \\
\hline 21 & 23 & 70 & 54 & 33 & 38 & \\
\hline 91 & 77 & 80 & 92 & 100 & 100 & \\
\hline 7 & 8 & 80 & 62 & 27 & 31 & \\
\hline 0 & 0 & 83 & 77 & 8 & 8 & \\
\hline
\end{tabular}


Desempenho com Alteração de Luminosidade

\begin{tabular}{|c|c|c|c|c|c|c|c|}
\hline \multicolumn{8}{|c|}{ Testes com a Base do Laboratório - Desempenho Com Alteração De Luminosidade } \\
\hline \multicolumn{8}{|c|}{ ORB - Lab } \\
\hline \multirow[b]{2}{*}{ Testes } & \multicolumn{4}{|c|}{ Score } & \multicolumn{3}{|c|}{ F1 Score } \\
\hline & Lata & \multicolumn{2}{|c|}{ Caixa } & Irregular & Lata & Caixa & Irregular \\
\hline 1 & & 0 & 69 & 69 & 0 & 50 & 69 \\
\hline 2 & & 0 & 62 & 69 & 0 & 46 & 69 \\
\hline 3 & & 0 & 46 & 92 & 0 & 36 & 92 \\
\hline 4 & & 0 & 62 & 69 & 0 & 46 & 82 \\
\hline 5 & & 0 & 62 & 85 & 0 & 46 & 76 \\
\hline 6 & & 0 & 69 & 92 & 0 & 50 & 83 \\
\hline 7 & & 0 & 62 & 77 & 0 & 46 & 71 \\
\hline 8 & & 0 & 54 & 92 & 0 & 41 & 96 \\
\hline 9 & & 0 & 62 & 77 & 0 & 46 & 87 \\
\hline 10 & & 0 & 77 & 92 & 0 & 54 & 92 \\
\hline \multicolumn{7}{|c|}{ ORB - Lab } & \\
\hline \multicolumn{2}{|c|}{ Lata } & & \multicolumn{2}{|c|}{ Caixa } & \multicolumn{2}{|c|}{ Irregular } & \\
\hline Precisão & Revocação & & Precisão & Revocação & Precisão & & \\
\hline 0 & & 0 & 39 & 69 & 69 & 69 & \\
\hline 0 & & 0 & 36 & 62 & 69 & 69 & \\
\hline 0 & & 0 & 32 & 46 & 92 & 92 & \\
\hline 0 & & 0 & 36 & 62 & 100 & 69 & \\
\hline 0 & & 0 & 36 & 62 & 69 & 85 & \\
\hline 0 & & 0 & 39 & 69 & 75 & 92 & \\
\hline 0 & & 0 & 36 & 62 & 67 & 77 & \\
\hline 0 & & 0 & 33 & 54 & 100 & 92 & \\
\hline 0 & & 0 & 36 & 62 & 100 & 77 & \\
\hline 0 & & 0 & 42 & 77 & 92 & 92 & \\
\hline
\end{tabular}

